\title{
Effects of Anti-viral Acute Phase Response on Hippocampal Glutamate Regulation
}

Holly C. Hunsberger

Follow this and additional works at: https://researchrepository.wvu.edu/etd

\section{Recommended Citation}

Hunsberger, Holly C., "Effects of Anti-viral Acute Phase Response on Hippocampal Glutamate Regulation" (2016). Graduate Theses, Dissertations, and Problem Reports. 5839.

https://researchrepository.wvu.edu/etd/5839

This Dissertation is protected by copyright and/or related rights. It has been brought to you by the The Research Repository @ WVU with permission from the rights-holder(s). You are free to use this Dissertation in any way that is permitted by the copyright and related rights legislation that applies to your use. For other uses you must obtain permission from the rights-holder(s) directly, unless additional rights are indicated by a Creative Commons license in the record and/ or on the work itself. This Dissertation has been accepted for inclusion in WVU Graduate Theses, Dissertations, and Problem Reports collection by an authorized administrator of The Research Repository @ WVU.

For more information, please contact researchrepository@mail.wvu.edu. 
Effects of Anti-viral Acute Phase Response on Hippocampal Glutamate Regulation

\author{
Holly C. Hunsberger
}

\author{
Dissertation submitted to \\ Eberly College of Arts and Sciences \\ at West Virginia University \\ in partial fulfillment of the requirements for the degree of
}

Doctorate of Philosophy in Psychology

\author{
Committee \\ Melissa Blank, Ph.D., Chair \\ Miranda N. Reed, Ph.D. \\ Elizabeth Kyonka, Ph.D. \\ Kevin Larkin, Ph.D. \\ Gregory Konat, Ph.D. \\ Department of Psychology \\ Morgantown, West Virginia \\ 2016
}

Keywords: Polyinosinic polycytidylic acid (PIC), glutamate, kainic acid, hippocampus, microelectrode array, hyperexcitability

Copyright 2016 Holly Hunsberger 


\begin{abstract}
Effects of Anti-viral Acute Phase Response on Hippocampal Glutamate Regulation
\end{abstract}

Holly Hunsberger

A large body of clinical evidence suggests that viral infections in the periphery can exacerbate neurodegenerative conditions such as Alzheimer's disease, Huntington's, disease, Parkinson's disease, multiple sclerosis, and seizures. The underlying mechanisms of these conditions involve the activation of the acute phase response (APR), part of the innate immune system, which recognizes viral molecular patterns. As neighboring cells become infected, inflammatory mediators are released into the bloodstream and relayed to the central nervous system where they produce a "mirror" inflammatory response. To induce the APR, polyinosinic-polycytidylic acid (PIC), a viral mimetic, is commonly used. PIC produces a robust and transient increase in inflammatory factors in the brain, which modify neuronal networks leading to behavioral traits referred to as sickness behavior.

Recent evidence also reveals an increase in kainic acid-induced seizure hypersusceptibility in PIC-challenged animals. Although the underlying mechanisms for this seizure hypersusceptibility are not well known, inflammatory mediators produced in response to PIC can act on excitatory glutamate receptors resulting in increased neuronal activity. Increased neuronal activity has been implicated in many neurodegenerative conditions. To examine glutamate's role in the pathophysiology of seizures after peripheral insult, microelectrode arrays were employed to measure glutamate levels in the hippocampus of mice. In Experiment 1, female C57BL/6 mice were i.p. injected with PIC, and 24 hours later glutamate levels were measured in each subregion of the hippocampus (DG, CA3, and CA1). PIC-challenge resulted in a robust increase in resting extracellular glutamate levels. Although potassium-evoked glutamate release was similar between PIC and saline mice, glutamate clearance was significantly decreased after PICchallenge. These results suggest functional alterations of astrocytes. Electrophysiological examination of hippocampal slices from PIC-challenged mice revealed an increase in basal synaptic transmission, increased probability of pre-synaptic glutamate release, and enhanced long-term potentiation (LTP). Altogether, these results reveal dysregulation of glutamate homeostasis and enhanced excitatory synaptic transmission, which could contribute to the seizure hypersusceptibility observed in PIC-challenged mice.

Experiment 1 characterized glutamate neurotransmission in an anesthetized animal after PIC injection, while Experiment 2 aimed to investigate the relationship between PIC challenge, glutamate homeostasis, and seizure severity in an awake behaving animal. MEAs were chronically implanted in the CA1 of the hippocampus to record tonic glutamate and glutamate transients, or spontaneous glutamate release before, during, and after KA-induced seizures across four days. Our results revealed an increase in tonic glutamate levels, an effect that gradually declined across the four days. These results are congruent with the decrease in seizure activity and inflammatory mediator

levels across days. The most notable finding was that tonic glutamate levels were predictive of seizure severity as indicated by an increase in the average and cumulative 
seizure scores. The results provide greater insight into the mechanisms underlying the changes that occur during cerebral inflammation and may provide a link between peripheral insult and the comorbidity of neurodegenerative conditions. 


\section{Acknowledgments}

Completion of the following dissertation would not have been possible without the guidance and support of several people. I am truly grateful to my parents and grandparents for instilling in me the values of hard work, independence, and perseverance. They taught me many of the skills needed to be successful in graduate school. In addition, I would also like to thank my brother for being a great roommate and for always making me smile. Without the love and support of my family, none of this would be possible.

I would like to give sincerest gratitude to my mentor, Dr. Miranda Reed. The projects outlined below became a reality because of her strong commitment to mentoring and fostering innovative ideas in the laboratory. For the past four years Dr. Reed has been instrumental in shaping my scientific career. She has given me the skills necessary to be successful in my future endeavors, but more importantly she has given me her time. I greatly appreciate all that she has done from helping me write my first manuscript, to allowing me to travel and present my findings. I look forward to continuing our relationship throughout the upcoming years. I would also like to thank Dr. Konat who has provided me with the necessary tools to complete my experiments. Without Dr. Konat and his expertise in molecular biology, much of this work would not be possible. I'm grateful to have collaborated with him and hope that the studies below will continue in the laboratory after I leave. Next I wish to thank Dr. Gerhardt and Dr. Quintero, from the University of Kentucky, for all of their help with the microelectrode technology used in this project. Finally, I would like to thank everyone else who served on my dissertation committee, Dr. Blank, Dr. Kyonka, and Dr. Larkin. Thank you all for your support, time, and patience as I traveled to Auburn University to complete my project. Although I've only spent a year at Auburn University, I have made new friends and collaborations that have helped with certain aspects of this project. I would like to thank Dr. Vishnu and his laboratory for their electrophysiology work (Chapter 2). Furthermore, I would like to thank my current lab mates, Sharay Setti, Ryan Heslin, Bamidele Jeminiwa, and past lab mates, Carolyn Rudy and Daniel Weitzner, and all of the undergraduates that aided in my project. I'm truly indebted to all of you.

Lastly, I'd like to give a big thank you to everyone who was there for me at West Virginia University, Brad Showman, Sabre Wood, Curtis Lee, Drs. Holly Fell, Ryan Fell, Stephanie Kincaid, and Molly Crowe, and soon to be Drs. Sara Nass, and Margeaux Gray. Thank you all for providing a fun environment and a shoulder to lean on, while I completed my graduate research. I am grateful for all of you. 
The text formatting for Chapter 2 is based on the style guide for the Journal of

Neurochemistry. The research in chapter 2 has been submitted and accepted.

\section{References}

Hunsberger, H. C., Wang, D., Petrisko, T. J., Alhowail, A., Setti, S. E., Suppiramaniam, V., Konat, G. W., \& Reed, M. N. (2016). Peripherally restricted viral challenge elevates extracellular glutamate and enhances synaptic transmission in the hippocampus (accepted Journal of Neurochemistry). 


\section{Table of Contents}

Acknowledgements.......................................................

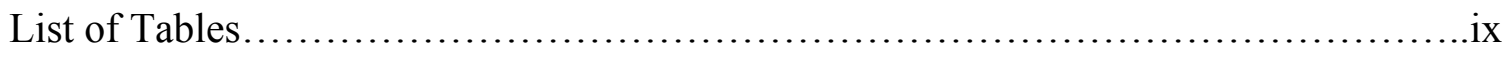

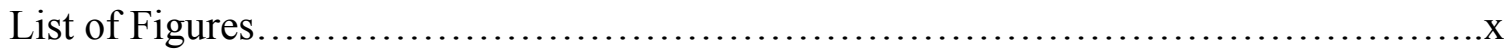

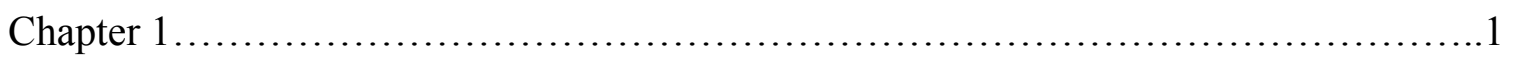

Introduction........................................................

Peripheral infection and neurodegenerative conditions.......................

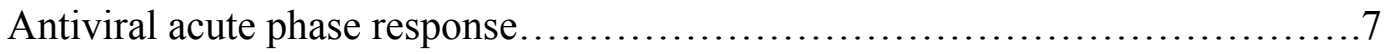

Peripheral infection and the CNS.....................................

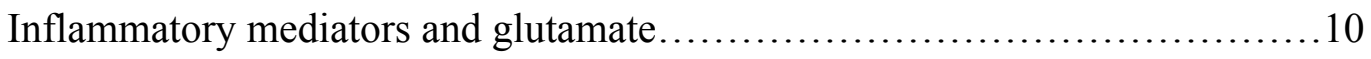

Cytokines..................................................... 10

Chemokines............................................... 12

Complement system......................................... 13

Hippocampal circuitry............................................ 14

Kainic-acid induced seizure model................................... 16

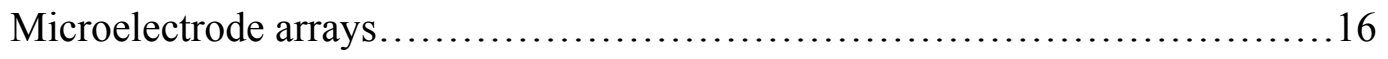

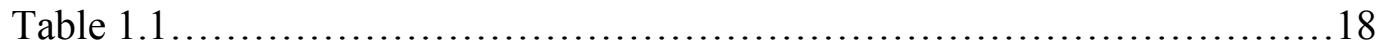

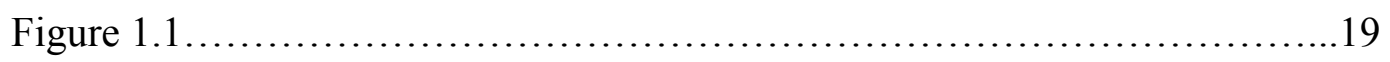

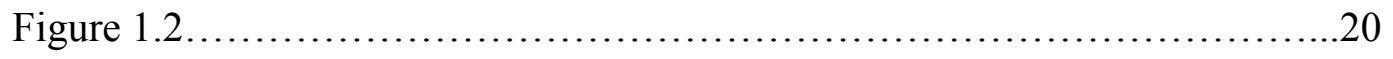

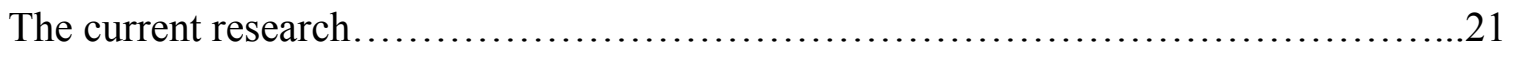




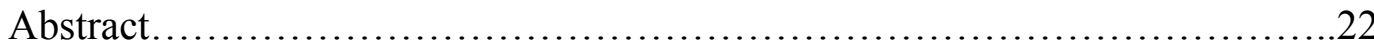

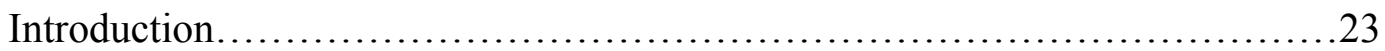

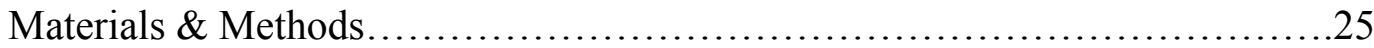

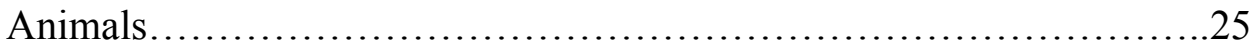

In vivo glutamate measurement...............................26

Hippocampal slice preparation.....................................27

Extracellular field potential recording............................27

Statistical analyses.............................................29

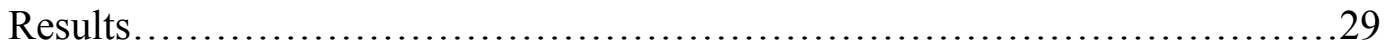

Discussion........................................................... 33

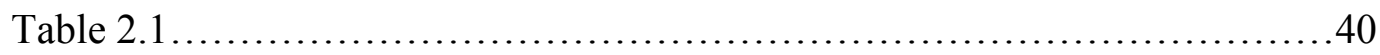

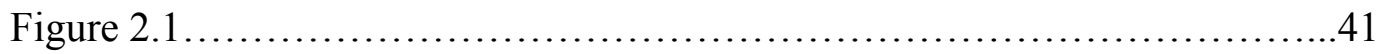

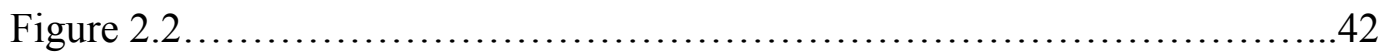

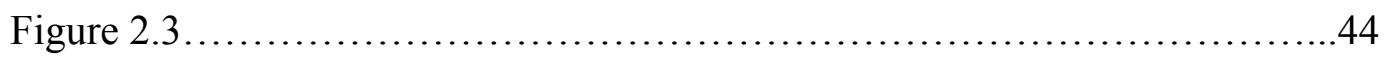

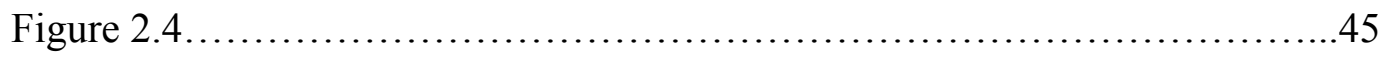

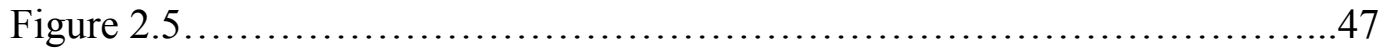

Reference List..................................................49 


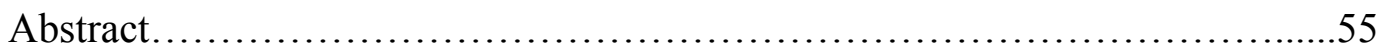

Introduction....................................................... 56

Materials \& Methods..................................................... 58

Animals..........................................................58

MEA preparation.................................................59

Electrode implantation........................................59

PIC injection..................................................60

Glutamate recordings in freely-moving mice......................6 60

Seizure induction...........................................61

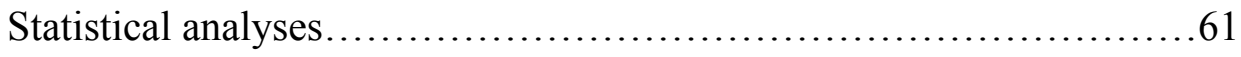

Results.............................................................6 62

Discussion............................................................. 64

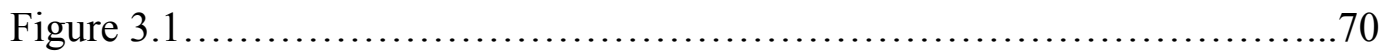

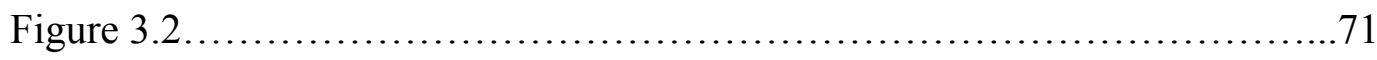

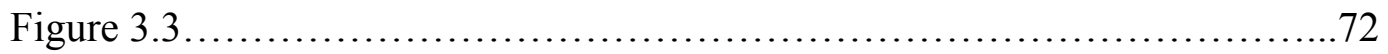

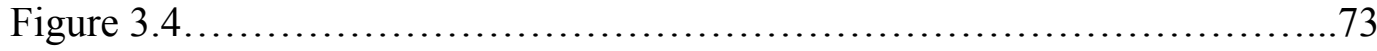

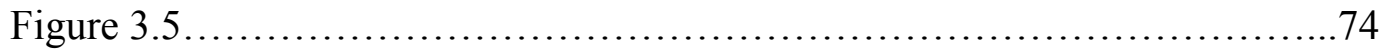

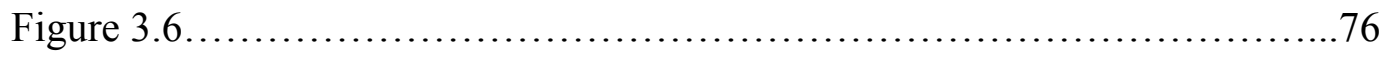

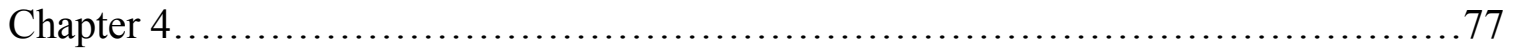


Significance......

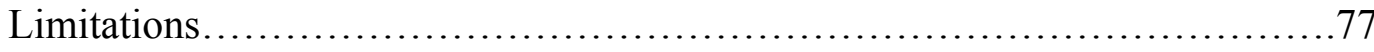

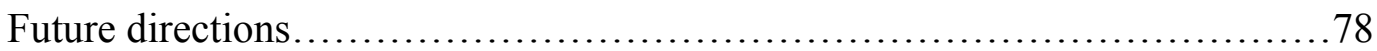

Supplemental table S1 .................................................... 79

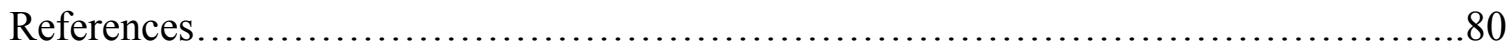

List of Tables

\section{Chapter 1}

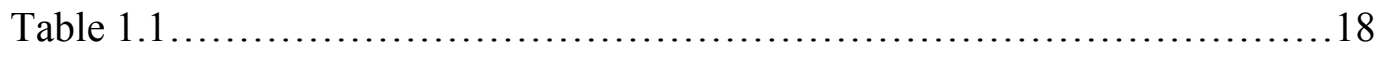

Chapter 2

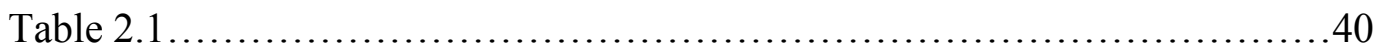

Supplemental

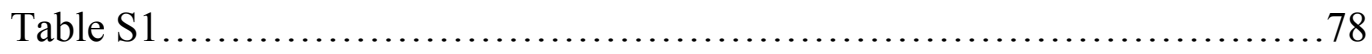




\section{List of Figures}

\section{Chapter 1}

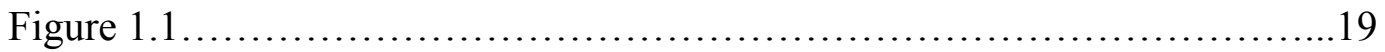

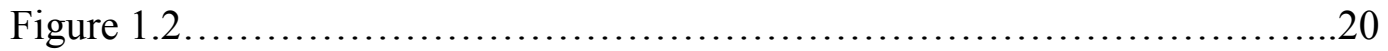

\section{Chapter 2}

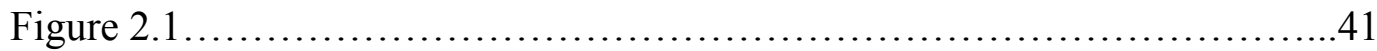

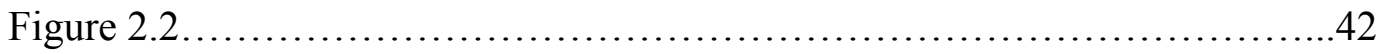

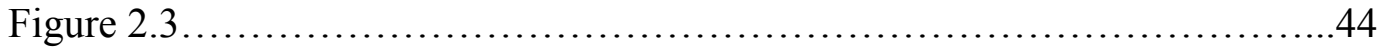

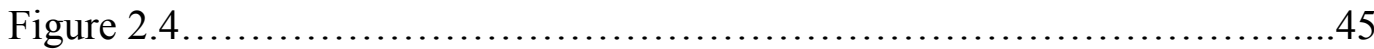

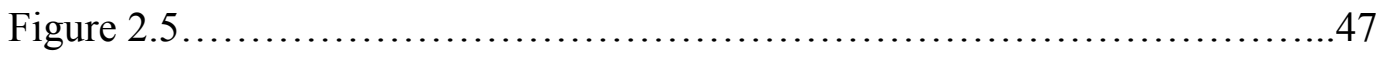

\section{Chapter 3}

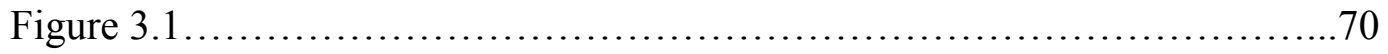

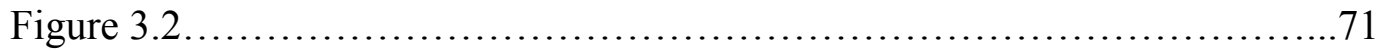

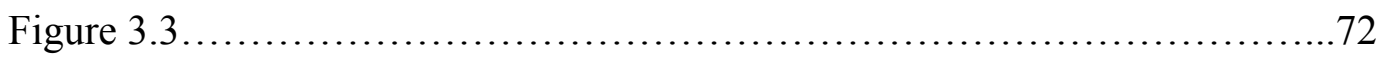

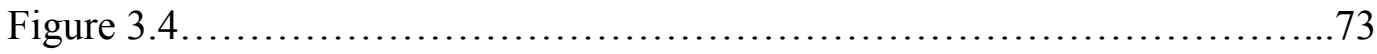

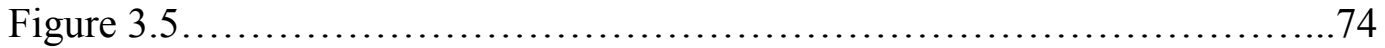

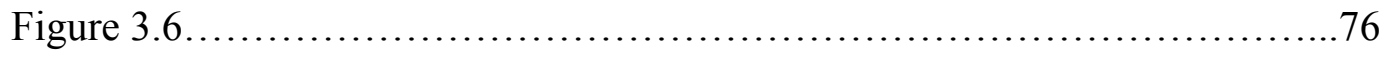




\section{Chapter 1}

\section{The role of glutamate excitatory neurotransmission after peripheral viral challenge}

Viral infections activate the acute phase response (APR), the body's first line of immune defense (Baumann \& Gauldie, 1994), to contain the spread of infection by initiating a signaling cascade of inflammatory mediators (e.g., cytokines and chemokines) in the periphery (Cunningham, Campion, Teeling, Felton, \& Perry, 2007; Dantzer, 2006; Dantzer \& Kelley, 2007). Following APR, the adaptive immune system works to reestablish homeostasis and promote healing. These peripherally-generated, blood-borne inflammatory mediators induce a "mirror" inflammatory response in the brain that modify the activity of neural networks to ultimately produce a behavioral complex of adaptive behaviors known as "sickness behavior" (Dantzer \& Kelley, 2007; Dantzer,

O'Connor, Freund, Johnson, \& Kelley, 2008; G. Konat, 2016; Quan \& Banks, 2007). Though alterations in neural networks, and the resulting sickness behavior, serve to protect the host, a growing body of evidence suggests these modifications may have deleterious effects in the presence of other neuropathological conditions. For example, viral infections in the periphery can exacerbate neurodegenerative conditions including seizures, Alzheimer's disease (AD), Parkinson's disease (PD), multiple sclerosis (MS), and Huntington's disease (HD) in humans (see Perry, Newman, \& Cunningham, 2003 for review). Experimental studies support these findings. Notably, peripheral injection of a viral mimetic, polyinosinic-polycytidylic acid (PIC), results in robust and protracted hypersusceptibility to kainic acid (KA) induced seizures in mice (Kirschman, Borysiewicz, Fil, \& Konat, 2011). 
Though the exact mechanisms by which viral infections exacerbate neurodegenerative conditions are not known, many of the major inflammatory mediators generated by viral infections have been shown to increase neuronal excitability (Galic, Riazi, \& Pittman, 2012; Hu, Sheng, Ehrlich, Peterson, \& Chao, 2000; Riazi et al., 2015; Viviani et al., 2003) and decrease neuronal inhibition (Stellwagen, Beattie, Seo, \& Malenka, 2005; S. Wang, Q. Cheng, S. Malik, \& J. Yang, 2000), both of which may lead to increased extracellular glutamate concentrations. Given recent evidence linking glutamatergic hyperactivity to AD (Bakker et al., 2012; Busche et al., 2012; Hunsberger, Rudy, Batten, Gerhardt, \& Reed, 2015; Hunsberger, Weitzner, et al., 2015), PD (Ahmed et al., 2011; Schapira, 2010), MS (Kostic, Zivkovic, \& Stojanovic, 2013), and seizures (Chapman, 2000; Soukupova et al., 2015), deciphering mechanisms by which peripheral viral infection elevates extracellular glutamate is critical to the prevention of infectionmediated exacerbations in neurodegenerative conditions. In Experiment 1, we explored the effects of a single peripheral injection of PIC on glutamate homeostasis and synaptic transmission. In Experiment 2, we examine the relationships among peripheral infection, glutamate homeostasis, and KA-induced seizures.

The following review will discuss evidence that peripheral infections exacerbate neuropathological conditions in both humans and animal models. To elucidate potential mechanisms, the role of the APR and resultant inflammatory factors in alterations of neural networks, with a focus on alterations in glutamate excitatory neurotransmission and homeostasis, will be reviewed.

\section{Peripheral infection and neurodegenerative conditions}


A body of clinical evidence has revealed that peripheral infections are comorbid with neurodegenerative conditions (Banks \& Robinson, 2010; Perry et al., 2003). For example, $\mathrm{AD}$ patients suffering from systemic infection exhibit greater cognitive impairment (Holmes et al., 2003). When examining twins with AD, those with severe systemic infection burden develop AD at an earlier age than the corresponding twin (Nee \& Lippa, 1999). In addition, one common characteristic at autopsy of individuals without dementia that exhibit a heavy beta-amyloid load, a hallmark feature of $\mathrm{AD}$, is lower levels of pro-inflammatory markers compared to AD patients (Lue, Brachova, Civin, \& Rogers, 1996). Other risk factors for AD include oral infection (Stein, Desrosiers, Donegan, Yepes, \& Kryscio, 2007), helicobacter gut bacteria (Kountouras et al., 2009; Kountouras et al., 2006), as well as delirium (Murray et al., 1993; Rahkonen, Luukkainen-Markkula, Paanila, Sivenius, \& Sulkava, 2000), which is significantly correlated with systemic infection (de Rooij, van Munster, Korevaar, \& Levi, 2007; van Munster et al., 2008). Often these infections can lead to or induce delirium in AD patients. In fact, the most common cause of delirium in elderly patients is infection (George, Bleasdale, \& Singleton, 1997). Together, these studies suggest peripheral infection exacerbates cognitive dysfunction in AD.

Inflammation and infection also correlate with pathology seen in patients with MS and PD. Notably, there are significant correlations between the number of relapses and the number of viral infections in MS patients (O. Andersen, Lygner, Bergstrom, Andersson, \& Vahlne, 1993). Upper respiratory tract infections increase the likelihood of relapse by 3-fold compared to the non-infected individuals (Edwards, Zvartau, Clarke, Irving, \& Blumhardt, 1998). Respiratory infections, such as pneumonia are the main 
causes of death in patients with PD (Beyer, Herlofson, Arsland, \& Larsen, 2001). Gastrointestinal infection can also exacerbate the progression of PD (Weller et al., 2005) possibly via the upregulation of specific inflammatory mediators, which have been observed in the cerebral spinal fluid (CSF) (Blum-Degen et al., 1995), serum (Dobbs et al., 1999), and post mortem tissue (Mogi et al., 1994) of those suffering from PD.

Evidence from animal models further supports that the APR is a comorbid factor in neurodegeneration. For example, a single systemic PIC injection disrupts memory in the fear conditioning test (CFC) (Kranjac et al., 2012). It also decreases marble burrowing behavior. This burrowing behavior is increased in aged mice and could be attributed to an age-dependent increase in inflammatory mediators in the hippocampus (McLinden et al., 2012). Furthermore, prolonged activation of the APR by repeated administration of PIC significantly increases levels of the amyloid-beta peptide (A $\left.\beta_{1-42}\right)$ in the hippocampus of non-transgenic mice (Weintraub et al., 2014). Moreover, increasing PIC induced $\mathrm{A} \beta_{1^{-42}}$ burden, a hallmark of $\mathrm{AD}$, is associated with memory deficits in the CFC (White et al., 2016). Interestingly, maternal immune activation also results in AD-like pathology in offspring. Systemic PIC injection during gestation causes offspring to develop $\mathrm{AD}$ pathology, including an increase in the amyloid precursor protein (APP), translocation of the tau protein to dendritic compartments, and a decrease in working memory (Krstic et al., 2012). If these mice are PIC challenged a second time in adulthood, gliosis and tau aggregation occur, both of which represent late stage pathology in $\mathrm{AD}$. In addition, transgenic $\mathrm{AD}$ mice injected with PIC exhibit an accelerated AD plaque deposition (Krstic et al., 2012). Together, these results suggest 
that peripheral PIC injection can lead to AD-like pathology and exacerbate neurodegenerative pathology that is already present.

It should be noted, however, that these results are not limited to systemic PIC injections. Many studies examining infection, inflammation, and seizure susceptibility have used bacterial models, such as lipopolysaccharide (LPS) - a ubiquitus component of the cell wall of gram negative bacteria, and have observed similar alterations as that observed with PIC injections (Riazi, Galic, \& Pittman, 2010; Sayyah, Javad-Pour, \& Ghazi-Khansari, 2003). For example, elevated $A \beta$ levels are observed in mice injected systemically with LPS (Ma et al., 2016). LPS challenged mice also exhibit memory deficits in the Morris Water Maze memory task (Ma et al., 2016), an increase in activated glycogen synthase kinase 3 beta (GSK3 $\beta$ ), which phosphorylates the tau protein, and a decrease in hippocampal metabolism (Carret-Rebillat et al., 2015), all of which are observed in AD patients (Leroy, Yilmaz, \& Brion, 2007; Possin et al., 2016; Yamaguchi et al., 1997). Tau hyperphosphorylation is further increased in a transgenic AD mouse model after LPS injection, an effect that is exacerbated in aged mice (Kitazawa, Oddo, Yamasaki, Green, \& LaFerla, 2005).

Other conditions such as PD and prion disease are also comorbid with viral infection in animal models. PD is characterized by a loss of dopamine (DA) neurons and motor impairments (Kakkar \& Dahiya, 2015). Injection of either PIC or LPS in animal models results in neuronal degeneration of dopamine neurons in the substantia nigra (SN) (Bobyn et al., 2012; Deleidi, Hallett, Koprich, Chung, \& Isacson, 2010; Smith et al., 2015). The loss of SN DA neurons is likely mediated by inflammatory factors, as blockade of interleukin-1 (IL-1) and tumor necrosis factor-1 (TNF-1) receptors protects 
against LPS-mediated DA loss in the SN (Koprich, Reske-Nielsen, Mithal, \& Isacson, 2008; McCoy et al., 2006). Amplified expression of pro-inflammatory mediators is also associated with accelerated disease progression in the ME7 mouse model of prion disease following systemic injection of either PIC or LPS (Cunningham, Wilcockson, Campion, Lunnon, \& Perry, 2005; Field, Campion, Warren, Murray, \& Cunningham, 2010).

Many of the aforementioned neurodegenerative diseases share a common characteristic, seizures. Seizures are often comorbid in AD (Chan, Jones, Bush, O'Brien, \& Kwan, 2015), PD (Feddersen et al., 2014), and MS (Allen, Seminog, \& Goldacre, 2013) and can appear after infection (Vezzani et al., 2016). The most common cause of seizures in children is fever (Berg, Darefsky, Holford, \& Shinnar, 1998), which results in the release of cytokines, specifically in the hippocampus (Dube, Vezzani, Behrens, Bartfai, \& Baram, 2005). In addition, individuals suffering from seizures are at an increased risk for developing neurodegenerative diseases (Ali, Chugh, \& Ekdahl, 2015; Cordonnier, Henon, Derambure, Pasquier, \& Leys, 2007). This evidence further supports the importance of determining the mechanisms of increased seizure susceptibility following PIC challenge.

As mentioned above, peritoneal injection of PIC renders the brain hyperexcitable, as seen from increased susceptibility to KA-induced seizures (Kirschman et al., 2011; Michalovicz \& Konat, 2014). Both the extent and duration of status epilepticus (SE) is significantly increased in PIC-challenged vs. saline-injected control mice. Intracerebroventricular (ICV) administration of PIC in 14 day-old rats results in greater susceptibility to lithium pilocarpine- and pentylenetetrazol- induced seizures and memory deficits in the CFC paradigm (Galic, Riazi, Henderson, Tsutsui, \& Pittman, 2009). In 
addition, maternal PIC challenge renders the offspring more susceptible to seizures. These mice also exhibit increased hippocampal hyperexcitability, an effect that is rescued by cytokine antibodies (Pineda et al., 2013). Together, these studies suggest that the comorbidity of viral infection with neurodegeneration is likely to involve hyperexcitability as a mechanistic link. This hyperexcitability is likely mediated in part by changes in the glutamatergic system, a major excitatory neural system in the brain.

\section{Antiviral acute phase response}

APR is activated by double-stranded ribonucleic acid (dSRNA), which is an intermediate of viral replication (Weber, Wagner, Rasmussen, Hartmann, \& Paludan, 2006). As the virus replicates, dsRNA species are released from infected cells and recognized by neighboring cells, which rapidly trigger APR (Jacobs \& Langland, 1996; Kimura-Takeuchi, Majde, Toth, \& Krueger, 1992). As an innate immune response, APR acts in a non specific manner recognizing pathogen associated molecular patterns (PAMPs) (Jacobs \& Langland, 1996). In contrast, the adaptive immune system is highly specific as seen from the production of antibodies and T cells (den Haan, Arens, \& van Zelm, 2014). PAMPs are molecules recognized by cells of the innate immune system in the host organism because they are absent in the host. These cells express several receptors that detect the presence of extra- and intra-cellular dsRNA (Berke, Li, \& Modis, 2013), resulting in the generation of type 1 interferons (IFNs) (Isaacs \& Lindenmann, 1957), cytokines, chemokines, (Bluthe et al., 1994), and other inflammatory mediators (Block \& Hong, 2005). Interferons belong to a large class of proteins known as cytokines, which communicate between cells to trigger protective defenses (Theofilopoulos, Baccala, Beutler, \& Kono, 2005). This first line of defense is critical 
for containing the spread of viral infections long before the adaptive immunity against viral antigens becomes effective.

To study anti-viral APR, synthetic dsRNA is often used in animal models (Traynor, Majde, Bohnet, \& Krueger, 2004). The PIC-based model is advantageous compared to true viral infections for several reasons. First, in contrast to viral inoculation, which requires prolonged and nonsynchronous incubation time to elicit the innate immune response, PIC response is very rapid (Fil, Borysiewicz, \& Konat, 2011; Homan, Zendzian, Schott, Levy, \& Adamson, 1972; G. W. Konat, Borysiewicz, Fil, \& James, 2009; Michalovicz, Lally, \& Konat, 2015), allowing for hourly kinetic analyses. Second, the biological activity of PIC is restricted to stimulation of the innate immune response and there are no confounding effects of pathogen-associated tissue damage (Kunzmann, Kretzschmar, Herrmann, \& Wilhelm, 2004). Third, adaptive immunity (e.g., antibodies and $\mathrm{T}$ cells) resulting from ensuing exposure of animals to viral antigens is eliminated (Fortier et al., 2004). Fifth, PIC is noninfectious, meaning that experiments can be conveniently performed under standard laboratory conditions (Fortier et al., 2004). Because PIC challenge is congruent with behavioral effects of peripheral viral infection in humans (Huckans et al., 2009; Loftis, Huckans, Ruimy, Hinrichs, \& Hauser, 2008), PIC is widely used as a potent inducer of antiviral APR (Guha-Thakurta \& Majde, 1997; Muller et al., 1994).

\section{Peripheral infection and the CNS}

The remodeling of neuronal networks seen after peripheral infection are likely due in part to inflammatory mediators that travel to the brain and target neurons and glia. These mediators infect the brain via various pathways. The neural route is represented by 
the primary afferent neurons that innervate the body site where the infectious process takes place (Watkins et al., 1994). The most important afferent responsible for neural transmission of peripheral signals is the vagus nerve (Bluthe et al., 1994), which extends from the brain stem to various abdominal organs. Cytokines can also reach the brain directly through the blood brain barrier (BBB) by transport proteins and endothelial cells or through circumventricular organs (CVOs) (Dantzer \& Kelley, 2007; Vitkovic et al., 2000). Endothelial cells, which line the inner surface of capillaries in the brain, are very responsive to proinflammatory cytokines. Once these cells are activated by cytokines, the $\mathrm{BBB}$ integrity declines and more cytokines are released into the brain parenchyma, a process known as transduction (de Vries et al., 1996; Forster et al., 2008). CVOs are areas of the brain that are selectively permeable to blood-borne molecules because they lack the $\mathrm{BBB}$, allowing substances that do not cross the $\mathrm{BBB}$ to trigger changes in brain function (Ganong, 2000).

Once in the brain, cytokines and chemokines act through a variety of mechanisms that influence changes in glutamate homeostasis. For example, PIC injection results in the upregulation of over 600 genes in the hippocampus, an area rich in glutamate and glutamate receptors (Fotuhi, Standaert, Testa, Penney, \& Young, 1994), for up to 72 hours (Michalovicz et al., 2015). Many of these genes "mirror" the release of cytokines and chemokines in the blood and peak at 6 hours after PIC injection and gradually decline (Cunningham et al., 2007; Fil et al., 2011; G. W. Konat et al., 2009; Michalovicz \& Konat, 2014; Michalovicz et al., 2015). Although many of these genes encode for inflammatory pathway components, there are a multitude of genes that relate to excitatory glutamatergic and inhibitory GABAergic neurotransmission (Michalovicz \& 
Konat, 2014) and could play a role in the increased seizure susceptibility seen in PIC challenged mice. Moreover, PIC injection results in a marked increase in $N$-Methyl-Daspartic acid (NMDA) and $\alpha$-amino-3-hydroxy-5-methyl-4-isoxazolepropionic acid (AMPA) glutamate receptor subunit expression (Galic et al., 2009), which could also contribute to the increased hypersusceptibility.

The four major cytokines released into the blood after PIC challenge that also surge in the brain include interferon $\beta$ (IFN $\beta$ ), interleukin 6 (IL-6), IL-1 $\beta$, and tumor necrosis factor alpha $(\mathrm{TNF} \alpha)$, all reaching their highest brain concentrations after 3 hours (Cunningham et al., 2007; Michalovicz \& Konat, 2014; Michalovicz et al., 2015). Brain cells, such as neurons, microglia, and astrocytes, express receptors for all of the aforementioned cytokines (McCusker \& Kelley, 2013).

\section{Inflammatory mediators and glutamate}

Cytokines. In the brain, IL-6 exerts its effects on neuronal functioning by inhibiting long-term potentiation and impairing cognition as seen from mice overexpressing IL-6 (Bellinger, Madamba, Campbell, \& Siggins, 1995). Furthermore, these mice have impaired development of inhibitory synapses and significantly larger numbers of mushroom-shaped dendritic spines, which are typically connected to excitatory synapses (Wei et al., 2012). In addition to changing synaptic morphology, IL-6 can cause a decrease in inhibition of postsynaptic potentials in the CA1 region of the hippocampus (Wei et al., 2012) and shift the balance between excitation and inhibition by promoting the former (Garcia-Oscos et al., 2012), which may be the reason that IL-6 has been implicated in neurodegeneration following epilepsy (Campbell et al., 1993; Kalueff, Lehtimaki, Ylinen, Honkaniemi, \& Peltola, 2004; Samland et al., 2003). Further, IL-6 
and IFN $\beta$ initiate a surge in IL-1 $\beta$ and TNF $\alpha$, creating a forward loop of continuous cytokine activity (McCusker \& Kelley, 2013). This surge in IL-1 $\beta$ activity can increase the activity of NMDA receptors (Viviani et al., 2003) and reduce the expression of astrocytic glutamate receptors (GLT-1) that remove glutamate from the extracellular space (Prow \& Irani, 2008), which presumably would increase extracellular glutamate levels.

The increased seizure susceptibility observed after PIC challenge (Kirschman et al., 2011; Michalovicz \& Konat, 2014) may result from a combination of increased excitatory pathways and decreased inhibitory pathways resulting in increased levels of glutamate. A potential source for this excess glutamate is an upregulation of glutaminase, the main enzyme responsible for glutamate production. Both IL- $1 \beta$ and TNF- $\alpha$, when applied to neuronal cultures, increase glutaminase activity, resulting in increased extracellular glutamate levels and excitotoxicity (Ye et al., 2013). TNF- $\alpha$ can also increase glutamate signaling by increasing glutamatergic AMPA receptor expression (Mizuno et al., 2008), while also promoting endocytosis of inhibitory GABA receptors (Pribiag \& Stellwagen, 2013).

IFN $\beta$ differs slightly form the other three major cytokines in that it is neuroprotective and when activated increases glutamate uptake by human fetal astrocytes (Hu et al., 2000). IFN $\beta$ has also been shown to block the production of glutamate and microglia-induced cell death following LPS stimulation of cortical neuronal and microglia co-cultures (Jin et al., 2007), while also promoting the secretion of nerve growth factor (NGF) by endothelial cells (Biernacki et al., 2005). Because IFN $\beta$ can rescue cells from death caused by pro-inflammatory cytokines released from activated 
microglia, IFN $\beta$ has been used as a treatment option for relapsing MS patients to reduce brain atrophy and improve axonal integrity (Q. Wang \& Mao-Draayer, 2015).

Interestingly, IFN $\beta$ gene expression is fifty percent lower in the hippocampus compared to the whole brain after PIC injection (Michalovicz \& Konat, 2014), suggesting that the neuroprotective effects of IFN $\beta$ are diminished in the hippocampus after PIC.

Chemokines. Several chemokine receptors and their respective ligands are also increased after PIC injection and appear to play a role in glutamate homeostasis (Fil et al., 2011; Michalovicz \& Konat, 2014). The CXCR3 receptor, upregulated after PIC injection and expressed on neurons, can increase the activity of neurons when activated by one of its ligands (i.e., CXCL10) (Nelson \& Gruol, 2004). For example, acute activation by CXCL10 increases spontaneous synaptic activity (Nelson \& Gruol, 2004), possibly via decreases in inhibitory GABA receptors and increases in excitatory glutamate receptors (Cho, Nelson, Bajova, \& Gruol, 2009). Furthermore, prolonged activation of CXCR3 results in a decrease in the cyclic adenosine monophosphate (cAMP) response elementbinding (CREB) protein (Bajova, Nelson, \& Gruol, 2008), which plays a role in memory formation, as well as a decrease in GAD65/57, a marker for inhibitory synapses, and a decrease in $\mathrm{GABA}_{A}$ and $\mathrm{GABA}_{B}$ receptor subunit expression (Cho et al., 2009). Moreover, CXCR3 activation promotes increases in synapsin 1, which has a role in neurotransmitter release, and NMDA receptor (NR1 subtype), both of which can increase synaptic activity (Cho et al., 2009). Although prolonged activation by CXCL10 results in increased neuronal activity, acute activation with this same ligand, leads to a decrease in LTP in hippocampal slices. (Vlkolinsky, Siggins, Campbell, \& Krucker, 2004). 
While CXCR3 activation appears to be associated with NMDA receptors, CXCR2 receptor activation is shown to increase glutamatergic AMPA receptor expression by its ligands, i.e., CXCL1 and CXCL2 (Lax et al., 2002; J. G. Wang et al., 2008). All of these receptors and ligands are upregulated after PIC injection (Fil et al., 2011; Michalovicz \& Konat, 2014). Important to glutamate homeostasis is the chemokine, Ccl2. For example, Ccl2 is increased in patients with pharmacoresistant epilepsy (He et al., 2013). Furthermore, blocking the Cc12 receptor, CCR2, decreases seizure activity in mice after LPS injection (Cerri et al., 2016). Because Ccl2 expression persists up to 72 hours post PIC injection (Michalovicz \& Konat, 2014), this chemokine may be crucial for the increased seizure activity observed in PIC challenged mice (Kirschman et al., 2011).

Complement system. Of the 625 genes analyzed in the hippocampus following PIC injection, the complement system pathway exhibits the greatest activation, and this activation correlates with seizure hypersusceptibility (Michalovicz et al., 2015). Complement proteins are part of the innate immune system and act by tagging pathogens for phagocytosis (Sarma \& Ward, 2011). There are eight complements upregulated after PIC, but the greatest increases are observed in complement factor B (CFB), C3, and C6 ( Michalovicz et al., 2015). The complement system can alter the glutamate homeostasts by suppressing glutamate uptake and increasing presynaptic release of glutamate (Kolev, Ruseva, Harris, Morgan, \& Donev, 2009; Merega, Di Prisco, Lanfranco, Severi, \& Pittaluga, 2014). This system may be a potential mechanism for the hyperexcitability observed after PIC challenge as complements can increase the total amount of glutamate in the extracellular space and can exacerbate neurodegeneration (Yanamadala \& Friedlander, 2010). Increases in, complement $C 3$ release are associated with an increase 
in AMPA membrane expression, synaptic excitation, and impairment of dendritic morphology, such as dendritic length and complexity (Alexander, Jacob, Bao, Macdonald, \& Quigg, 2005; Lian et al., 2015). Inhibition of the complement C3 receptor attenuates memory deficits in APP transgenic AD mice (Lian et al., 2015). Furthermore, mice deficient in C3 develop significantly fewer seizures following viral encephalomyelitis (Libbey, Kirkman, Wilcox, White, \& Fujinami, 2010). In stroke (Elvington et al., 2012) and AD (Strohmeyer, Shen, \& Rogers, 2000), both of which exhibit a hyperexcitability phenotype, CFB is activated and colocalizes with neurons. The effects of this colocalization are not well known, but may contribute to cell death and infarct volume observed after stroke (Elvington et al., 2012).

Chemokines, cytokines, and the complement system activated after peripheral viral infection may play a vital role in inducing hyperexcitability in the CNS. Activation of these mediators carries a risk for exacerbating seizures and other neurodegenerative conditions. Prolonged exposure or further insult could lead to glutamate dysregulation through increases in glutamate release, decreases in glutamate clearance mechanisms, and dysfunctioning glutamate receptors. Understanding these mechanisms could provide a therapeutic target after infection and possibly prevent neurodegenerative pathology. As mentioned previously, the hippocampus represents the most at risk brain region for neurodegeneration (Braak \& Braak, 1998) and is the origin of seizure activity during temporal lobe epilepsy in humans (Goldberg \& Coulter, 2013) and animals (Lu et al., 2016). Therefore, the current project will focus on alterations in glutamate levels in three subregions of the hippocampus following PIC injection.

\section{Hippocampal circuitry}


The hippocampus is one of the first regions affected in $\mathrm{AD}$ (Braak \& Braak, 1998) and is the ictal site for KA-induced seizures (Perry et al., 2003). This increased vulnerability may be related to the high concentration of glutamate receptors (Greenamyre \& Young, 1989) that mediate communication of the trisynaptic circuit of the hippocampus. This circuit is composed of distinct subregions including the dentate gyrus (DG), cornuammonis 3 (CA3) and cornuammonis 1 (CA1) (Figure 1). Although the pathway works as a circuit, each subregion has unique characteristics, including differences in synaptic connectivity, surface expression of glutamate receptors, gene expression profiles, and levels of glutamate release and clearance following potassium chloride (KCl)-evoked release (Greene, Borges, \& Dingledine, 2009; Gegelashvili \& Schousboe, 1998; Wilson et al., 2005). Information enters this one-way loop via axons of the entorhinal cortex known as perforant fibers (P. Andersen, Bliss, \& Skrede, 1971). These axons make the loop's first connection, with the granule cells of the dentate gyrus (DG) (Lomo, 2009; Sloviter \& Lomo, 2012). From these cells, the mossy fibers project to make the second connection in the CA3 area (Treves \& Rolls, 1992). Through the Schaffer collaterals fibers, the CA3 sends projections to the CA1, which completes the loop (Amaral, Dolorfo, \& Alvarez-Royo, 1991). Interestingly, the CA3 is also a region of high excitability because approximately 95 percent of the pyramidal cells receive input from other CA3 pyramidal cells known as recurrent fibers, meaning that the CA3 fires within its own region to form an associative network (Kandel \& Spencer, 1961). The CA1 region also exhibits intrinsic hyperexcitability in $\mathrm{AD}$ mice (Kerrigan, Brown, \& Randall, 2014). Because of these subregion specific alterations, we will examine glutamate regulation in the $\mathrm{DG}, \mathrm{CA} 3$, and CA1 separately. 


\section{Kainic acid-induced seizure model}

To study the effects of viral infection on glutamate dysregulation, we will use a KA-induced seizure model (Ben-Ari, 1985). PIC-challenged mice are more susceptible to KA-induced seizures (Kirschman et al., 2011), and hippocampal inflammatory responses are exacerbated (Michalovicz \& Konat, 2014). KA is a nondegradable analog of glutamate and potent neurotoxin that exerts its epileptic properties by acting on neuronal kainic acid receptors (KARs) (Hollmann \& Heinemann, 1994; Monaghan \& Cotman, 1982). The CA3 pyramidal cells are particularly susceptible to the epileptogenic action of KA because this area is enriched with high-affinity KA-receptors (Robinson \& Deadwyler, 1981). Upon binding to KARs, KA induces a multitude of cellular events, including the influx of cellular calcium (Nistri \& Cherubini, 1991) and neuronal apoptosis (Vincent \& Mulle, 2009). Although there is no experimental model that reproduces all of the features of temporal lobe epilepsy (TLE), the KA model induces seizures and neuropathological lesions that are similar to those occurring in patients with temporal lobe epilepsy (TLE) (Ben-Ari, Lagowska, Tremblay, \& Le Gal La Salle, 1979).

\section{Microelectrode arrays}

To study glutamate dysregulation in the DG, CA3, and CA1, we employ a novel technique, in vivo amperometry coupled to enzyme-based microelectrode arrays (MEAs) (Figure 2). Although microdialysis is the standard for sampling analyte concentrations in vivo, this technique suffers from many disadvantages (Westerink, Damsma, Rollema, De Vries, \& Horn, 1987). For example, spatial and temporal limitations of microdialysis restrict the ability to sample dynamic changes in glutamate near the synapse (Hillered, Vespa, \& Hovda, 2005; Obrenovitch, Urenjak, Zilkha, \& Jay, 2000). The large sample 
area (1-4mm in length) often causes damage and limits the detection of neuronal release (Borland, Shi, Yang, \& Michael, 2005; Jaquins-Gerstl \& Michael, 2009). In addition, the low temporal resolution (1-20 $\mathrm{min}$ ) of microdialysis is inadequate to measure the fast dynamics of glutamate uptake and clearance (Diamond, 2005). MEAs are advantageous because they allow for such measures due to their high temporal resolution $(10 \mathrm{~Hz})$, low limit of detection $(<0.5 \mu \mathrm{M})$, and high spatial resolution to selectively measure extracellular glutamate close to synapses (Burmeister \& Gerhardt, 2001; Burmeister et al., 2002b). Another benefit of MEAs over other ex vivo methods is the ability to study brain regions in vivo without disrupting their extrinsic and intrinsic connections, a particularly important consideration when examining the complex neural networks of the hippocampus. 


\section{Chapter 1 Table}

\begin{tabular}{|c|c|c|c|c|c|}
\hline Cytokines & Receptor & Glutamate Regulation & Neuronal activity & Memory & Associated diseases \\
\hline IFN $\beta$ & IFN $\beta$ receptor & $\uparrow$ Glutamate uptake & Prevents neuronal loss & \begin{tabular}{|c|} 
Cognitive \\
impairment in \\
mice lacking gene
\end{tabular} & $\begin{array}{l}\text { Neuroprotective, used in } \\
\text { treatment of epilepsy }\end{array}$ \\
\hline IL-6 & IL-6 receptor & $\begin{array}{l}\uparrow \text { connections to } \\
\text { excitatory synapses }\end{array}$ & $\downarrow \quad$ LTP & Impairs cognition & Epilepsy and neurodegeneration \\
\hline IL-1 $\beta$ & IL-1 $\beta$ receptor & $\begin{array}{c}\text { 个 Glutamate levels, } \\
\text { AMPA expression, } \downarrow \\
\text { GABA receptors, and } \\
\text { GLT-1 }\end{array}$ & $\begin{array}{l}\text { 个 Activity of NMDA } \\
\text { receptors }\end{array}$ & $\begin{array}{l}\text { Impairs CFC } \\
\text { memory }\end{array}$ & Neurodegeneration \\
\hline TNFa & TNFa receptor & $\begin{array}{l}\text { 个 Glutamate levels, } \\
\text { AMPA expression, } \downarrow \\
\text { GABA receptors }\end{array}$ & $\uparrow \quad$ NMDA activity & $\begin{array}{l}\text { Spatial memory } \\
\text { impairment }\end{array}$ & Neurodegeneration \\
\hline \multicolumn{6}{|l|}{ Chemokines } \\
\hline CXCL9, CXCL10, CXCL11 & CXCR3 & $\begin{array}{c}\uparrow \quad \text { Glutamate } \\
\text { receptors, } \downarrow \text { GABA } \\
\text { receptors }\end{array}$ & $\begin{array}{c}\uparrow \text { Spontaneous } \\
\text { neuronal activity, } \downarrow \\
\text { inhibitory synapses }\end{array}$ & $\begin{array}{c}\downarrow_{\text {cAMP }} \\
\text { (Important for long } \\
\text { term memory) }\end{array}$ & Neurodegeneration \\
\hline CXCL1, CXCL2 & CXCR2 & 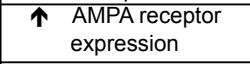 & $\uparrow$ NMDA activity & $\begin{array}{c}\text { Memory deficits in } \\
\text { novel object test }\end{array}$ & Neurodegeneration \\
\hline Ccl2 & CCR2 & $\begin{array}{c}\text { 个 Metabotrpoic } \\
\text { glutamate receptor } \\
\text { activation }\end{array}$ & $\uparrow$ Seizure activity & $\begin{array}{c}\text { Memory deficits in } \\
\text { radial arm water } \\
\text { maze }\end{array}$ & Pharmacoresistant epilepsy \\
\hline \multicolumn{6}{|l|}{ Complements } \\
\hline C3 & CR1 & $\begin{array}{c}\uparrow \quad \text { AMPA expression, } \\
\text { impairs dendritic } \\
\text { morphology }\end{array}$ & $\uparrow$ Synaptic excitation & $\begin{array}{c}\text { Memory } \\
\text { impairment in } \\
\text { MWM and Water } \\
\text { radial arm maze }\end{array}$ & Neurodegeneration \\
\hline CFB & $\begin{array}{c}\text { Major } \\
\text { histocompatibility } \\
\text { complex }(\mathrm{MHC})\end{array}$ & unknown & Colocalizes with neurons & unknown & Stroke and neurodegeneration \\
\hline
\end{tabular}

Table 1.1. Inflammatory mediators and glutamate homeostasis. Circulating

inflammatory mediators in the CNS produced after PIC-challenge cause changes in

glutamate regulation, neuronal activity, and memory. This table summarizes the changes

resulting from peripheral inflammation. 


\section{Chapter 1 Figures}

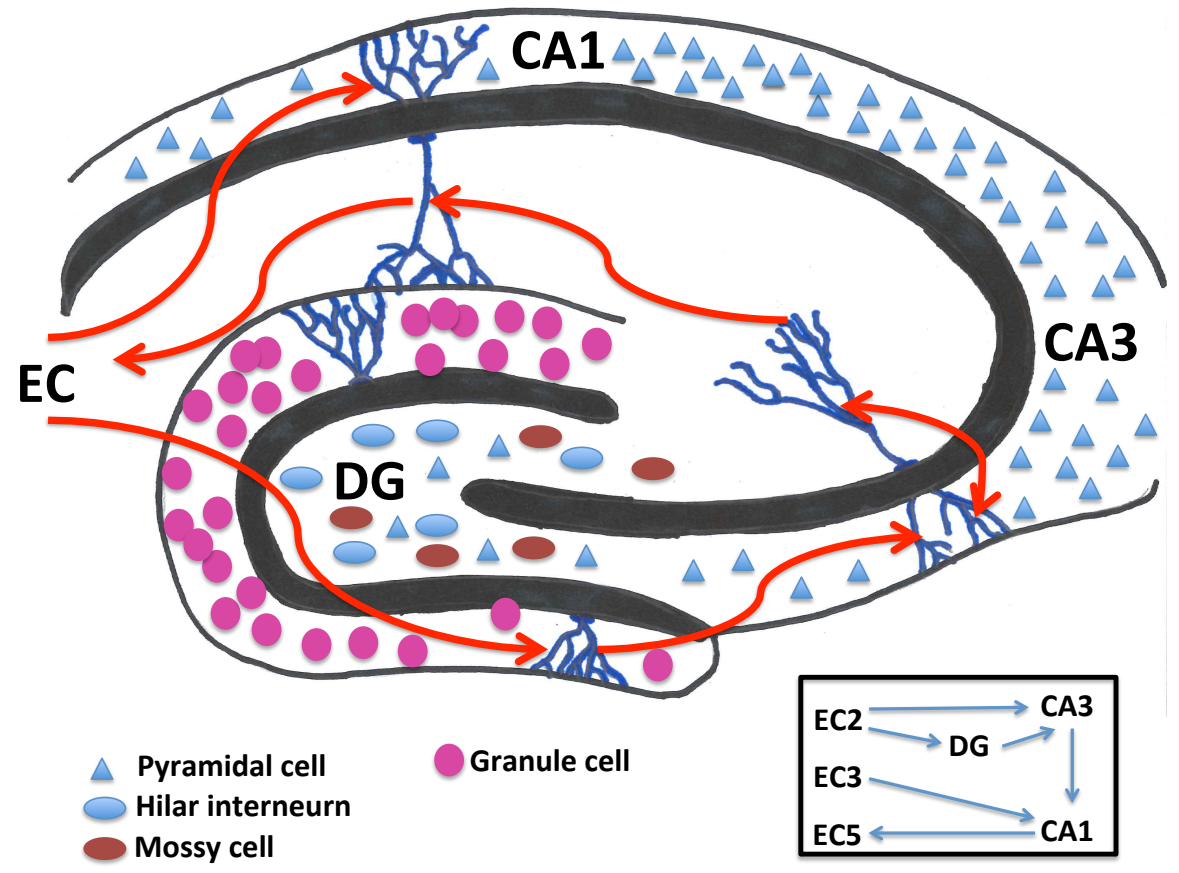

Figure 1.1. Hippocampal schematic. Information enters the hippocampus from different layers of the entorhinal cortex $(\mathrm{EC} 2,3,5)$ and signals travel through the trisynaptic loop. Layer 2 projects signals to the granule cells of the dentate gyrus (DG). Signals from the mossy fiber cells in the DG then progress to the CA3 region and are received in the CA1 via the Shaffer collateral fibers. The CA1 region completes the loop by sending signals to 
layer 5 of the EC. The EC2 and EC3 can also project directly to the CA3 and CA1, respectively. It should be noted that the CA3 consists of recurrent fibers that can propagate signals withing the CA3.

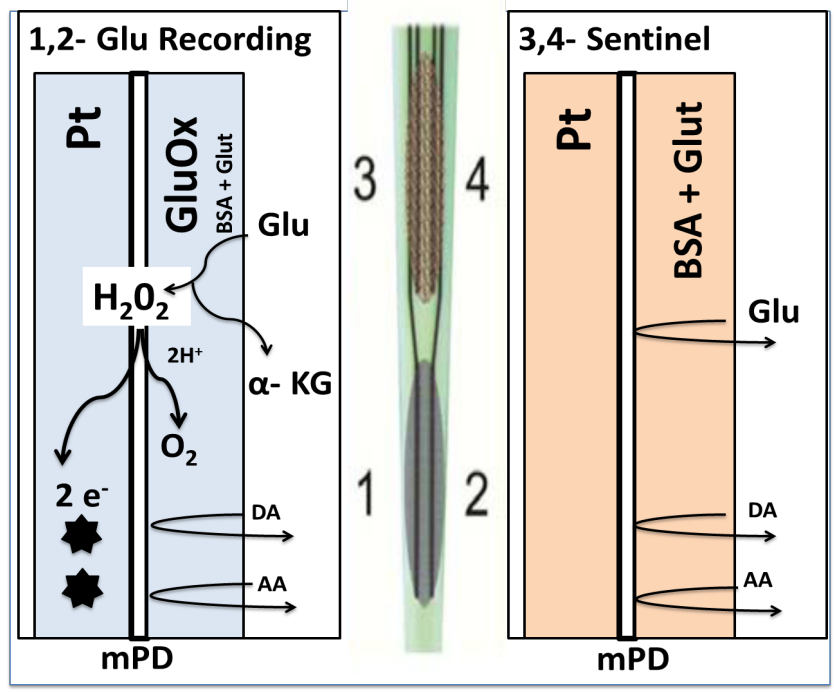

Figure 1.2. Diagram of the microelectrode array (MEA). The MEA consists of four platinum recording sites all of which are mPD plated. Two sites are coated with glutamate oxidase (1,2-Glu Recording) and the top two sites are coated with an inactive protein matrix (3,4-Sentinel). When glutamate comes into contact with the recording sites, it is broken down into alpha-ketoglutarate and the reporter molecule, hydrogen peroxide. Although sentinel sites allow smaller molecules to pass through the exclusion layer, larger interferents, such as ascorbic acid and dopamine are blocked. Therefore, we can subtract the difference between the two sites to determine the concentration of glutamate without noise or artifact. 


\section{The current research}

The aims of the current study were first to characterize glutamate levels in anesthetized mice after PIC-challenge and second to study the role of glutamate during KA-induced seizures in awake behaving animals after PIC-challenge. The exact mechanisms by which peripheral viral infections exacerbate neurodegenerative conditions is not known, but many major inflammatory mediators generated in response to peripheral viral challenge have been shown to increase neuronal excitability (Galic et al., 2012; Hu et al., 2000; Riazi et al., 2015; Viviani et al., 2003) and decrease neuronal inhibition (Stellwagen et al., 2005; S. Wang et al., 2000), both of which may lead to increased extracellular glutamate concentrations. These changes in neuronal signaling may be due to the changes in glutamate receptor expression resulting from a surge of inflammatory factors as shown in table 1.1. These changes in glutamate homeostasis are also related to memory impairment and often exacerbate neurodegenerative conditions. Given recent evidence linking glutamatergic hyperactivity to AD (Bakker et al., 2012; Busche et al., 2012; Hunsberger, Rudy, et al., 2015; Hunsberger, Weitzner, et al., 2015), PD (Ahmed et al., 2011; Schapira, 2010), MS (Kostic et al., 2013), and seizures (Chapman, 2000; Soukupova et al., 2015), deciphering mechanisms by which peripheral viral infection elevates extracellular glutamate is critical to the prevention of infectionmediated exacerbations in neurodegenerative conditions. 


\title{
Chapter 2
}

\section{Peripherally restricted viral challenge elevates extracellular glutamate and enhances synaptic transmission in the hippocampus.}

\begin{abstract}
Peripheral infections increase the propensity and severity of seizures in susceptible populations. We have previously shown that intraperitoneal (i.p.) injection of a viral mimic, polyinosinic-polycytidylic acid (PIC), elicits hypersusceptibility of mice to kainic acid (KA)-induced seizures. The present study was undertaken to determine whether this seizure hypersusceptibility entails alterations in glutamate signaling. Female C57BL/6 mice were i.p. injected with PIC, and after 24 hours, glutamate homeostasis in the hippocampus was monitored using the enzyme-based microelectrode arrays. PIC challenge robustly increased the level of resting extracellular glutamate. While presynaptic potassium-evoked glutamate release was not affected, glutamate uptake was profoundly impaired and non-vesicular glutamate release was augmented, indicating functional alterations of astrocytes. Electrophysiological examination of hippocampal slices from PIC-challenged mice revealed a several fold increase in the basal synaptic transmission as compared to control slices. PIC challenge also increased the probability of presynaptic glutamate release as seen from a reduction of paired-pulse facilitation
\end{abstract}


(PPF) and synaptic plasticity as seen from an enhancement of long-term potentiation (LTP). Altogether, our results implicate a dysregulation of astrocytic glutamate metabolism and an alteration of excitatory synaptic transmission as the underlying mechanism for the development of hippocampal hyperexcitability, and consequently seizure hypersusceptibility following peripheral PIC challenge.

\section{Introduction}

Seizures represent a major neuropathological affliction and an important cause of longterm disability. Seizures result from excessive and/or synchronous neuronal activity in the brain. Cerebral inflammation following trauma, ischemia, infections, tumors, etc., has been recognized as an important pathological feature that predisposes and/or elicits seizures (Marchi et al. 2009; Vezzani and Granata 2005; Ravizza et al. 2011). The underlying mechanisms entail the activation of resident innate immune cells, chiefly microglia and astrocytes, as well as the recruitment and activation of peripheral leukocytes leading to the production of a plethora of cytokines, chemokines, prostaglandins and other inflammatory agents. These inflammatory agents may increase excitatory inputs, decrease inhibitory inputs, or both, resulting in hyperexcitability of the neuronal networks, a hallmark of seizures.

Notably, also peripheral inflammation can increase seizure propensity in susceptible individuals (Tellez-Zenteno et al. 2005; Scheid and Teich 2007; Verrotti et al. 2009). The underlying mechanisms involve relaying peripheral innate immunity signals to the brain whereby they induce a "mirror inflammation" (Dantzer and Kelley 2007; Dantzer et al. 2008; Quan and Banks 2007). Several experimental studies dovetail with these clinical 
data. For example, the simulation of bacterial infection via intraperitoneal (i.p.) injection of a bacterial endotoxin, lipopolysaccharide (LPS) increases seizure susceptibility in mice as seen from a decrease in the threshold of clonic seizures instigated by pentylenetetrazole (PTZ) (Sayyah et al. 2003). In a rat model of inflammatory bowel diseases, intracolonical injection of 2,4,6-trinitrobenzene sulfonic acid (TNBS) increases the susceptibility to PTZ-induced seizures (Riazi et al. 2008). Moreover, experimental arthritis and subcutaneous granuloma decrease the onset and increase the score of PTZevoked seizures (Rao et al. 2008).

We have also shown that peripheral viral challenge robustly increases seizure susceptibility (Kirschman et al. 2011; Michalovicz and Konat 2014). In this experimental paradigm, intraperitoneal injection of a viral mimetic, polyinosinic-polycytidylic acid (PIC) results in a several-fold increase in the extent and duration of status epilepticus induced by kainic acid (KA) in mice (Kirschman et al. 2011). This seizure hypersusceptibility is protracted for three days after PIC challenge (Michalovicz and Konat 2014). Of note, PIC is an unstable inflammagen that is rapidly degraded in the bodily fluids (Krasowska-Zoladek et al. 2007), and when injected intraperitoneally does not reach the circulation (Fil et al. 2011). Therefore, PIC challenge represents a bolus stimulation of the innate immune cells within the peritoneal cavity, and these peripherally-generated inflammatory mediators instigate a cerebral response (Konat 2015). In particular, PIC challenge triggers a robust but transient surge of blood cytokines, i.e., interferon $\beta$ (IFN $\beta$ ), interleukin $1 \beta$ (IL-1 $\beta$ ), IL-6 and tumor necrosis factor $\alpha$ (TNF $\alpha)$ (Michalovicz and Konat 2014; Cunningham et al. 2007). This cytokine surge 
instigates a global cerebral response as seen from the upregulation of a myriad of inflammatory genes in all major brain regions (Cunningham et al. 2007; Konat et al. 2009; Fil et al. 2011). In the hippocampus, the ictal site of KA-induced seizures (Ben-Ari and Cossart 2000), PIC challenge dysregulates the expression of over six hundred genes that, in addition to inflammatory and stress proteins, encode several neurotransmissionrelated proteins and microRNAs (Michalovicz and Konat 2014;Michalovicz et al. 2015). This genomic reprograming undoubtedly underlies the development of seizure hypersusceptibility, albeit specific cellular and molecular pathways have not been defined.

The present study was undertaken to test the hypothesis that hyperexcitability ensuing PIC challenge features dysregulation of glutamate homeostasis. We employed the enzyme-based microelectrode technology for in vivo monitoring of extracellular glutamate levels in the hippocampus to identify neurotransmission-associated events affected by PIC challenge. The characterization of glutamate homeostasis was complemented with an electrophysiological study assessing synaptic transmission and plasticity in acute hippocampal slices.

\section{Materials \& Methods}

\section{Animals}

Eleven-week-old C57BL/6 female mice obtained from Charles River (Wilmington, MA) were group housed with free access to food and water in a temperature and humiditycontrolled colony room with a 12:12 light/dark cycle. Female mice were used to provide 
compatibility with previous studies (Cunningham et al. 2007; Fil et al. 2011; Konat et al. 2009; Michalovicz and Konat 2014). Acute antiviral response was induced by i.p. injection of $12 \mathrm{mg} / \mathrm{kg}$ of PIC (Invivogen, San Diego, CA) in saline. Mice injected with $100 \mu \mathrm{L}$ of saline served as vehicle controls. Mice were examined $24 \mathrm{~h}$ after PIC or saline injection. The West Virginia University and Auburn University Animal Care and Use Committees approved all experimental procedures.

\section{In vivo glutamate measurement}

Changes in extracellular glutamate in the hippocampus were monitored using the microelectrode arrays (MEA) technique (Burmeister and Gerhardt 2001) as previously described (Hunsberger et al. 2015a; Hunsberger et al. 2015b). Briefly, the electrodes obtained from Quanteon (Nicholasville, KY) were coated with glutamate oxidase and calibrated, as exemplified in Figure 2.1. A glass micropipette (Quanteon) was mounted to the arrays for intracranial drug delivery. Mice were anesthetized with isoflurane (1-4\% continuous inhalation), placed in a stereotaxic device (David Kopf Instruments, Tujunga, $\mathrm{CA}$ ) and the MEA/micropipette assemblies were inserted into the hippocampal subregions, i.e., dentate gyrus (DG), cornu ammonis 1 (CA1) and cornu ammonis 3 (CA3). The stereotaxic coordinates from the bregma were AP: $-2.3 \mathrm{~mm}, \mathrm{ML}:+/-1.5 \mathrm{~mm}$, DV: $2.1 \mathrm{~mm}$ for DG, AP: $-2.3 \mathrm{~mm}, \mathrm{ML}:+/-2.7 \mathrm{~mm}, \mathrm{DV}: 2.25 \mathrm{~mm}$ for CA3 and AP: $-2.3 \mathrm{~mm}$, ML: $+/-1.7 \mathrm{~mm}$, DV: $1.4 \mathrm{~mm}$ for CA1. A reference electrode was implanted under the skin in a remote site. All MEA recordings were performed at $10 \mathrm{~Hz}$ using constantpotential amperometry. All measurements and injections were performed after a stable baseline was reached (20-45 min). Both hemispheres were used for drug injection, and sub-regions within a hemisphere, were counterbalanced. 
Tonic glutamate levels were calculated in all three sub-regions by averaging extracellular glutamate levels over 10-s periods. Evoked release was induced in a subset of animals by delivering $50-100 \mathrm{~nL}$ of $70 \mathrm{mM}$ of potassium chloride $(\mathrm{KCl})$ solution every 2-3 min. The amplitudes of ten reproducible signals were averaged and compared. To measure glutamate uptake, a subset of animals received 1-2 injections at $50 \mathrm{~nL}$ increments within a 50-250 $\mathrm{nL}$ range of $200 \mu \mathrm{M}$ glutamate (Sigma-Aldrich, St. Louis, MO) delivered every 2-3 minutes in one hemisphere. Temporal clearance of glutamate was monitored and expressed as the net area under the curve (AUC). Glutamate release in a subset of animals was measured in the opposite hemisphere following inhibition of glutamate uptake with 50-250 $\mathrm{nL}$ of $500 \mu \mathrm{M}$ DL-threo- $\beta$-benzyloxyaspartate (TBOA; Tocris, Ellisville, MO). The amperometric data were analyzed using a custom Microsoft Excel software program (MatLab) as previously described (Hunsberger et al. 2015a; Hunsberger et al. 2015b). Data from some hippocampal regions were excluded for reasons including failure of the MEA or clogging of the micropipette. The number of mice per treatment group for glutamate measurements is indicated in Table 2.1.

\section{Hippocampal slice preparation}

Animals were euthanized with carbon dioxide, the hippocampi were isolated and $350-\mu \mathrm{m}$ thick transverse slices were prepared using a Leica VT1200S Vibratome (Leica Microsystems, Wetzlar, Germany). Slices were incubated at room temperature in artificial cerebrospinal fluid (ACSF; $124 \mathrm{mM} \mathrm{NaCl}, 3 \mathrm{mM} \mathrm{KCl}, 1.2 \mathrm{mM} \mathrm{MgSO}_{4}, 2.1 \mathrm{mM}$ $\mathrm{CaCl}_{2}, 1.4 \mathrm{mM} \mathrm{Na}_{2} \mathrm{PO}_{4}, 26 \mathrm{mM} \mathrm{NaHCO}_{3}, 20 \mathrm{mM}$ dextrose, $\mathrm{pH}$ 7.4) saturated with $95 \%$ 
$\mathrm{O}_{2} / 5 \% \mathrm{CO}_{2}$. After one-hour incubation, slices were transferred into a recording chamber for electrophysiological measurements as previously described (Wang \& Zheng 2015).

\section{Extracellular field potential recording}

The slices were examined) with an Olympus BX50WI microscope equipped with a highresolution, high-sensitivity CCD camera (Dage-MTI, Michigan City, IN). A bipolar stimulating electrode (100- $\mu \mathrm{m}$ separation, $\mathrm{FHC}$, Bowdoinham, ME) was placed in the Schaffer collateral pathway. A patch pipette drawn with the P87 Brown-Flaming Puller, (Sutter Instruments, Novato, CA) and filled with ACSF (2-5 M $\Omega, 1.5 \mathrm{~mm} \mathrm{OD}, 0.86 \mathrm{~mm}$ ID) was placed in the stratum radiatum of CA1 to record field excitatory postsynaptic potentials (fEPSPs). All parameters, including pulse duration, width, and frequency were computer controlled. Constant-current pulse intensities were controlled by a stimulus isolation unit A360 (WPI, Sarasota, FL).

Basal synaptic transmission, represented by input-output responses, was determined as ratios of the slopes of fEPSP and plotted as a function of stimulus intensities. For paired pulse facilitation (PPF), pairs of stimuli separated by varying intervals between them were delivered to the stratum radiatum at $0.05 \mathrm{~Hz}$. Paired responses were averaged, and ratios of fEPSP slopes from the second stimulus (fESPS2) to fEPSP slopes from the first stimulus (fESPS1) were calculated and plotted as a function of interstimulus intervals. Long-term potentiation (LTP) was evaluated after $10 \mathrm{~min}$ of stable baseline period. Initial recordings were carried out with low frequency stimulation $(0.05 \mathrm{~Hz})$ at intensities of 0 $500 \mu \mathrm{A}$ to determine the maximal excitatory potential. For LTP experiments the stimulus intensity was adjusted to produce $50 \%$ of the amplitude at which initial population spikes 
begin to appear. LTP was induced with 5 high frequency stimuli (HFS; 100 pulses, $100 \mathrm{~Hz}$ ) every 20 seconds. LTP was measured 55-60 minutes post HFS.

The data were recorded online using the WinLTP 2.2 software (University of Bristol, UK). Standard off-line analyses of the data were conducted using Prism software (GraphPad Prism version 5.00, San Diego California, USA). Results are expressed as means \pm SEMs.

Statistical analyses. Results were evaluated by the one-way ANOVA using JMP (SAS, Cary, NC) and SPSS v.21 (SPSS Inc., Chicago, IL) for glutamate and electrophysiological data, respectively. For electrophysiological data, significant omnibus tests were followed by Student's t-tests. Results are presented as means \pm SEMs, and differences between groups were considered statistically significant at $\mathrm{p} \leq 0.05$.

\section{Results}

An increased glutamatergic transmission is a plausible mechanism underscoring PICinduced hypersusceptibility to KA-induced seizures found in previous studies (Kirschman et al. 2011; Michalovicz and Konat 2014). Here, we assessed glutamate homeostasis in the hippocampus, the ictal site of KA-induced seizures (Ben-Ari and Cossart 2000), using enzyme-based microelectrode technology that allows real-time monitoring of extracellular glutamate in vivo. We used isoflurane to avoid anestheticinduced changes in resting glutamate levels (Mattinson et al. 2011), and measured glutamate in hippocampal subregions known to be rich in glutamate receptors, i.e., DG, CA1 and CA3 (Nimchinsky et al. 2004;Pettit and Augustine 2000). All measurements were performed $24 \mathrm{~h}$ after i.p. injection of PIC or saline. As shown in Fig. 2.2a, PIC- 
challenge induced a robust increase in tonic, resting glutamate levels in all three subregions. The highest increase of 11 -fold over control was observed in $\mathrm{DG}[\mathrm{F}(1,18)=$ $41.49, p<.0001] . \mathrm{CA} 1[\mathrm{~F}(1,19)=15.58, p=.0009]$ and $\mathrm{CA} 3[\mathrm{~F}(1,18)=18.94, p=$ $.0004]$ featured 9.8-fold and 5.8-fold increase, respectively.

Several mechanisms can be considered to account for the increase of tonic glutamate. For example, PIC challenge may alter the capacity or "ceiling" of neuronal terminals to release glutamate (Hinzman et al. 2010). To test this possibility, we used the paradigm of potassium-evoked glutamate release (Day et al. 2006). As shown in Fig. 2.2b, the injection of $\mathrm{KCl}$ induced a transient (approximately $5 \mathrm{~s}$ ) elevation of extracellular glutamate. No differences were observed between PIC-challenged vs. control mice in any sub-region $(\mathrm{DG}[\mathrm{F}(1,7)=.11, p=.75]$; CA1 $[\mathrm{F}(1,7)=.002, p=.96]$; CA3 $[\mathrm{F}(1,7)=.04$, $p=.84]$; Fig. 2c). These results indicate that PIC challenge does not increase the neurotransmitter content in presynaptic terminals.

A decreased glutamate clearance represents an alternative mechanism for the rise of extracellular glutamate. To test this option, we injected exogenous glutamate, and monitored its clearance by measuring net AUC. We first compared the amplitude of glutamate signals following injection of exogenous glutamate to confirm differences in net AUC between the PIC-challenged and saline-injected mice following application of exogenous glutamate were due to alterations in the uptake and not to differences in the amount of applied glutamate (Hunsberger et al. 2015a; Hunsberger et al. 2015b). Prior to AUC measurement, maximal amplitudes of the glutamate signal were determined to 
ensure reproducibility of glutamate injection. Fig. 2.3a shows no significant differences in the maximal amplitudes in any sub-region in control vs. PIC-challenged mice (DG $[\mathrm{F}(1,9)=.06, p=.81] ; \mathrm{CA} 1[\mathrm{~F}(1,7)=.25, p=.63] ; \mathrm{CA} 3[\mathrm{~F}(1,9)=.43, p=.53])$. Also, no effect of PIC challenge on the diffusion of exogenous glutamate within the tissue expressed as the $T_{\text {rise }}$ values, i.e., the time for the signal to reach maximum amplitude (Sykova et al. 1998), was evident in any sub-region $(\mathrm{DG}[\mathrm{F}(1,9)=.07, p=.80]$; CA1 $[\mathrm{F}(1,7)=.25, p=.63] ; \mathrm{CA} 3[\mathrm{~F}(1,9)=.24, p=.63]$; Fig. 2.3b), suggesting any reductions in glutamate uptake were not because of diffusion from the point source (micropipette) to the MEA. Temporal analysis of glutamate levels following its injection revealed a profoundly delayed clearance profile in PIC-challenged mice (Fig. 2.3c), indicative of an impairment of the neurotransmitter's uptake. The quantitation of this impairment is shown in Fig. 2.3d. The greatest increase in net AUC induced by PIC challenge of 8.3fold over control was found in CA3 $[\mathrm{F}(1,9)=11.55, p=.008]$. The values for DG $[\mathrm{F}(1,9)$ $=13.77, p=.005]$ and CA1 $[\mathrm{F}(1,7)=18.16, p=.004]$ were 6.7 -fold and 3.8 -fold, respectively.

The augmentation of tonic glutamate may also result from an increased release of glutamate by astrocytes. We inhibited glutamate uptake with TBOA, a competitive nontransportable EAAT blocker (Shimamoto et al. 1998; Montiel et al. 2005; Tovar et al. 2009) to confirm the involvement of these receptors and to unmask the release of glutamate (Jabaudon et al. 1999). Local application of TBOA produced a transient increase in the extracellular glutamate concentration in both PIC-challenged and control mice (Fig. 2.4a), although the amplitude of this increase differed (Fig. 2.4b). Thus, DG 
$[\mathrm{F}(1,8)=5.80, p=.04]$ and $\mathrm{CA} 1[\mathrm{~F}(1,8)=7.06, p=.03]$ featured an 18- and 17-fold increase in PIC-challenged vs. control mice. In contrast, PIC challenge had no effect on glutamate release in CA3 $[\mathrm{F}(1,8)=.51, p=.50]$.

The increased tonic glutamate, the impaired glutamate uptake, and the increased glutamate release implicated that PIC challenge might enhance glutamatergic neurotransmission in the hippocampus. To verify this notion, we examined basal synaptic transmission and synaptic plasticity in hippocampal slices by field recordings. Fig. 2.5a shows representative traces of EPSPs in hippocampi from PIC challenged vs. control mice. PIC challenge markedly increased the amplitude and slope of the EPSP. As seen from Fig. 2.5b, PIC challenge profoundly enhanced basal synaptic transmission denoted by input-output responses of the neuronal networks (stimulus response curve) $[\mathrm{F}(1,41)=30.35, \mathrm{p}<0.0001]$, at each point of measurement $[p \mathrm{~s}>.05]$. Throughout the range of stimulus intensities from 50 to $500 \mu \mathrm{A}$, the synaptic efficiency increased by over 2.5fold in slices from PIC-challenged mice as compared to slices from saline-injected mice. A change in basal synaptic transmission may result from alterations in pre- post- and peri-synaptic elements. To further characterize which component across the synapse actually contributed to PIC-induced increased synaptic transmission, we used the PPF protocol that reflects residual calcium levels, a presynaptic mechanism that plays a major role in short-term and long-term plasticity. PIC challenge decreased $\operatorname{PPF}[F(1,19)=7.391$, $\mathrm{p}=0.014]$ at the short $(50 \mathrm{~ms})$ stimulus interval $[p<.05]$, indicating an increase in presynaptic release probability due to alteration in either presynaptic compartment or astrocyte calcium signaling (Fig. 2.5c). Albeit, no effect was observed at longer intervals 
[ps>.0.5]. LTP, a cellular substrate of plasticity that may feature both pre- and postsynaptic expression (Padamsey and Emptage 2014), was significantly increased by PIC challenge $[F(1,68)=2.47, p=.0007$; Fig. $2.5 \mathrm{~d}]$.

\section{Discussion}

The major finding of our study is that peripheral PIC challenge disrupts cerebral glutamate homeostasis, resulting in a robust increase in the basal extracellular glutamate concentration (Fig. 2.2a). This increase is likely to underlie hippocampal hypersusceptibility to KA-induced seizures in PIC challenged mice (Kirschman et al. 2011; Michalovicz and Konat 2014). In support of this notion, increased tonic glutamate levels have been shown to correlate positively with the severity of focal motor seizures induced by intrahippocampal injection of 4-aminopyridine (4-AP) (Stephens et al. 2014). Also, astrocytic release of glutamate has been shown to facilitate the initiation of seizures (Kang et al. 2005), while the suppression of glial glutamate release leads to decreased seizure susceptibility (De Bundel D. et al. 2011). In addition, human epileptogenic hippocampi exhibit augmented basal glutamate levels during interictal periods that may contribute to seizure generation (Cavus et al. 2005). Moreover, the overflow of extracellular glutamate has been recognized as a key factor in the development of neuronal hyperexcitability (Featherstone and Shippy 2008). For example, dysregulation of extracellular glutamate homeostasis has been directly linked to hyperexcitability of cortical and spinal cord neurons at diverse pathological conditions (Campbell et al. 2012; Campbell et al. 2014; Campbell and Hablitz 2004; Campbell and Hablitz 2008; Putatunda et al. 2014). Glutamate-induced hyperexcitability is chiefly mediated by 
ionotropic glutamate receptors, in particular, NMDA receptors, but the involvement of metabotropic glutamate receptors has also been implicated (Featherstone and Shippy 2008). The mechanism entails a direct ligation of the receptors, although other, more circuitous pathways may also be involved. Consequently, we posit that the amplified response of the CA1 pyramidal cells induced by the upsurge of extracellular glutamate in PIC challenged mice contributed to the enhanced synaptic transmission (Fig. 2.5b), PPF (Fig. 2.5c), and LTP (Fig. 2.5d). However, a possibility that PIC challenge might also reduce inhibitory signaling can be considered. For example, a reduction in the number of inhibitory synapses was observed in the cortex of mice following repeated LPS injections (Chen et al. 2014).

The elevation of tonic glutamate could be due to increased glutamate release, decreased glutamate uptake, or both. Local application of potassium evoked the same amounts of glutamate in PIC and control hippocampi (Fig. 2.2c), indicating no alteration in the capacity or ceiling of presynaptic release of this neurotransmitter. However, the clearance of injected glutamate was profoundly hampered (Fig. 2.3d), indicating an impairment of glutamate uptake by PIC challenge. Inflammatory cytokines upregulated in the hippocampus in response to PIC challenge might mediate this impairment. For example, IL-1 $\beta$ and TNF $\alpha$ inhibit astrocytic glutamate uptake (Hu et al. 2000; Ye and Sontheimer 1996), and the Tnfa and $I l l b$ gene expression is upregulated in the hippocampi of PICchallenged mice as compared to controls (Michalovicz and Konat 2014).

The excitatory amino acid transporters 1 and 2 (EAAT1/2) expressed almost exclusively in astrocytes play the major role in the uptake of glutamate (Niciu et al. 2012). The application of TBOA, a specific competitive inhibitor of EAAT1/2 (Shimamoto et al. 
1998), induced a transient increase of extracellular glutamate (Fig. 2.4), indicating the involvement of these transporters. However, the contribution of neuronal transporters cannot be ruled out. Moreover, in DG and CA1 of PIC challenged animals, local TBOA application elicited much greater glutamate spikes than in control tissues. Because blocking of EAAT unmasks glutamate release (Jabaudon et al. 1999), our results suggest that PIC challenge not only impairs glutamate uptake but also augments glutamate release from astrocytes. This result is consistent with previous studies showing the enhancement of astrocytic glutamate release by inflammatory mediators, i.e., IL-1 (Casamenti et al. 1999), TNF $\alpha$ and prostaglandins (Bezzi et al. 2001). Altogether, our results strongly implicate astrocytes as cellular targets for inflammatory mediators generated in response to PIC challenge.

In contrast to DG and CA1, no difference between PIC challenged and control mice in the post-TBOA glutamate amplitude was detectable in CA3 (Fig. 2.4), suggesting that the release of glutamate in this subregion is not affected by the inflammatory milieu instigated by PIC challenge. Because presynaptic glutamate release was not altered in CA3 (Fig. 2.2c), the astrocytic release mechanisms are likely candidates to account for this region-specificity. Astrocytes release glutamate through different mechanisms, e.g., $\mathrm{Ca}^{2+}$-dependent exocytosis, glutamate exchange via the cystine-glutamate antiporter (Xc) and reversal of uptake by glutamate transporters (Malarkey and Parpura 2008). It is tempting to speculate that unlike DG and CA1 astrocytes, CA3 astrocytes use mechanisms that are not susceptible to the inflammatory milieu induced by PIC challenge. Such a differential response is buttressed by a previous observation that in the presence of TBOA, tetraethylammonium chloride elicits a several-fold greater glutamate 
release in CA3 than in CA1 or DG (Chiba et al, 2010). However, specific mechanisms may vary between these two paradigms.

Field recordings in hippocampal slices prepared from PIC-challenged vs. control mice are congruent with the dysregulated glutamate homeostasis observed in vivo. Thus, the robust increase in the basal glutamatergic synaptic transmission (Fig. 2.5b) likely resulted from the elevation of extracellular glutamate (Fig. 2.2a). The underlying mechanisms might involve the activation of extrasynaptic glutamate receptors (Petralia 2012). PPF, an index of short-term plasticity, reflects synaptic efficacy determined by the probability of presynaptic neurotransmitter release (Zucker and Regehr 2002). PIC challenge significantly reduced PPF (Fig. 2.5c), indicating that increased probability of glutamate release at the terminals of the Schaffer collaterals might contribute to the increased synaptic transmission. However, this increased presynaptic activity is in divergence with unchanged potassium-evoked glutamate amplitudes (Fig. 2.2c), another facet of the presynaptic neurotransmitter release. A plausible explanation is that the glutamate amplitudes measure the maximum capacity for release by depleting presynaptic glutamate pool with large doses of potassium, and these measurements may not be compatible with the physiological/functional release measured by PPF. Furthermore, LTP that can be expressed at postsynaptic as well as presynaptic loci (Padamsey and Emptage 2014) was increased by PIC challenge (Fig. 2.5d), indicating an enhancement of synaptic strength. Altogether, these results show that PIC challenge increases both basal synaptic transmission and synaptic plasticity.

In addition, the slice experiments provide compelling evidence for the intrinsic nature of the hippocampal alterations induced in PIC-challenged mice. For instance, peripheral 
inflammation might have increased the permeability of KA and/or glutamate through the blood-brain barrier (BBB), leading to hyperexcitability of hippocampal networks that would manifest as seizure hypersusceptibility. However, the robustly augmented excitatory synaptic transmission in the perfused slices from PIC-challenged as compared to control animals shows that the hyperexcitability indeed originates in the hippocampal parenchyma. This finding corroborates our previous study showing greatly increased spontaneous ictal activity elicited with 4-aminopurine in hippocampal slices from PICchallenged vs. control mice (Konat et al. 2012). As discussed above the augmentation of synaptic transmission results from the elevation of extracellular glutamate. Ergo, the slice studies also indirectly verify the intrinsic nature of glutamate dysregulation observed in vivo.

We have recently shown that PIC challenge profoundly upregulates expression of the complement in the hippocampus, and that this upregulation is commensurate with the period of seizure hypersusceptibility (Michalovicz et al. 2015). The complement is a major mediator of synaptic modifications (Stevens et al. 2007; Schafer et al. 2012;

Stephan et al. 2013), and complement proteins have proconvulsive activity when injected into the hippocampus (Xiong et al. 2003). Therefore, it's tempting to speculate that the alteration of glutamate homeostasis and hyperexcitability might be induced by the complement proteins. The mechanisms of such alterations might entail anaphylatoxins generated through the complement activation. Anaphylatoxins can activate their cognate receptors on microglia, astrocytes and neurons resulting in the generation of inflammatory factors that affect function of the postsynaptic terminals. For example, Il$1 \beta$ (Viviani et al. 2003; Yang et al. 2005), IL-6 (Xiaoqin et al. 2005; Samland et al. 
2003), TNF $\alpha$ (Beattie et al. 2002; Stellwagen et al. 2005), IFN $\beta$ (Hadjilambreva et al. 2005), CXCL10 (Ragozzino et al. 1998), CXCL1/2 (Giovannelli et al. 1998; Ragozzino et al. 1998) and the prostaglandin PGE2 (Chen and Bazan 2005) can enhance glutamatergic synaptic transmission. Thus, in addition to the disruption of glutamate homeostasis discussed formerly, inflammatory factors may induce hyperexcitability of the hippocampal neurons. Alternatively, complement proteins or their derivatives/complexes might bind to synaptic structures resulting in functional impairment of surface receptors that control glutamate homeostasis and/or synaptic transmission.

Recently, seizure hypersusceptibility of rats subjected to colonic inflammation (Riazi et al. 2008) has been linked to an increased synaptic transmission in the hippocampus (Riazi et al. 2015), albeit the extent of this increase was much less than the increase observed here. In contrast to our study, the colonic inflammation reduced LTP in hippocampal slices. Therefore, it seems that hippocampal hyperexcitability may be a common mechanism by which peripheral inflammation increases seizure susceptibility, but the effects on synaptic plasticity vary depending on the inflammatory paradigm.

In conclusion, our results indicate that inflammation instigated by peripheral PIC challenge enhances excitatory synaptic transmission and plasticity in the hippocampus by elevating extracellular glutamate concentration and increasing presynaptic activity. These putative pathway are likely responsible for the development of seizure hypersusceptibility. Our results warrant a comprehensive investigation of the underlying mechanisms at both the cellular and molecular level to provide a foundation for the 
development of therapeutic strategies for the management of inflammation-related seizures. 


\section{Chapter 2 Table}

\begin{tabular}{|c|c|c|c|c|c|c|}
\hline & \multicolumn{2}{|c|}{$\underline{\mathrm{DG}}$} & \multicolumn{2}{|c|}{$\underline{\mathrm{CA} 3}$} & \multicolumn{2}{|c|}{$\underline{\mathrm{CA} 1}$} \\
\hline & PIC & Saline & PIC & Saline & $\mathrm{PIC}$ & Saline \\
\hline Tonic & 11 & 9 & 11 & 9 & 12 & 9 \\
\hline $\mathrm{KCl}$ & 5 & 4 & 5 & 4 & 5 & 4 \\
\hline $\begin{array}{l}\text { Exogenous } \\
\text { glutamate }\end{array}$ & 5 & 6 & 6 & 5 & 4 & 5 \\
\hline TBOA & 6 & 4 & 6 & 4 & 6 & 4 \\
\hline
\end{tabular}

Table 2.1. Number of mice used in glutamate measurement experiments. 


\section{Chapter 2 Figures}

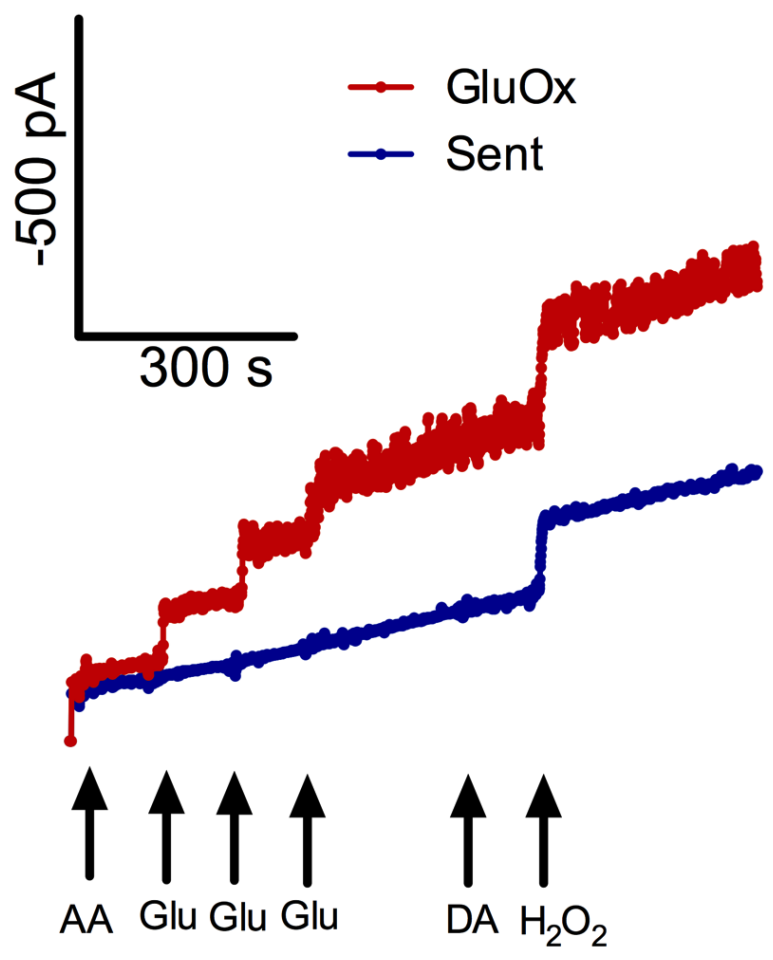

Figure 2.1. In vitro calibration of a self-referencing microelectrode measuring the change in current (pA) on a glutamate oxidase site (GluOx; red) vs. a sentinel site (Sent; blue). Interferents, such as ascorbic acid (AA) and dopamine (DA), did not alter the current at either glutamate oxidase or sentinel sites. Addition of glutamate (Glu) produced a stepwise current increase on the glutamate oxidase site, but no change on the sentinel site. Hydrogen peroxide $\left(\mathrm{H}_{2} \mathrm{O}_{2}\right)$ produced an increase in current on both sites. Sensitivity, slope, limit of detection, and $\mathrm{R}^{2}$ values were calculated after calibration. 

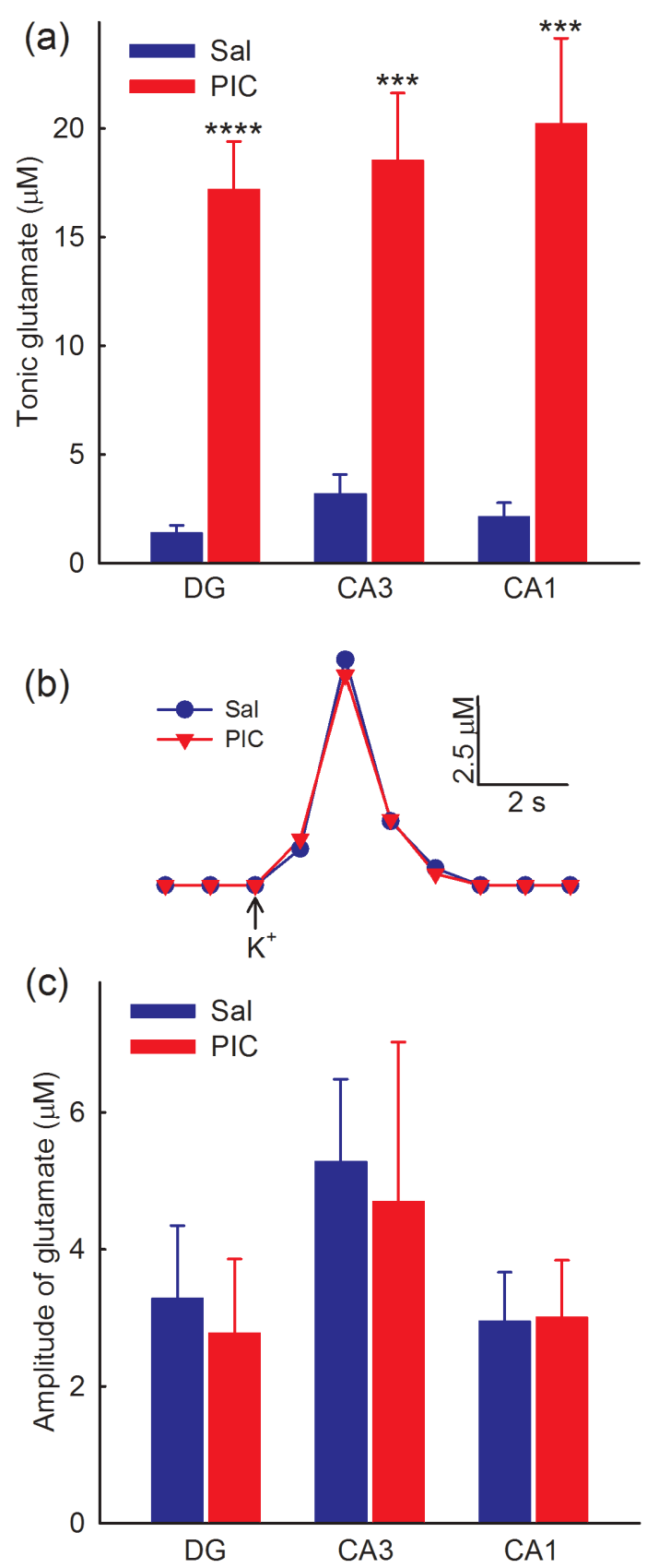

Figure 2.2. Tonic glutamate levels and evoked glutamate release in the hippocampus. Mice were intraperitoneally injected with PIC or saline (control). After $24 \mathrm{~h}$, hippocampal glutamate was analyzed by the enzyme based microelectrode technique in the dentate gyrus (DG), cornu ammonis 1 (CA1) and cornu ammonis 3 (CA3). (a) Extracellular tonic glutamate levels in the hippocampal sub-regions. (b) Baseline- 
matched representative traces of $\mathrm{K}^{+}$evoked release of glutamate in CA3. (c) The amplitudes of $\mathrm{K}^{+}$evoked release of glutamate in the hippocampal sub-regions. For details see Methods. Bars represent means \pm SEMs. Asterisks denote values significantly different from respective controls $* * * \mathrm{p} \leq .001, * * * * \mathrm{p} \leq .0001)$ 

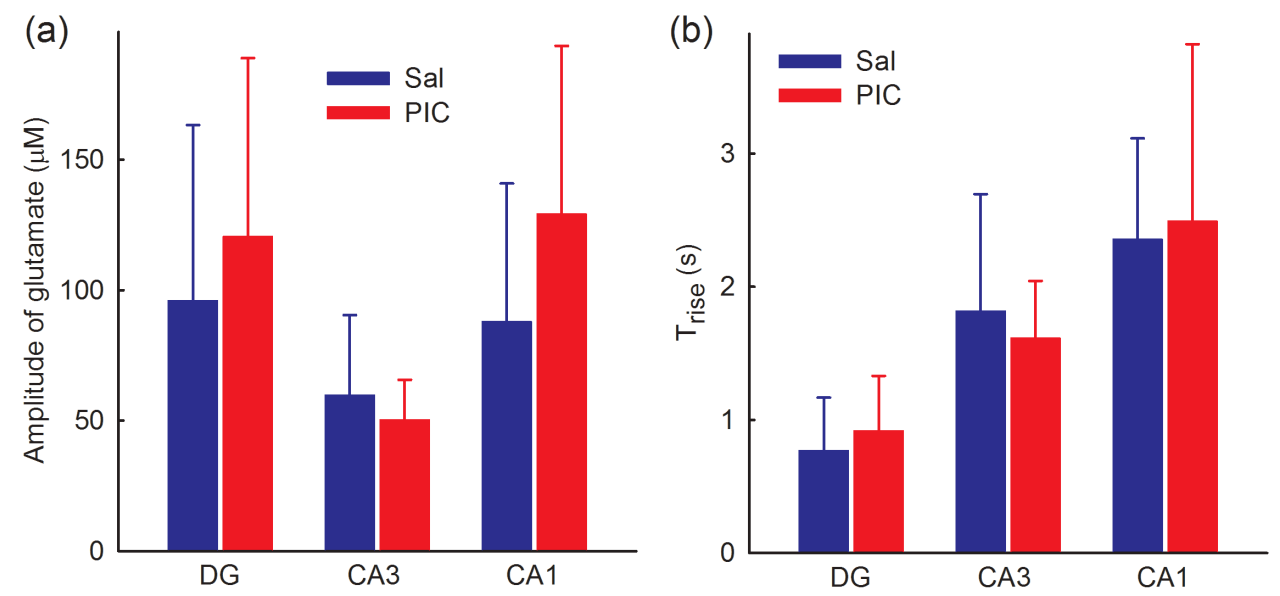

(c)

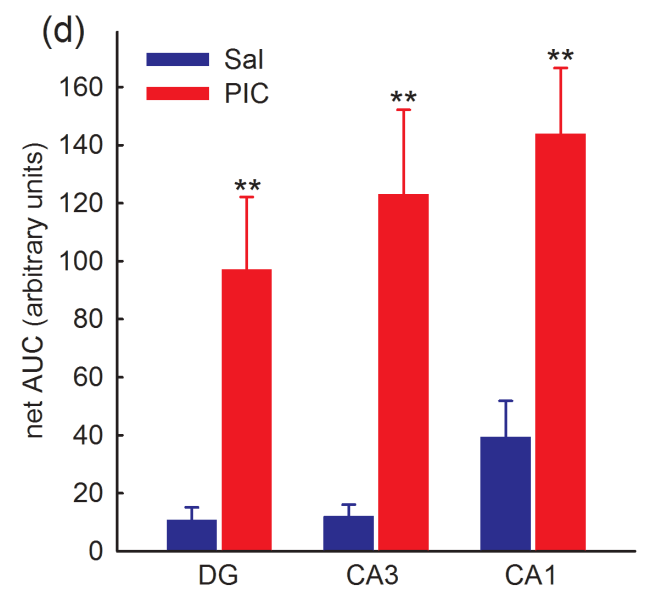

Figure 2.3. The uptake of exogenous glutamate in the hippocampus. Mice were intraperitoneally injected with PIC or saline (control). After $24 \mathrm{~h}$, hippocampal glutamate was analyzed by the enzyme based microelectrode technique in different hippocampal sub-regions as indicated. (a) The amplitude of signals following local injection of 200 $\mu \mathrm{M}$ glutamate. (b) Glutamate diffusion expressed as time to reach maximum amplitude $\left(\mathrm{T}_{\text {rise }}\right)$. (c) Peak-matched representative traces in the DG. (d) Glutamate uptake expressed as the net area under the curve (AUC). For details see Methods. Bars represent means \pm SEM. Asterisks denote significant differences from respective controls $(* * \mathrm{p} \leq .01)$. 
(a)
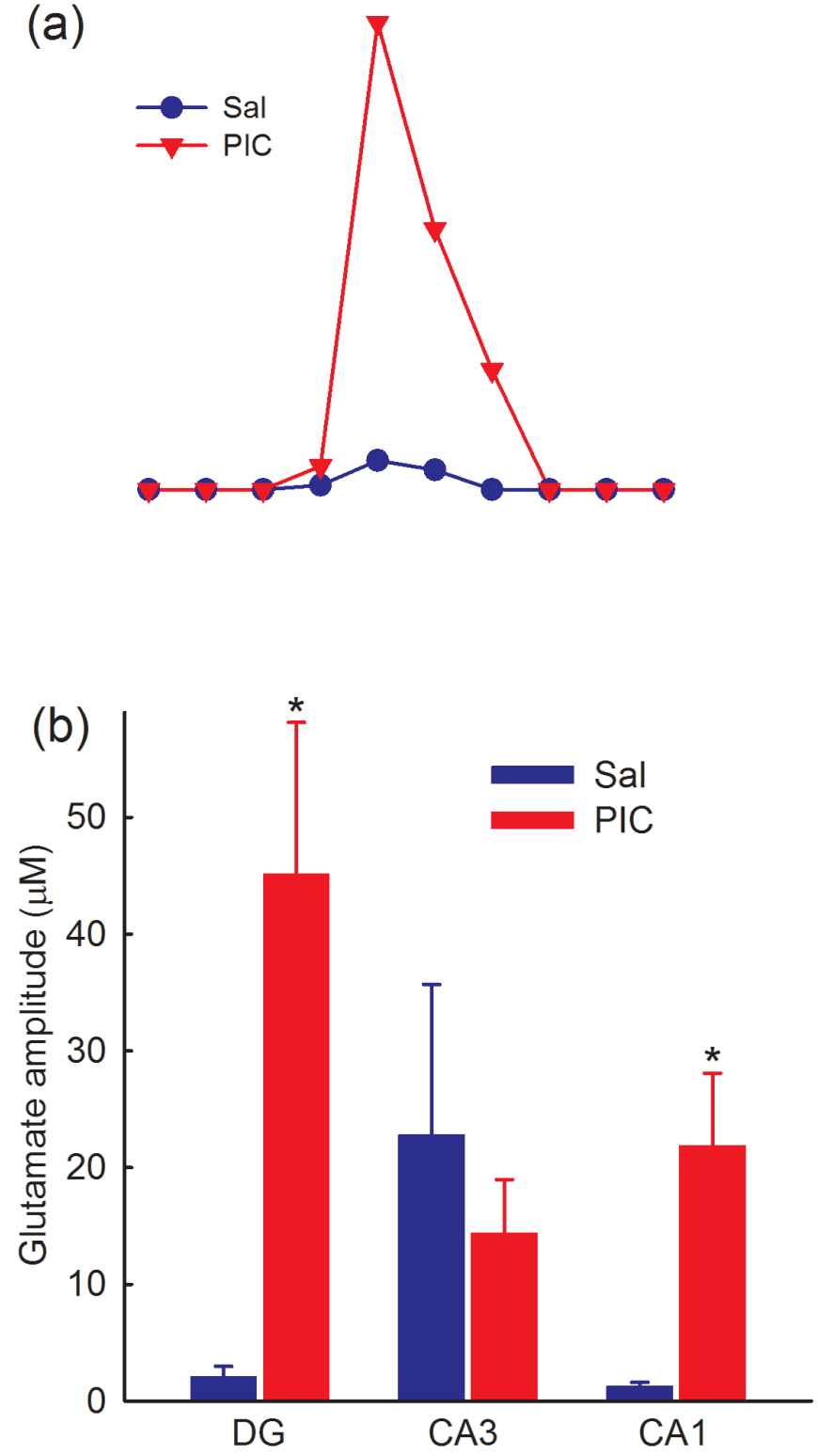

Figure 2.4. Spontaneous release of extracellular glutamate in the hippocampus. Mice were i.p. injected with $12 \mathrm{mg} / \mathrm{kg}$ of PIC or saline (control). After $24 \mathrm{~h}$, glutamate uptake was blocked by the application of $500 \mu \mathrm{M}$ TBOA to unmask glutamate release, and the levels of extracellular glutamate were determined in different hippocampal sub-regions as indicated. (a) A representative trace of transient glutamate release in DG in PIC- and 
saline-injected mice. (b) The amplitude of extracellular glutamate in the hippocampal sub-regions following TBOA application. For details see Methods. Bars represent means \pm SEM. Asterisks denote significant differences from respective controls $(* p \leq .05)$. 
(a)
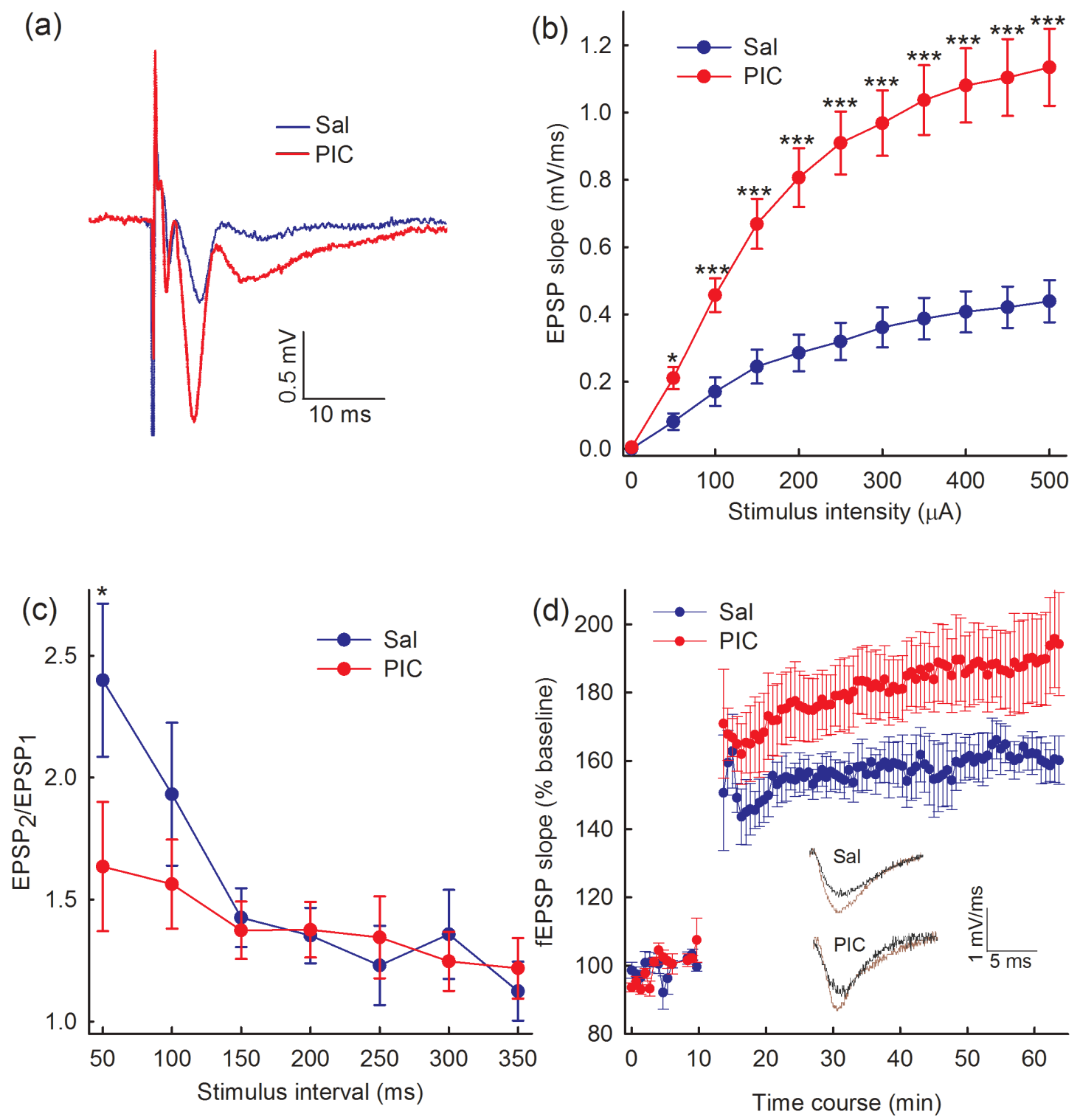

Figure 2.5. Synaptic transmission in hippocampal slices. Mice were intraperitoneally injected with PIC or saline (control), and after $24 \mathrm{~h}$, hippocampal slices were prepared. The Schaffer collateral pathways of CA3 were stimulated, and fEPSPs evoked in the striatum radiatum of CA1 were recorded. (a) Representative traces of fEPSPs evoked at a stimulus intensity of $200 \mu \mathrm{A}$. (b) Basic synaptic transmission as the fEPSP slope measured at increasing stimulus intensity (c) Paired-pulse facilitation expressed as the change of ratios of the second stimulus fEPSP slopes to the first stimulus fEPSP slopes 
plotted as a function of interstimulus intervals. (d) Long term potentiation calculated as the fEPSP ratio over time. Inset: Representative traces shown include data collected from saline-injected and PIC-challenged animals during baseline recordings (black) overlayed on traces during 55-60 minute LTP (brown). For details see Methods. Symbols represent means \pm SEMs from 3 mice (12 slices) per group. Asterisks denote significant differences from respective controls (Student's t-test; * $\mathrm{p} \leq .05, * * * \mathrm{p} \leq .001$ ). 


\section{Reference List}

Beattie E. C., Stellwagen D., Morishita W., Bresnahan J. C., Ha B. K., Von Z. M., Beattie M. S. and Malenka R. C. (2002) Control of synaptic strength by glial TNFalpha. Science 295, 2282-2285.

Ben-Ari Y. and Cossart R. (2000) Kainate, a double agent that generates seizures: two decades of progress. Trends Neurosci. 23, 580-587.

Bezzi P., Domercq M., Brambilla L., Galli R., Schols D., De C. E., Vescovi A., Bagetta G., Kollias G., Meldolesi J. and Volterra A. (2001) CXCR4-activated astrocyte glutamate release via TNFalpha: amplification by microglia triggers neurotoxicity. Nat. Neurosci. 4, 702-710.

Burmeister J. J. and Gerhardt G. A. (2001) Self-referencing ceramic-based multisite microelectrodes for the detection and elimination of interferences from the measurement of L-glutamate and other analytes. Anal. Chem. 73, 1037-1042.

Campbell S. L., Buckingham S. C. and Sontheimer H. (2012) Human glioma cells induce hyperexcitability in cortical networks. Epilepsia 53, 1360-1370.

Campbell S. L. and Hablitz J. J. (2004) Glutamate transporters regulate excitability in local networks in rat neocortex. Neuroscience 127, 625-635.

Campbell S. L. and Hablitz J. J. (2008) Decreased glutamate transport enhances excitability in a rat model of cortical dysplasia. Neurobiol. Dis. 32, 254-261.

Campbell S. L., Hablitz J. J. and Olsen M. L. (2014) Functional changes in glutamate transporters and astrocyte biophysical properties in a rodent model of focal cortical dysplasia. Front Cell Neurosci. 8, 425.

Casamenti F., Prosperi C., Scali C., Giovannelli L., Colivicchi M. A., Faussone-Pellegrini M. S. and Pepeu G. (1999) Interleukin-1beta activates forebrain glial cells and increases nitric oxide production and cortical glutamate and GABA release in vivo: implications for Alzheimer's disease. Neuroscience 91, 831-842.

Cavus I., Kasoff W. S., Cassaday M. P., Jacob R., Gueorguieva R., Sherwin R. S., Krystal J. H., Spencer D. D. and Abi-Saab W. M. (2005) Extracellular metabolites in the cortex and hippocampus of epileptic patients. Ann. Neurol. 57, 226-235.

Chen C. and Bazan N. G. (2005) Endogenous PGE2 regulates membrane excitability and synaptic transmission in hippocampal CA1 pyramidal neurons. J. Neurophysiol. 93, 929941.

Chen Z., Jalabi W., Hu W., Park H. J., Gale J. T., Kidd G. J., Bernatowicz R., Gossman Z. C., Chen J. T., Dutta R. and Trapp B. D. (2014) Microglial displacement of inhibitory synapses provides neuroprotection in the adult brain. Nat. Commun. 5, 4486. 
Cunningham C., Campion S., Teeling J., Felton L. and Perry V. H. (2007) The sickness behaviour and CNS inflammatory mediator profile induced by systemic challenge of mice with synthetic double-stranded RNA (poly I:C). Brain Behav. Immun. 21, 490-502.

Dantzer R. and Kelley K. W. (2007) Twenty years of research on cytokine-induced sickness behavior. Brain Behav. Immun. 21, 153-160.

Dantzer R., O'Connor J. C., Freund G. G., Johnson R. W. and Kelley K. W. (2008) From inflammation to sickness and depression: when the immune system subjugates the brain. Nat. Rev. Neurosci. 9, 46-56.

Day B. K., Pomerleau F., Burmeister J. J., Huettl P. and Gerhardt G. A. (2006) Microelectrode array studies of basal and potassium-evoked release of L-glutamate in the anesthetized rat brain. $J$ Neurochem. 96, 1626-1635.

De Bundel D., Schallier A., Loyens E., Fernando R., Miyashita H., Van L. J., Vermoesen K., Bannai S., Sato H., Michotte Y., Smolders I. and Massie A. (2011) Loss of system $\mathrm{x}(\mathrm{c})$ - does not induce oxidative stress but decreases extracellular glutamate in hippocampus and influences spatial working memory and limbic seizure susceptibility. $J$ Neurosci. 31, 5792-5803.

Featherstone D. E. and Shippy S. A. (2008) Regulation of synaptic transmission by ambient extracellular glutamate. Neuroscientist. 14, 171-181.

Fil D., Borysiewicz E. and Konat G. W. (2011) A broad upregulation of cerebral chemokine genes by peripherally-generated inflammatory mediators. Metab Brain Dis. 26, 49-59.

Giovannelli A., Limatola C., Ragozzino D., Mileo A. M., Ruggieri A., Ciotti M. T., Mercanti D., Santoni A. and Eusebi F. (1998) CXC chemokines interleukin-8 (IL-8) and growth-related gene product alpha (GROalpha) modulate Purkinje neuron activity in mouse cerebellum. J Neuroimmunol. 92, 122-132.

Hadjilambreva G., Mix E., Rolfs A., Muller J. and Strauss U. (2005) Neuromodulation by a cytokine: interferon-beta differentially augments neocortical neuronal activity and excitability. J. Neurophysiol. 93, 843-852.

Hinzman J. M., Thomas T. C., Burmeister J. J., Quintero J. E., Huettl P., Pomerleau F., Gerhardt G. A. and Lifshitz J. (2010) Diffuse brain injury elevates tonic glutamate levels and potassium-evoked glutamate release in discrete brain regions at two days post-injury: an enzyme-based microelectrode array study. J Neurotrauma 27, 889-899.

Hu S., Sheng W. S., Ehrlich L. C., Peterson P. K. and Chao C. C. (2000) Cytokine effects on glutamate uptake by human astrocytes. Neuroimmunomodulation. 7, 153-159.

Hunsberger H. C., Rudy C. C., Batten S. R., Gerhardt G. A. and Reed M. N. (2015a) P301L tau expression affects glutamate release and clearance in the hippocampal trisynaptic pathway. J. Neurochem. 132, 169-182. 
Hunsberger H. C., Weitzner D. S., Rudy C. C., Hickman J. E., Libell E. M., Speer R. R., Gerhardt G. A. and Reed M. N. (2015b) Riluzole rescues glutamate alterations, cognitive deficits, and tau pathology associated with P301L tau expression. J. Neurochem. 135, 381-394.

Jabaudon D., Shimamoto K., Yasuda-Kamatani Y., Scanziani M., Gahwiler B. H. and Gerber U. (1999) Inhibition of uptake unmasks rapid extracellular turnover of glutamate of nonvesicular origin. Proc. Natl. Acad. Sci. U. S. A 96, 8733-8738.

Kang N., Xu J., Xu Q., Nedergaard M. and Kang J. (2005) Astrocytic glutamate releaseinduced transient depolarization and epileptiform discharges in hippocampal CA1 pyramidal neurons. J Neurophysiol. 94, 4121-4130.

Kirschman L. T., Borysiewicz E., Fil D. and Konat G. W. (2011) Peripheral immune challenge with dsRNA enhances kainic acid-induced status epilepticus. Metab Brain Dis. 26, 91-93.

Konat G. (2015) Cerebral response to peripheral challenge with a viral mimetic. Neurochem. Res. (in press).

Konat G. W., Borysiewicz E., Fil D. and James I. (2009) Peripheral challenge with double-stranded RNA elicits global up-regulation of cytokine gene expression in the brain. J Neurosci. Res. 87, 1381-1388.

Konat G. W., Kirschman L. T., Borysiewicz E. and Agmon A. (2012) Peripheral inflammation induces protracted hyperexcitability of hippocampal neurons, pp. PTW0309.

Krasowska-Zoladek A., Banaszewska M., Kraszpulski M. and Konat G. W. (2007) Kinetics of inflammatory response of astrocytes induced by TLR 3 and TLR4 ligation. $J$. Neurosci. Res. 85, 205-212.

Malarkey E. B. and Parpura V. (2008) Mechanisms of glutamate release from astrocytes. Neurochem. Int. 52, 142-154.

Marchi N., Fan Q., Ghosh C., Fazio V., Bertolini F., Betto G., Batra A., Carlton E., Najm I., Granata T. and Janigro D. (2009) Antagonism of peripheral inflammation reduces the severity of status epilepticus. Neurobiol. Dis. 33, 171-181.

Mattinson C. E., Burmeister J. J., Quintero J. E., Pomerleau F., Huettl P. and Gerhardt G. A. (2011) Tonic and phasic release of glutamate and acetylcholine neurotransmission in sub-regions of the rat prefrontal cortex using enzyme-based microelectrode arrays. $J$ Neurosci. Methods 202, 199-208.

Michalovicz L. T., Lally B. E. and Konat G. W. (2015) Peripheral challenge with a viral mimic upregulates expression of the complement genes in the hippocampus. $J$

Neuroimmunol. 285, 137-142. 
Michalovicz L. T. and Konat G. W. (2014) Peripherally restricted acute phase response to a viral mimic alters hippocampal gene expression. Metab Brain Dis. 29, 75-86.

Montiel T., Camacho A., Estrada-Sanchez A. M. and Massieu L. (2005) Differential effects of the substrate inhibitor 1-trans-pyrrolidine-2,4-dicarboxylate (PDC) and the nonsubstrate inhibitor DL-threo-beta-benzyloxyaspartate (DL-TBOA) of glutamate transporters on neuronal damage and extracellular amino acid levels in rat brain in vivo. Neuroscience 133, 667-678.

Niciu M. J., Kelmendi B. and Sanacora G. (2012) Overview of glutamatergic neurotransmission in the nervous system. Pharmacol. Biochem. Behav. 100, 656-664.

Nimchinsky E. A., Yasuda R., Oertner T. G. and Svoboda K. (2004) The number of glutamate receptors opened by synaptic stimulation in single hippocampal spines. $J$ Neurosci. 24, 2054-2064.

Padamsey Z. and Emptage N. (2014) Two sides to long-term potentiation: a view towards reconciliation. Philos. Trans. R. Soc. Lond B Biol. Sci. 369, 20130154.

Petralia R. S. (2012) Distribution of extrasynaptic NMDA receptors on neurons. ScientificWorldJournal. 2012, 267120.

Pettit D. L. and Augustine G. J. (2000) Distribution of functional glutamate and GABA receptors on hippocampal pyramidal cells and interneurons. $J$ Neurophysiol. 84, 28-38.

Putatunda R., Hala T. J., Chin J. and Lepore A. C. (2014) Chronic at-level thermal hyperalgesia following rat cervical contusion spinal cord injury is accompanied by neuronal and astrocyte activation and loss of the astrocyte glutamate transporter, GLT1, in superficial dorsal horn. Brain Res. 1581, 64-79.

Quan N. and Banks W. A. (2007) Brain-immune communication pathways. Brain Behav. Immun. 21, 727-735.

Ragozzino D., Giovannelli A., Mileo A. M., Limatola C., Santoni A. and Eusebi F. (1998) Modulation of the neurotransmitter release in rat cerebellar neurons by GRO beta. Neuroreport 9, 3601-3606.

Rao R. S., Medhi B., Saikia U. N., Arora S. K., Toor J. S., Khanduja K. L. and Pandhi P. (2008) Experimentally induced various inflammatory models and seizure: understanding the role of cytokine in rat. Eur. Neuropsychopharmacol. 18, 760-767.

Ravizza T., Balosso S. and Vezzani A. (2011) Inflammation and prevention of epileptogenesis. Neurosci. Lett.

Riazi K., Galic M. A., Kentner A. C., Reid A. Y., Sharkey K. A. and Pittman Q. J. (2015) Microglia-dependent alteration of glutamatergic synaptic transmission and plasticity in the hippocampus during peripheral inflammation. J. Neurosci. 35, 4942-4952. 
Riazi K., Galic M. A., Kuzmiski J. B., Ho W., Sharkey K. A. and Pittman Q. J. (2008) Microglial activation and TNFalpha production mediate altered CNS excitability following peripheral inflammation. Proc. Natl. Acad. Sci. U. S. A 105, 17151-17156.

Samland H., Huitron-Resendiz S., Masliah E., Criado J., Henriksen S. J. and Campbell I. L. (2003) Profound increase in sensitivity to glutamatergic- but not cholinergic agonistinduced seizures in transgenic mice with astrocyte production of IL-6. J. Neurosci. Res. 73, 176-187.

Sayyah M., Javad-Pour M. and Ghazi-Khansari M. (2003) The bacterial endotoxin lipopolysaccharide enhances seizure susceptibility in mice: involvement of proinflammatory factors: nitric oxide and prostaglandins. Neuroscience 122, 1073-1080.

Schafer D. P., Lehrman E. K., Kautzman A. G., Koyama R., Mardinly A. R., Yamasaki R., Ransohoff R. M., Greenberg M. E., Barres B. A. and Stevens B. (2012) Microglia sculpt postnatal neural circuits in an activity and complement-dependent manner. Neuron 74, 691-705.

Scheid R. and Teich N. (2007) Neurologic manifestations of ulcerative colitis. Eur. J. Neurol. 14, 483-493.

Shimamoto K., Lebrun B., Yasuda-Kamatani Y., Sakaitani M., Shigeri Y., Yumoto N. and Nakajima T. (1998) DL-threo-beta-benzyloxyaspartate, a potent blocker of excitatory amino acid transporters. Mol. Pharmacol. 53, 195-201.

Stellwagen D., Beattie E. C., Seo J. Y. and Malenka R. C. (2005) Differential regulation of AMPA receptor and GABA receptor trafficking by tumor necrosis factor-alpha. $J$. Neurosci. 25, 3219-3228.

Stephan A. H., Madison D. V., Mateos J. M., Fraser D. A., Lovelett E. A., Coutellier L., Kim L., Tsai H. H., Huang E. J., Rowitch D. H., Berns D. S., Tenner A. J., Shamloo M. and Barres B. A. (2013) A dramatic increase of C1q protein in the CNS during normal aging. J. Neurosci. 33, 13460-13474.

Stephens M. L., Williamson A., Deel M. E., Bensalem-Owen M., Davis V. A., Slevin J., Pomerleau F., Huettl P. and Gerhardt G. A. (2014) Tonic glutamate in CA1 of aging rats correlates with phasic glutamate dysregulation during seizure. Epilepsia 55, 1817-1825.

Stevens B., Allen N. J., Vazquez L. E., Howell G. R., Christopherson K. S., Nouri N., Micheva K. D., Mehalow A. K., Huberman A. D., Stafford B., Sher A., Litke A. M., Lambris J. D., Smith S. J., John S. W. and Barres B. A. (2007) The classical complement cascade mediates CNS synapse elimination. Cell 131, 1164-1178.

Sykova E., Mazel T. and Simonova Z. (1998) Diffusion constraints and neuron-glia interaction during aging. Exp. Gerontol. 33, 837-851.

Tellez-Zenteno J. F., Matijevic S. and Wiebe S. (2005) Somatic comorbidity of epilepsy in the general population in Canada. Epilepsia 46, 1955-1962. 
Tovar K. R., Maher B. J. and Westbrook G. L. (2009) Direct actions of carbenoxolone on synaptic transmission and neuronal membrane properties. $J$ Neurophysiol. 102, 974-978.

Verrotti A., Tocco A. M., Coppola G. G., Altobelli E. and Chiarelli F. (2009) Afebrile benign convulsions with mild gastroenteritis: a new entity? Acta Neurol. Scand. 120, 7379.

Vezzani A. and Granata T. (2005) Brain inflammation in epilepsy: experimental and clinical evidence. Epilepsia 46, 1724-1743.

Viviani B., Bartesaghi S., Gardoni F., Vezzani A., Behrens M. M., Bartfai T., Binaglia M., Corsini E., Di Luca M., Galli C. L. and Marinovich M. (2003) Interleukin-1beta enhances NMDA receptor-mediated intracellular calcium increase through activation of the Src family of kinases. J. Neurosci. 23, 8692-8700.

Xiaoqin Z., Zhengli L., Changgeng Z., Xiaojing W. and Li L. (2005) Changes in behavior and amino acid neurotransmitters in the brain of rats with seizure induced by IL-1beta or IL-6. J Huazhong. Univ Sci. Technolog. Med. Sci. 25, 236-239.

Xiong Z. Q., Qian W., Suzuki K. and McNamara J. O. (2003) Formation of complement membrane attack complex in mammalian cerebral cortex evokes seizures and neurodegeneration. J. Neurosci. 23, 955-960.

Yang S., Liu Z. W., Wen L., Qiao H. F., Zhou W. X. and Zhang Y. X. (2005) Interleukin1 beta enhances NMDA receptor-mediated current but inhibits excitatory synaptic transmission. Brain Res. 1034, 172-179.

Ye Z. C. and Sontheimer H. (1996) Cytokine modulation of glial glutamate uptake: a possible involvement of nitric oxide. Neuroreport 7, 2181-2185.

Zucker R. S. and Regehr W. G. (2002) Short-term synaptic plasticity. Annu. Rev. Physiol 64, 355-405. 


\title{
Chapter 3
}

\section{Antiviral acute phase response increases tonic glutamate levels and seizure severity}

\begin{abstract}
Cerebral inflammation, resulting from peripheral bacterial and viral infection, is associated with epilepsy and other neurodegenerative conditions. Recent evidence reveals that intraperitoneal (i.p.) injection of a viral mimic, polyinosinic-polycytidylic acid (PIC), elicits a profound increase in kainic acid (KA)-induced seizure susceptibility compared to saline-treated controls. We have previously shown that systemic injection of PIC results in a robust increase in tonic glutamate levels in anesthetized mice most likely due to a decrease in glutamate clearance. The current study was undertaken to determine the relationship between PIC challenge and glutamate homeostasis in awake, behaving mice. Because the hippocampus is the ictal site for KA-induced seizures, we implanted microelectrode arrays into the CA1 of the hippocampus to record tonic and transient glutamate levels. Our results revealed an increase in tonic glutamate levels following PIC challenge, which gradually declined over four days. Tonic glutamate levels were also predictive of KA-induced seizure severity, as indicated by an increase in the average and cumulative seizure scores. These results implicate that the elevation of glutamate by PIC challenge is likely to underlie enhanced seizure susceptibility.
\end{abstract}




\section{Introduction}

Peripheral inflammation is a primary factor in the pathophysiology of seizures and development of epilepsy (Vezzani \& Granata, 2005). Moreover, individuals with cerebral inflammation, resulting from infection or trauma, are often more prone to seizures (Tellez-Zenteno, Matijevic, \& Wiebe, 2005). Seizures are characterized by abnormal neuronal firing most likely resulting from an increase in excitatory glutamate neurotransmission and decrease in GABA inhibitory neurotransmission (Rowley, Martin, \& Marsden, 1995). Although the molecular mechanisms underlying seizure onset and severity are not well understood, recent evidence suggests that inflammatory mediators, in response to peripheral inflammation, can cause neuronal and glial changes in the central nervous system (CNS) (Marchi et al., 2009; Viviani et al., 2003; Wang, Q. Cheng, S. Malik, \& J. Yang, 2000; S. Wang et al., 2000; Wilkinson, Mathieson, \& Pittman, 1993). These changes may shift the balance between excitation and inhibition towards neuronal hyperexcitability.

To study the cerebral effects of peripheral inflammation, polyinosinicpolycytidylic acid (PIC), a viral mimetic, is often injected i.p. the acute phase response (APR) (Cunningham et al., 2007). The APR results in the generation of type 1 interferons and other inflammatory factors (Muller et al., 1994) that are produced in the periphery and relayed to the brain. PIC-challenge in rodents results in sickness behavior (Cunningham et al., 2007) and an upregulation of cytokine, chemokine, and complement genes in the CNS (Fil et al., 2011; G. W. Konat et al., 2009; Michalovicz \& Konat, 2014; Michalovicz et al., 2015). These changes peak between 3 and 6 hours, and in some cases, 
are observed for up to 3 days post PIC injection (Fil et al., 2011; G. W. Konat et al., 2009; Michalovicz \& Konat, 2014; Michalovicz et al., 2015).

Though alterations in neural networks, and the resulting sickness behavior, serve to protect the host, a growing body of evidence suggests these modifications may have deleterious effects in the presence of other neuropathological conditions. For example, viral infections in the periphery can exacerbate neurodegenerative conditions, including Alzheimer's disease, Parkinson's disease, multiple sclerosis, Huntington's disease, and seizures in humans (see Perry et al., 2003 for review). Previous work shows that PICchallenged mice exhibit an increase in the extent and duration of kainic acid (KA)induced seizures (Kirschman et al., 2011). This seizure hypersusceptibility is protracted for 3 days (Michalovicz \& Konat, 2014). Our recent work suggests that glutamate, the primary excitatory neurotransmitter, may mediate the seizure hypersusceptibility observed after PIC insult as seen from an increase in tonic glutamate levels in the hippocampal subregions of anesthetized PIC-challenged mice compared to saline-treated controls (Hunsberger et al., 2016). In addition, recent studies examining the effects of aging on seizure severity and glutamate homeostasis in rats revealed a strong association between pre-seizure tonic (resting) glutamate levels in the CA1 of the hippocampus and seizure intensity (Stephens et al., 2014). Notably, pre-seizure tonic glutamate levels were also predictive of glutamate transient amplitude during seizure in these animals.

Glutamate transients are spontaneous bursts of glutamate that until recently were not detectable with previous recording techniques (i.e., microdialysis) (Hascup et al., 2011). The need to monitor the fast temporal dynamics of glutamate neurotransmission has been recognized and achieved by the development of the microelectrode array (MEA) 
technology (Burmeister et al., 2002a; Hascup et al., 2011). To determine the relationship between peripheral inflammation, seizure susceptibility, and glutamate homeostasis, we employed the MEA technology in awake-behaving mice. Because the hippocampus is the primary site of ictal onset instigated by KA injection (Ben-Ari \& Cossart, 2000) and cerebral changes are observed for up to 3 days following PIC injection (Michalovicz \& Konat, 2014), seizures were induced and glutamate measured for four days in the CA1 of the hippocampus of PIC-challenged mice. The CA1 was chosen based on our previous studies revealing robust changes in glutamate homeostasis and synaptic neurotransmission in this region (Hunsberger et al., 2016).

\section{Materials \& Methods}

Animals. Eight-week-old female mice of a C57BL/6 background strain obtained from Jackson labs (Bar Harbor, ME) were group housed with free access to food and water in a temperature- and humidity-controlled colony room with a 12:12 light/dark cycle. Female mice were used to provide compatibility with previous studies, (Cunningham et al., 2007; Fil et al., 2011; Hunsberger et al., 2016; G. W. Konat et al., 2009; Michalovicz \& Konat, 2014). Mice were weighed daily for the duration of the study. The West Virginia University and Auburn University Animal Care and Use Committees approved all experimental procedures.

MEA preparation. Self-referencing, ceramic-based MEAs were assembled and prepared for in vivo recordings as previously described (Burmeister, Moxon, \& Gerhardt, 2000; Burmeister et al., 2002a). Briefly, MEAs obtained from Quanteon (Nicholasville, KY, USA) were coated with glutamate oxidase (recording sites) and nonactive protein, $1 \%$ BSA/glutaraldehyde (sentinel sites), for self-referenced comparison. Prior to use, 
MEAs were calibrated as previously described (Hunsberger, Rudy, et al., 2015; Hunsberger et al., 2016; Hunsberger, Weitzner, et al., 2015) and modified for freelymoving recordings in awake animals. To modify the MEAs, the MEA paddle was shortened and attached to a miniature omnetics connector (Omnetics Connector Corporation; Minneapolis, MN) to create a pedestal connected by copper wires. Copper wires were prepared by stripping the ends and soldering one end to the gold-plated pin on the omnetics connector and the other to one of the four sites on the MEA paddle. To secure the paddle to the omnetics connector and ensure that moisture did not penetrate the pedestal, waterproof epoxy was applied, and the copper wires were tucked around the connector (Rutherford, Pomerleau, Huettl, Stromberg, \& Gerhardt, 2007; Stephens et al., 2014). The completed pedestal was allowed to dry for at least 24 hours. An Ag/Cl reference electrode was also prepared and soldered to a gold-plated pin.

Electrode Implantation. On Day 1 of the experiment, mice were anesthetized with isoflurane (1-4\% inhalation; continuous), placed into a stereotaxic device (Stoelting, Wood Dale IL, USA), and a glutamate-selective MEA pedestal was implanted into either the right or left hemisphere of the CA1 (AP: $-2.3 \mathrm{~mm}$, ML: $+/-1.7 \mathrm{~mm}$, DV: $1.4 \mathrm{~mm}$ ) based on stereotaxic coordinates (Paxinos \& Franklin, 2012). Three small holes were drilled in the skull, two of which were used for a stainless steel screw to serve as an anchor, and the third hole used for placement of the reference electrode. The assembly was then secured with four layers of acrylic resin (Lang Dental, Wheeling IL, USA). After surgery, mice were placed on a heating pad to help maintain body temperature until recovered from anesthesia. Injection of bupivicaine $(1-2 \mathrm{mg} / \mathrm{kg})$ was given immediately 
after surgery to alleviate pain. Fluids containing ketoprofen $(2-5 \mathrm{mg} / \mathrm{kg})$ were given as mice recovered for 3 days.

PIC injection. After 3 days of recovery (Day 4), the acute antiviral response was induced by intraperitoneal (i.p.) injection of $12 \mathrm{mg} / \mathrm{kg}$ of ultrapure PIC (Invivogen, San Diego, CA) in saline. Mice injected with $100 \mu \mathrm{L}$ of saline served as vehicle controls. To confirm successful i.p. injection, the development of sickness behavior was assessed 3 hours after PIC injection using the rearing test as previously described (Michalovicz \& Konat, 2014; Michalovicz et al., 2015). Briefly, three hours after PIC or saline injection, mice were placed in an open-field chamber (14.5 in. (H) x 17.5 in. (L)) and allowed to acclimate for 5 minutes. After 5 minutes, rearing behavior was recorded for 15 minutes. A decrease in the number of rears was indicative of sickness behavior.

Glutamate recordings in freely-moving mice. Twenty-four hours after PIC injection (Day5), mice were placed in an observation chamber (14.5 in. (H) x 17.5 in. (L)), at which time the MEA pedestal was connected to the FAST-16 mkkII system. After reaching a stable baseline (approximately 30 minutes), tonic glutamate levels, sampled approximately every 5 to 10 minutes, and spontaneous glutamate transients, sampled continuously, were measured for 1 hour. For spontaneous glutamate transients, the FAST16 mkII MATLAB interface was set to continuously detect peaks above a signal to noise ratio of 2.5 with a moving baseline of 10 points (or 5s) (Hascup et al., 2011). Because transients were only observed on the glutamate oxidase sites and not the recording sites, these signals were representative of glutamate and not noise or artifact (Hascup et al., 2011; Stephens et al., 2014). Measures derived from the MATLAB interface included tonic (or resting) glutamate $(\mu \mathrm{M})$ and five transient parameters: 1$)$ area 
under the curve (AUC), 2) transient maximum amplitude $(\mu \mathrm{M}), 3)$ transient duration (seconds), 4) inter-transient interval (seconds), and (5) transient frequency.

Seizure induction. Because the hyperexcitable phenotype induced by PIC injection lasts approximately 3 days (Michalovicz \& Konat, 2014), seizures were induced on Days 5, 6, 7, and 8. Briefly, after obtaining pre-seizure glutamate measurements, mice were subcutaneously (s.c.) injected with $12 \mathrm{mg} / \mathrm{kg}$ of kainic acid (KA) to induce status epilepticus (SE) under continuous glutamate recording. Mice injected with saline (SAL; $50 \mu \mathrm{L})$ served as vehicle controls. Seizure severity was graded by blinded observers in 5minute increments. The scores ranged from 0 to 6 broken down as follows: 0 , no response; 1, immobility; 2 , rigid posture; 3 , scratching/circling/head bobbing; 4, forelimb clonus/rearing/falling; 5 , repetitious pattern 4; 6, severe tonic-clonic seizures (Morrison et al., 1996). Seizures lasted approximately 100-200 minutes, and glutamate measurements were recorded throughout this period. Twenty minutes after seizures ceased, post-seizure glutamate measurements were taken for 10 minutes.

Statistical analyses. Results were evaluated by repeated measures ANOVAs using JMP (SAS, Cary, NC 27513). Within-subject measures included Day (Days 5-8) and Phase (pre-seizure, during seizure, and post-seizure). A Grubb's test was used to identify outliers. Significant omnibus tests were followed by t-test post hoc comparisons. Due to the nonlinearity of the data, spearman correlations were also run to determine the relation between pre-seizure tonic glutamate and seizure scores. Results were presented as mean \pm SEM, and differences between groups were considered statistically significant at $p \leq 0.05$.

\section{Results}


Temporal changes in body weight following microelectrode implantation and PIC challenge.

Because PIC-challenge induces transient weight loss (Cunningham et al., 2007), body weight was recorded for the length of the experiment. PIC-challenge induced a significant decrease in bodyweight $24 \mathrm{~h}$ after injection, i.e., Day 5 (Day*Group effect, $\mathrm{F}(7,182)=3.08, p=.004$; Fig. 3.1]. Bodyweights returned to control levels after $24 \mathrm{~h}$ (Day 6), indicating only temporary body weight loss.

\section{The effect of PIC-challenge on glutamate homeostasis.}

Our previous work demonstrates that PIC-challenge significantly increases tonic glutamate levels 24 hours after PIC injection in anesthetized mice (Hunsberger et al., 2016). To determine whether this increase is transient, the temporal effects of PICchallenge were examined by comparing the PIC-SAL vs. SAL-SAL groups from 24 hours (Day 5) to 96 hours (Day 8) after PIC injection. Tonic glutamate levels were transiently elevated by PIC-challenge with the highest levels at $24 \mathrm{~h}$ (Day 5) (Group effect, $\mathrm{F}(1,9)=5.00, p=.05$; Fig. 3.2A). PIC-challenge did not significantly alter transient duration, amplitude, net AUC, inter-transient interval, or transient frequency ( $p$ 's $>.05$; Fig. 3.2B-F).

\section{The effect of PIC-challenge on KA-induced seizures.}

As previously demonstrated in naïve mice (Kirschman et al., 2011; Michalovicz \& Konat, 2014), PIC-challenge also resulted in a transient increase in the susceptibility to KA-induced seizures in mice implanted with MEA. The average seizure score (Day*Group effect, $\mathrm{F}(3,33)=15.98, p=.0001$; Fig. 3.3A), seizure duration (Day*Group 
effect, $\mathrm{F}(3,33)=14.17, p=.0001$; Fig. 3.3B), and cumulative seizure score (Day*Group effect, $\mathrm{F}(3,33)=9.74, p=.0001$; Fig. 3.3C) were highest 24 hours after PIC injection (Day 5), remained significantly elevated at $48 \mathrm{~h}$ (Day 6), and returned to control levels at $72 \mathrm{~h}$ (Day 7). Moreover, repeated daily injections of KA did not change the body weight of the animals for Days 5-8 ( $p>.05)$, indicating no gross adverse effects of the SE (Fig. 3.3D).

To determine if pre-seizure tonic glutamate levels would predict seizure severity, Spearman correlations analyses were performed using data from Day 5. The results demonstrate that baseline tonic glutamate levels in the CA1 significantly correlates with both the average seizure score $\left(\mathrm{R}^{2}=.65, p=.02\right.$; Fig. $\left.3.4 \mathrm{~A}\right)$ and cumulative seizure score $\left(\mathrm{R}^{2}=.87, p=.0002\right.$; Fig. 3.4B).

\section{Seizure-induced changes in glutamate homeostasis.}

We next sought to determine whether SE changes tonic and transient glutamate in PIC-challenged (PIC-KA) vs. saline-injected mice (SAL-KA). Following KA-injection, tonic and transient glutamate levels were measured for the duration of seizures (100-200 min). PIC-challenge significantly increased tonic glutamate levels during seizure [Group effect, $\mathrm{F}(1,10)=5.08, p=.04$; Fig. 3.5A] with the greatest increase at $24 \mathrm{~h}$ (Day 5). However, PIC-challenge did not significantly alter transient duration, amplitude, net AUC, inter-transient interval, or transient frequency between the groups during seizure ( $p$ 's>.05; Fig. 3.5B-F).

Our previous data suggest that the most robust cerebral changes occur 24 hours after PIC injection (Fil et al., 2011; Hunsberger et al., 2016; Michalovicz \& Konat, 2014; Michalovicz et al., 2015). Therefore, 24 hours after PIC injection (Day 5), seizure- 
induced changes in glutamate homeostasis were examined by comparing the PIC-KA and SAL-KA groups across the 3 phases: pre-seizure, seizure, and post-seizure. For all 3 phases, tonic glutamate levels were significantly increased in PIC-challenged mice compared to saline-injected controls. In addition, PIC-challenged mice exhibited a significant increase in tonic levels as a result of seizure induction with KA, whereas the saline-injected mice did not [Phase*Group effect, $\mathrm{F}(2,18)=5.7, p=.01$; Fig. 3.6A]. There were no changes in transient duration, amplitude, net AUC, inter-transient interval, or transient frequency across the 3 phases ( $p$ 's $>.05$; Fig. 3.6B-F).

\section{Discussion}

The current study examined the relationship between glutamate homeostasis and seizure severity after peripheral viral challenge. The work presented here expands on previous findings that peripheral viral challenge with PIC increases susceptibility to KAinduced seizures as indicated by increased average and cumulative seizure score (Kirschman et al., 2011) and elevates extracellular tonic glutamate levels in the hippocampus (Hunsberger et al., 2016). The ability to measure glutamate homeostasis and seizure behavior in the same animal revealed a strong association between preseizure tonic glutamate levels and seizure severity. Consistent with previous studies (Michalovicz \& Konat, 2014), increased seizure susceptibility in PIC-challenged animals was highest $24 \mathrm{~h}$ after PIC injection and remained elevated for $48 \mathrm{~h}$. Tonic glutamate levels also gradually declined across days after PIC challenge, which matches the pattern of inflammatory milieu following this peripheral insult (Fil et al., 2011; G. W. Konat et al., 2009; Michalovicz \& Konat, 2014; Michalovicz et al., 2015). 
Prior to seizure induction, tonic glutamate levels were recorded and found to be increased 24 hours after PIC-challenge, before gradually decreasing to control levels across the four days. This transient increase in glutamate $24 \mathrm{~h}$ after PIC injection is congruent with our previous studies in anesthetized mice (Hunsberger et al., 2016) and may be the result of inflammatory mediators that reach the CNS after PIC insult (Fil et al., 2011; G. W. Konat et al., 2009; Michalovicz et al., 2015). These inflammatory mediators can cause changes in excitatory glutamate neurotransmission and inhibitory GABA transmission that lead to hyperexcitability. For example, cytokines, chemokines, and complements upregulated after PIC-challenge can increase glutamate receptor expression and enhance function leading to increased glutamate signaling. In support of this, mice overexpressing the cytokine, IL-6, exhibit impaired development of inhibitory synapses and larger excitatory synaptic connections (Wei et al., 2012). Furthermore, glutamatergic NMDA receptor expression is increased in the presence of IL-1 $\beta$ (Viviani et al., 2003), while expression of astrocytic glutamate transporters (GLT-1) is reduced (Prow \& Irani, 2008). The reduction in GLT-1, which removes glutamate from the extracellular space, may explain the increased tonic glutamate levels observed after PICchallenge.

Compared to our previous study in which the effects of PIC challenge on tonic glutamate was examined in anesthetized mice (Hunsberger et al., 2016), both PIC- and saline-treated animals in the current study exhibited approximately 2-fold higher levels of tonic glutamate. The increase in tonic glutamate levels in the current study may be due to inflammation resulting from MEA-implantation surgery or because the animal is awake, as opposed to anesthetized, during glutamate recordings. Examination of glutamate after 
a longer recovery period in future studies may help address the concern regarding surgery-related inflammation. Although isoflurane anesthesia, used in our previous experiment, does not likely decrease glutamate levels the way other anesthesias do (Westphalen \& Hemmings, 2003), it is possible that the glutamatergic system is dampened under anesthesia (Westphalen, Kwak, Daniels, \& Hemmings, 2011).

For the first time in the PIC model, glutamate transients were characterized using the MEA technology. Surprisingly, there were no differences in glutamate transients between the groups prior to seizure onset. In contrast, a previous study in aged rats experiencing 4-aminopyridine (4-AP) induced seizures revealed increases in glutamate transient amplitude and the frequency of glutamate transients that were predictive of seizure severity (Stephens et al., 2014). However, there are several differences in experimental design that could have contributed to the contrasting results. Differences include the use of rats as opposed to mice, injecting 4-AP directly into the hippocampus instead of a systemic injection of kainic acid, and age of the animals tested (i.e., 8 week old mice vs. 3-24 month old rats). This latter difference may be particularly important. Whereas a single injection of PIC induces a transient and acute increase in inflammatory mediators, aging is associated with chronic increases in proinflammatory cytokine levels (Michaud et al., 2013). Thus, it is possible that an acute insult (e.g., a single injection of PIC) may be insufficient to trigger changes in glutamate transient neurotransmission, despite producing robust alterations in tonic glutamate levels. Future studies examining the effects of repeated PIC injection on glutamate transients is warranted.

It is possible that glutamate transients are of neuronal origin and are therefore unaffected by inflammatory mediators produced in response to PIC. In support of this, 
glutamate transient signals are greatly reduced by local application of tetrodotoxin (TTX), a neurotoxin, or $\omega$-conotoxin, a calcium channel blocker (Hascup et al., 2011; E. R. Hascup et al., 2010). Because recent evidence shows that astrocytic glutamate release is not calcium dependent (Agulhon, Fiacco, \& McCarthy, 2010), glutamate transient levels are most likely controlled by neuronal mechanisms.

The most interesting finding of this study may be the relationship between tonic glutamate levels and seizure severity. These results suggest that inflammatory mediators produced in response to peripheral inflammation can disrupt glutamate homeostasis and change functional outcomes as seen from an increase in average seizure score and cumulative seizure score in PIC-challenged mice. Similar results were observed when examining pre-seizure tonic glutamate levels and seizure severity after intrahippocampal injection of 4-AP in aging rats; higher baseline levels of tonic glutamate were predictive of seizure severity (Stephens et al., 2014). Concurrent with animal studies, human studies reveal that basal glutamate is elevated in the hippocampus of patients with refractory temporal lobe epilepsy (During \& Spencer, 1993) and that these elevated levels are related to higher seizure frequency (Cavus et al., 2005). Studies examining tissue from chronic epileptic patients suggest inflammation may play a role in the pathophysiology of seizures. For example, increased levels of inflammatory mediators and their receptors are seen in activated glial cells, neurons, and endothelial cells (Marchi et al., 2010; Ravizza et al., 2008).

PIC-challenge also resulted in elevated tonic glutamate levels during seizure, an increase that was exacerbated by KA-induced seizures. Extracellular tonic glutamate is controlled by the balance of glutamate release and uptake. It is possible that during 
seizure more glutamate is released, however, evidence supports the notion that inflammatory mediators act on glutamate clearance mechanisms. Specifically, astrocytic glutamate transporters (GLT-1 and GLAST) are decreased in aged rodents (Brothers et al., 2013) and in cultures exposed to lipopolysaccharide (LPS), which elicits an antibacterial immune response (Tilleux \& Hermans, 2008). Moreover, our previous work revealed that glutamate clearance is decreased by PIC-challenge and that neuronal glutamate release mechanisms remain unaffected (Hunsberger et al., 2016). It should be noted that astrocytes can also release glutamate into the extracellular space, and this process is enhanced by inflammatory mediators. For example, TNF $\alpha$ is known to increase synaptic transmission and can stimulate the release of glutamate from astrocytes (Santello, Bezzi, \& Volterra, 2011). Moreover, the cystine/glutamate antiporter, another potential source of nonsynaptic glutamate, has been implicated in epileptic seizures (Buckingham et al., 2011), and is upregulated after ischemic injury (Soria et al., 2014), where inflammation plays an important role in the pathogenesis (Elkind, Cheng, Rundek, Boden-Albala, \& Sacco, 2004; McColl, Rothwell, \& Allan, 2007). These additional sources of extracellular glutamate release in combination with the decrease in glutamate clearance could potentially impact the amount of glutamate in the extracellular space and likely contribute to the seizure hypersusceptibility observed in our PIC animals. Future studies examining glutamate release and uptake during seizure will help to delineate the role of each in mediating seizure hypersusceptibility in PIC-challenged mice.

Overall, our results provide evidence that peripheral viral challenge results in altered glutamate homeostasis that is predictive of seizure severity. Build up of extracellular glutamate following PIC challenge may contribute to the pathology of 
neurodegenerative conditions that are comorbid with peripheral infection, such as Alzheimer disease and seizures. Therefore, deciphering mechanisms by which peripheral viral infection elevates extracellular glutamate is critical to the prevention of infectionmediated exacerbations in neurodegenerative conditions. 


\section{Chapter 3 Figures}

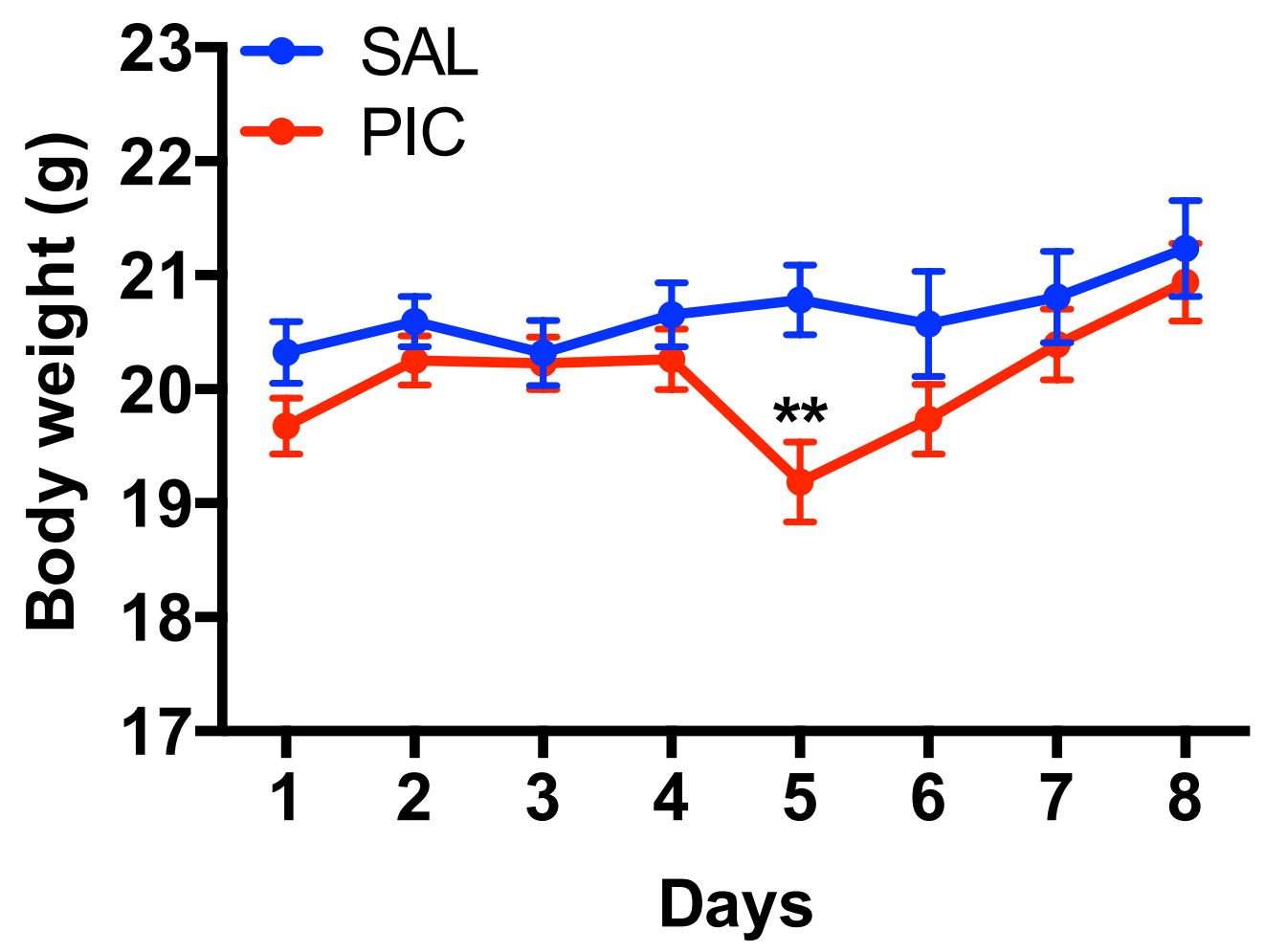

Figure 3.1. Temporal changes in body weight following MEA implantation and PIC challenge. Mice were implanted with MEA pedestals and challenged with $12 \mathrm{mg} / \mathrm{kg}$ of PIC on Day 4 post-surgery. Saline-injected mice served as respective controls. Symbols represent means \pm SEM from 13 to 15 animals. Asterisks denote significant differences from saline controls $(* * p \leq .01)$. 
(a)

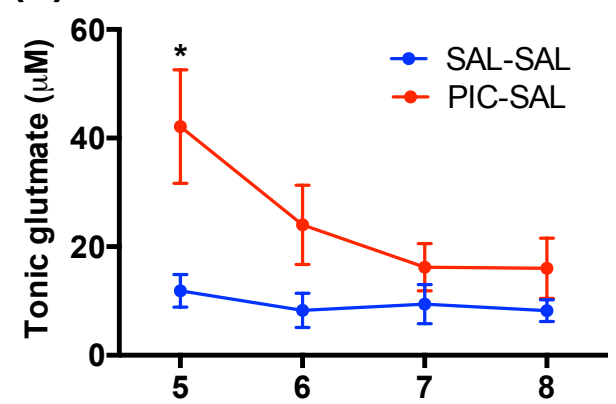

(c)

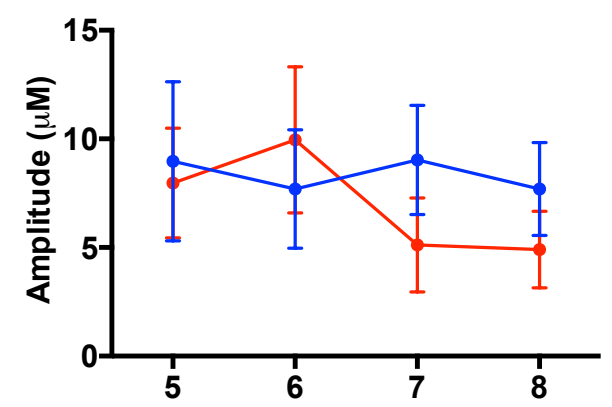

(e)

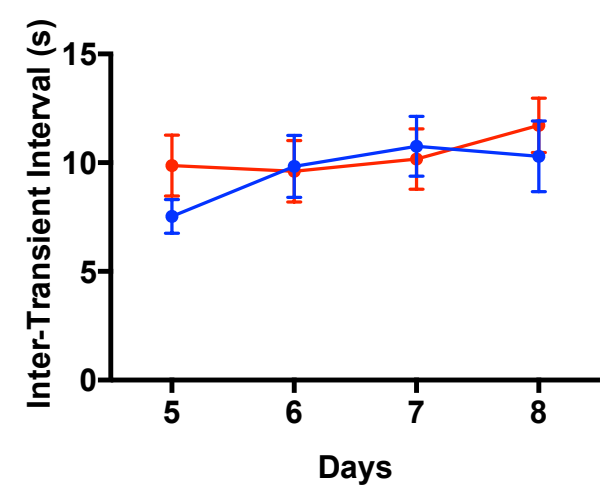

(b)

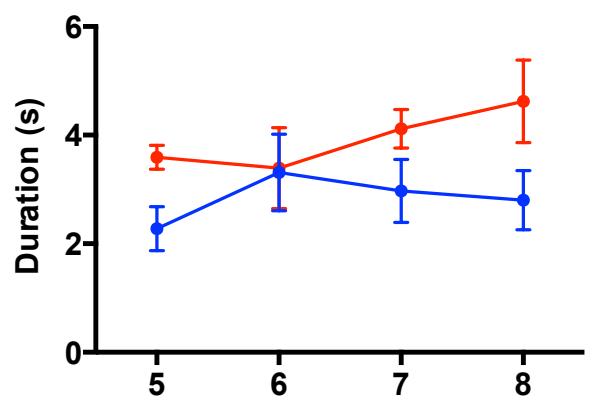

(d)

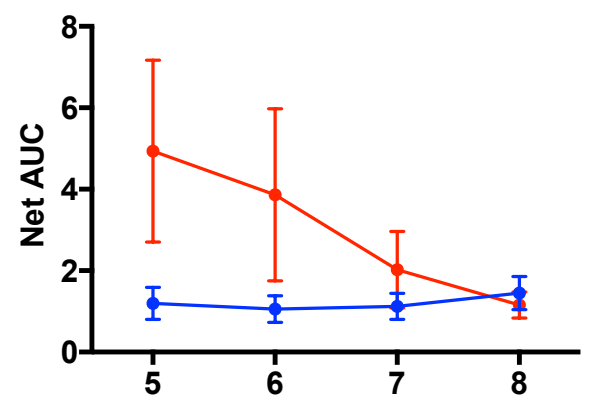

(f)

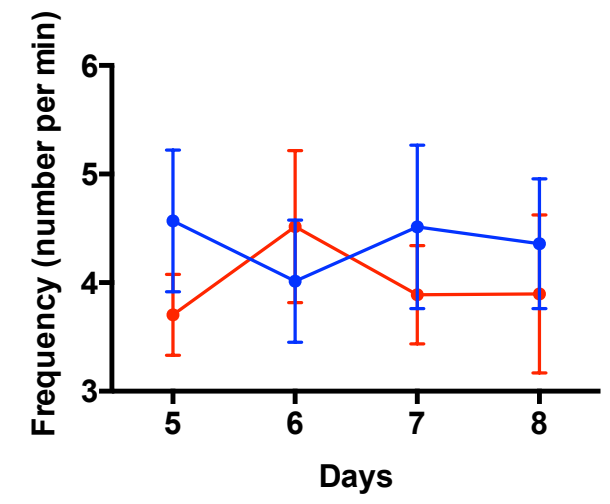

Figure 3.2. Changes in glutamate homeostasis induced by PIC challenge. Mice implanted with MEA pedestals were challenged with PIC on Day 4, and extracellular glutamate was analyzed on Days 5-8. (a) Tonic glutamate levels, (b) glutamate transient duration, (c) amplitude, (d) area under the curve (AUC), (e) net inter-transient interval 
and (f) transient frequency. Symbols represent means \pm SEM from 5 to 7 animals per group. Asterisks denote significant differences from saline controls $(* p \leq .05)$.

(a)

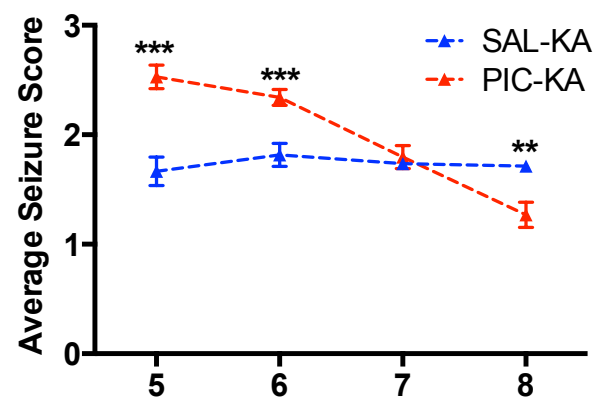

(c)

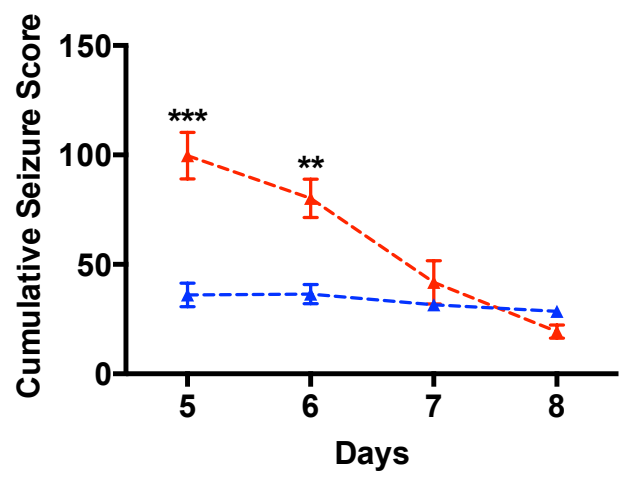

(b)

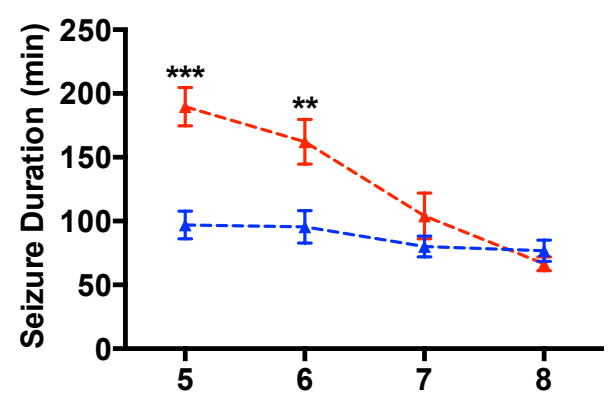

(d)

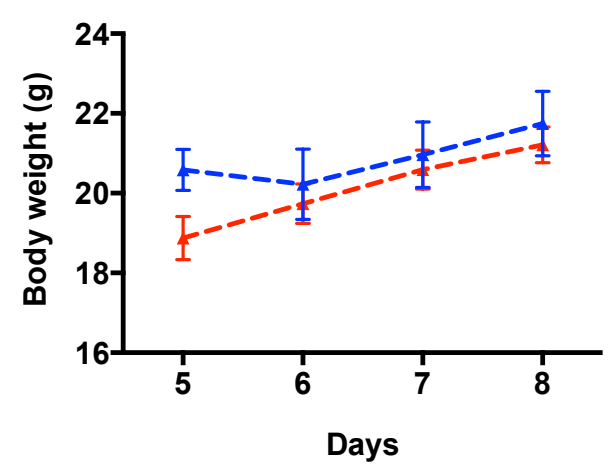

Figure 3.3. Enhancing effect of PIC-challenge on KA-induced seizures. Mice implanted with MEA pedestals were challenged with PIC on Day 4 and status epilepticus (SE) was induced by subcutaneous injection of $12 \mathrm{mg} / \mathrm{kg}$ of KA on Days 5, 6, 7 and 8 (PIC-KA group). Mice injected with saline in lieu of PIC served as controls (SAL-KA). Seizures were expressed as average seizure score (a), seizure duration (b), and cumulative seizure score (c). Also, the effect of SE on the body weight was monitored (d). Symbols 
represent means \pm SEM from 5 to 8 animals per group. Asterisks denote significant differences from saline controls $\left(* * p \leq .01,{ }^{* * *} p \leq .001\right)$.

A.

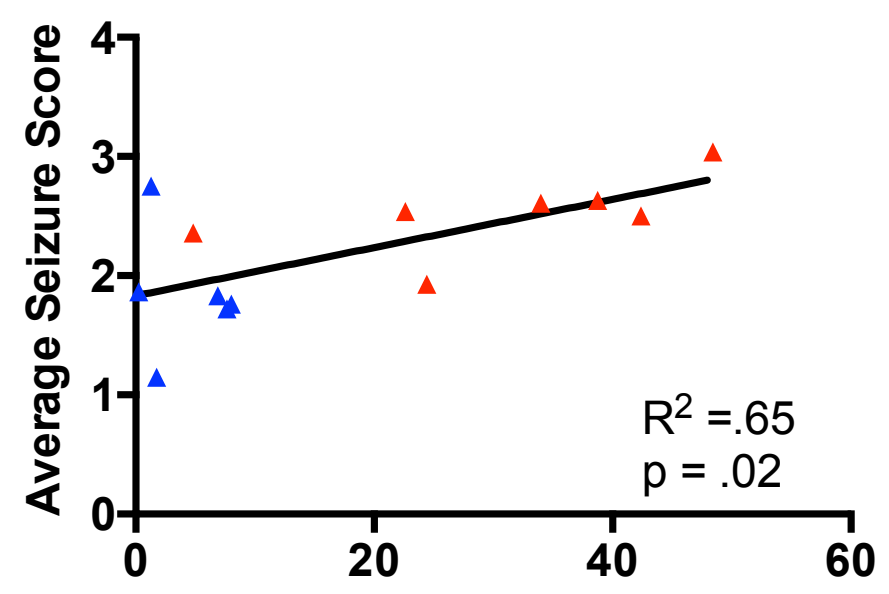

B.

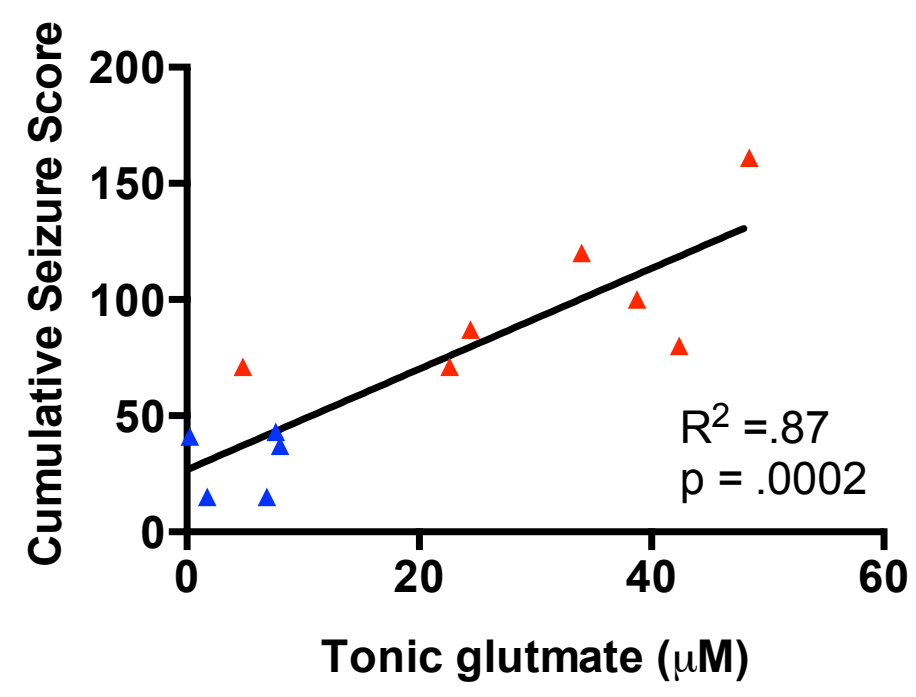

Figure 3.4. The relationship between tonic glutamate level and seizure intensity. Tonic glutamate was determined in animals described in Fig. 3 before injection of KA. 
These values were plotted against the average (a) and cumulative (b) seizure scores during SE. The correlation was analyzed by the Spearman's rank correlation.

(a)

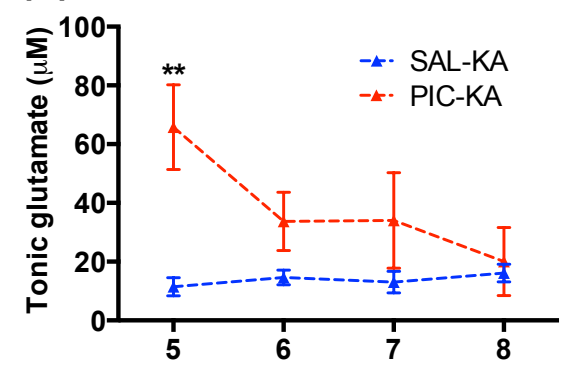

(c)

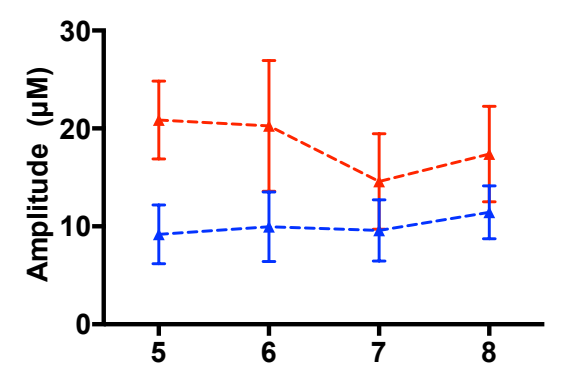

(e)

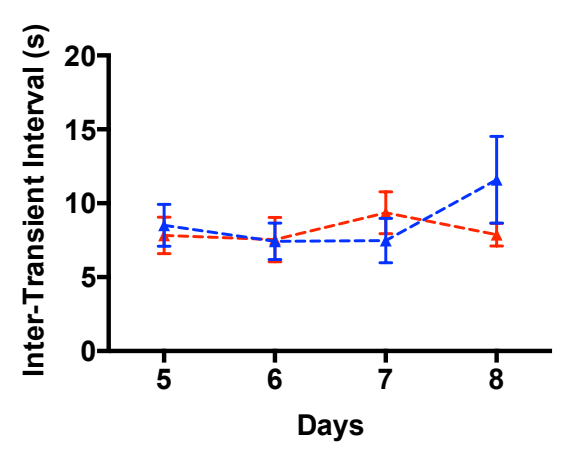

(b)

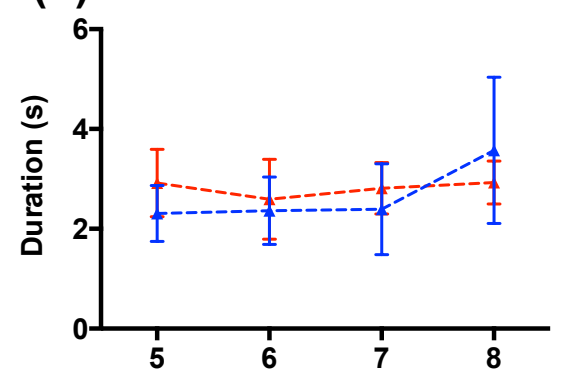

(d)

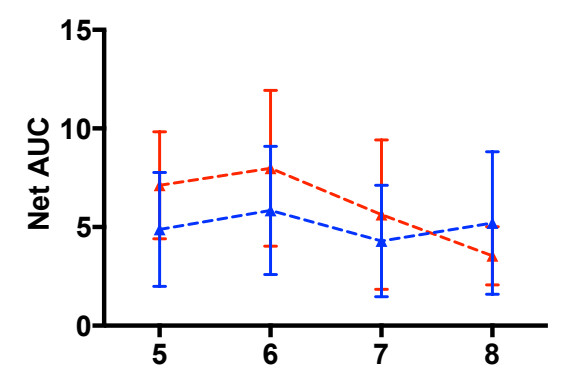

(f)

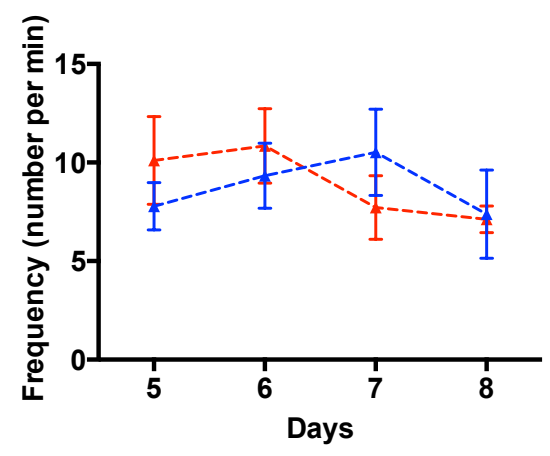

Figure 3.5. SE-induced changes in glutamate homeostasis. SE was induced in mice implanted with MEA pedestals as in Fig. 3. Tonic glutamate levels (a), duration of 
glutamate transients (b), amplitude of glutamate transients (c), area under the curve (AUC) (d), net inter-transient interval (e) and transient frequency (f) were monitored. Symbols represent means \pm SEM from 5 to 8 animals per group. Asterisks denote significant differences between PIC-KA and SAL-KA groups $(* * p \leq .01)$. 
(a) SAL-KA

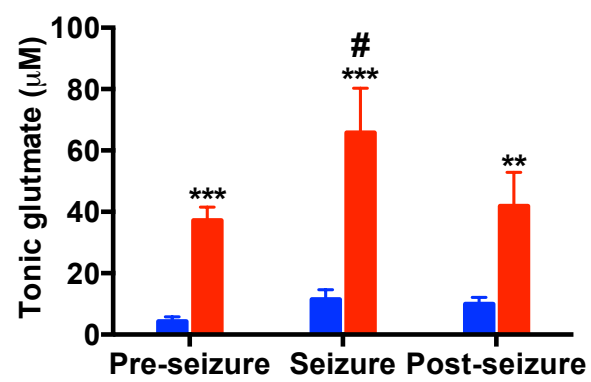

(c)

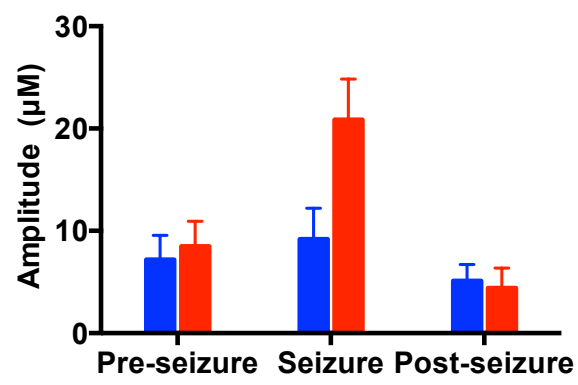

(e)

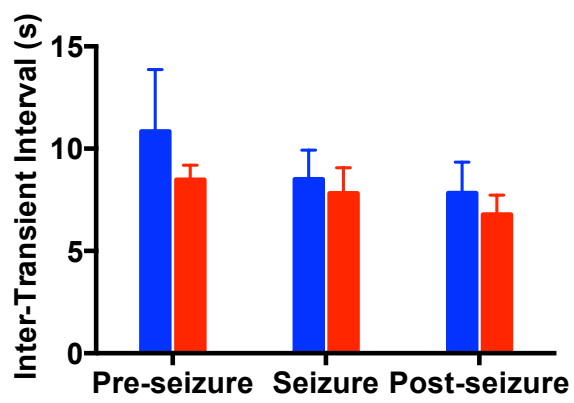

(b)

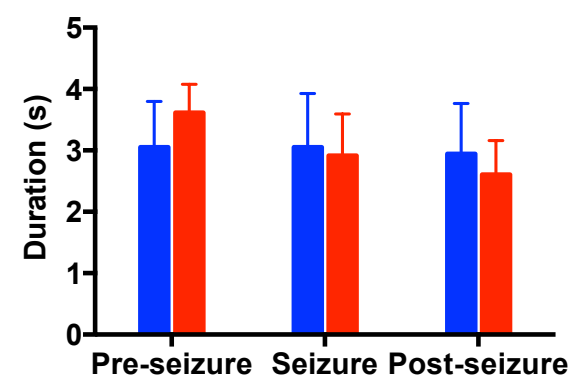

(d)

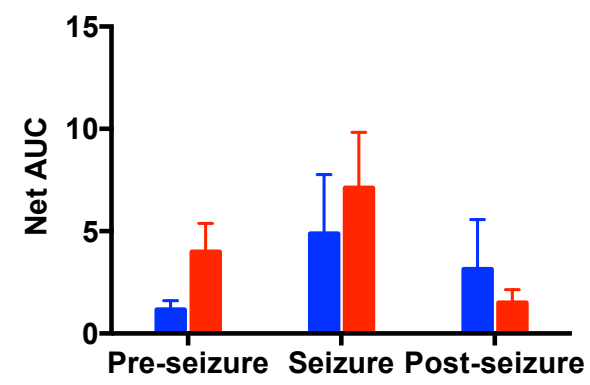

(f)

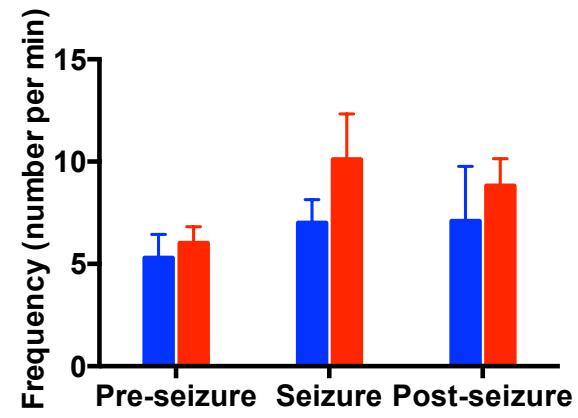

Figure 3.6. Temporal changes in glutamate homeostasis induced by SE. Mice implanted with MEA pedestals were challenged with PIC on Day 4 and status epilepticus (SE) was induced by KA on Day 5 as in Fig. 3 (PIC-KA group). Mice injected with saline in lieu of PIC served as respective controls (SAL-KA). Tonic glutamate and 
glutamate transient were measured prior, during, and after SE (for details see M\&M). (a) Tonic glutamate levels (a), glutamate transient duration (b), amplitude (c), area under the curve (AUC) (d), net inter-transient interval (e), and transient frequency (f). Bars represent means \pm SEM from 5 to 8 animals per group. Asterisks denote significant differences from saline controls $(* * p \leq .01, * * * p \leq .001)$. \# Symbol denotes significant differences between pre-seizure and seizure $(\# p \leq .05)$.

\section{Chapter 4}

Translational significance. Our findings of increased tonic glutamate levels and synaptic neurotransmission after PIC challenge provide a possible link between peripheral viral infection and neurodegenerative conditions. We were also able to show that tonic glutamate levels are predictive of seizure severity, which suggests that glutamate is playing a role in seizure activity and possibly the hyperexcitability observed after PIC challenge. Findings of increased hyperexcitability are important because hyperexcitability is a common feature in many neurodegenerative conditions, such as Alzheimer's disease. The elucidation of this link offers new options for therapeutic approaches to prevent infection-mediated exacerbations in neurodegenerative diseases.

Limitations. In Experiment 1 we observed increased tonic glutamate possibly resulting from a decrease in glutamate clearance. However, it is difficult to conclude the mechanisms that are responsible for this decrease in glutamate clearance. Future studies will need to examine glutamate clearance transporter expression using western blots as well as using various drugs (e.g., TTX) to block glutamate release mechanisms. 
Furthermore, the use of anesthesia in Experiment 1 may have suppressed glutamate signaling, however, this limitation was addressed by using awake behaving animals in Experiment 2.

Although Experiment 2 tonic glutamate levels were consistent with our previous results, we did observe variability in glutamate transient levels. This variability may have hindered our ability to observe significant changes and future studies will need to use a greater sample size. In addition, glass micropipettes can be attached to the implanted MEAs to measure evoked release and clearance in the awake behaving animals. In Experiment 2, our MEA setup did not contain a micropipette, as we were primarily interested in spontaneous glutamate events.

Future Directions. Future work will examine protein changes resulting from PIC-challenge as well as measuring glutamate changes throughout the whole brain. Because inhibitory GABA neurotransmission has also been shown to decrease in response to inflammatory mediators, future studies will measure GABA levels and receptor expression. To determine if viral challenge can exacerbate neurodegenerative pathology, repeated administration of PIC will be examined in a transgenic AD mouse model. 


\section{Supplemental Table}

\begin{tabular}{|l|c|c|}
\hline \multicolumn{3}{|c|}{ Number of rears } \\
\hline & SAL & PIC \\
\hline Experiment 1 & 71.8 & 46.7 \\
\hline Experiment 2 & 64.9 & 35.2 \\
\hline
\end{tabular}

Table S1. The average number of rears three hours after saline or PIC injection for Experiments $1 \& 2$. 


\section{Reference List}

Agulhon, C., Fiacco, T. A., \& McCarthy, K. D. (2010). Hippocampal short- and long-term plasticity are not modulated by astrocyte Ca2+ signaling. Science, 327(5970), 12501254. doi: 10.1126/science.1184821

Ahmed, I., Bose, S. K., Pavese, N., Ramlackhansingh, A., Turkheimer, F., Hotton, G., ... Brooks, D. J. (2011). Glutamate NMDA receptor dysregulation in Parkinson's disease with dyskinesias. Brain, 134(Pt 4), 979-986. doi: 10.1093/brain/awr028

Alexander, J. J., Jacob, A., Bao, L., Macdonald, R. L., \& Quigg, R. J. (2005). Complementdependent apoptosis and inflammatory gene changes in murine lupus cerebritis. $J$ Immunol, 175(12), 8312-8319.

Ali, I., Chugh, D., \& Ekdahl, C. T. (2015). Role of fractalkine-CX3CR1 pathway in seizureinduced microglial activation, neurodegeneration, and neuroblast production in the adult rat brain. Neurobiol Dis, 74, 194-203. doi: 10.1016/j.nbd.2014.11.009

Allen, A. N., Seminog, O. O., \& Goldacre, M. J. (2013). Association between multiple sclerosis and epilepsy: large population-based record-linkage studies. BMC Neurol, 13, 189. doi: 10.1186/1471-2377-13-189

Amaral, D. G., Dolorfo, C., \& Alvarez-Royo, P. (1991). Organization of CA1 projections to the subiculum: a PHA-L analysis in the rat. Hippocampus, 1(4), 415-435. doi: 10.1002/hipo.450010410

Andersen, O., Lygner, P. E., Bergstrom, T., Andersson, M., \& Vahlne, A. (1993). Viral infections trigger multiple sclerosis relapses: a prospective seroepidemiological study. J Neurol, 240(7), 417-422.

Andersen, P., Bliss, T. V., \& Skrede, K. K. (1971). Lamellar organization of hippocampal pathways. Exp Brain Res, 13(2), 222-238.

Bajova, H., Nelson, T. E., \& Gruol, D. L. (2008). Chronic CXCL10 alters the level of activated ERK1/2 and transcriptional factors CREB and NF-kappaB in hippocampal neuronal cell culture. J Neuroimmunol, 195(1-2), 36-46. doi: 10.1016/j.jneuroim.2008.01.003

Bakker, A., Krauss, G. L., Albert, M. S., Speck, C. L., Jones, L. R., Stark, C. E., ... Gallagher, M. (2012). Reduction of hippocampal hyperactivity improves cognition in amnestic mild cognitive impairment. Neuron, 74(3), 467-474. doi: 10.1016/j.neuron.2012.03.023

Banks, W. A., \& Robinson, S. M. (2010). Minimal penetration of lipopolysaccharide across the murine blood-brain barrier. Brain Behav Immun, 24(1), 102-109. doi: 10.1016/j.bbi.2009.09.001

Baumann, H., \& Gauldie, J. (1994). The acute phase response. Immunol Today, 15(2), 74-80. doi: 10.1016/0167-5699(94)90137-6

Bellinger, F. P., Madamba, S. G., Campbell, I. L., \& Siggins, G. R. (1995). Reduced long-term potentiation in the dentate gyrus of transgenic mice with cerebral overexpression of interleukin-6. Neurosci Lett, 198(2), 95-98.

Ben-Ari, Y. (1985). Limbic seizure and brain damage produced by kainic acid: mechanisms and relevance to human temporal lobe epilepsy. Neuroscience, 14(2), 375-403.

Ben-Ari, Y., \& Cossart, R. (2000). Kainate, a double agent that generates seizures: two decades of progress. Trends Neurosci, 23(11), 580-587. 
Ben-Ari, Y., Lagowska, J., Tremblay, E., \& Le Gal La Salle, G. (1979). A new model of focal status epilepticus: intra-amygdaloid application of kainic acid elicits repetitive secondarily generalized convulsive seizures. Brain Res, 163(1), 176-179.

Berg, A. T., Darefsky, A. S., Holford, T. R., \& Shinnar, S. (1998). Seizures with fever after unprovoked seizures: an analysis in children followed from the time of a first febrile seizure. Epilepsia, 39(1), 77-80.

Berke, I. C., Li, Y., \& Modis, Y. (2013). Structural basis of innate immune recognition of viral RNA. Cell Microbiol, 15(3), 386-394. doi: 10.1111/cmi.12061

Beyer, M. K., Herlofson, K., Arsland, D., \& Larsen, J. P. (2001). Causes of death in a community-based study of Parkinson's disease. Acta Neurol Scand, 103(1), 7-11.

Biernacki, K., Antel, J. P., Blain, M., Narayanan, S., Arnold, D. L., \& Prat, A. (2005). Interferon beta promotes nerve growth factor secretion early in the course of multiple sclerosis. Arch Neurol, 62(4), 563-568. doi: 10.1001/archneur.62.4.563

Block, M. L., \& Hong, J. S. (2005). Microglia and inflammation-mediated neurodegeneration: multiple triggers with a common mechanism. Prog Neurobiol, 76(2), 77-98. doi: 10.1016/j.pneurobio.2005.06.004

Blum-Degen, D., Muller, T., Kuhn, W., Gerlach, M., Przuntek, H., \& Riederer, P. (1995). Interleukin- 1 beta and interleukin- 6 are elevated in the cerebrospinal fluid of Alzheimer's and de novo Parkinson's disease patients. Neurosci Lett, 202(1-2), 1720.

Bluthe, R. M., Walter, V., Parnet, P., Laye, S., Lestage, J., Verrier, D., ... Dantzer, R. (1994). Lipopolysaccharide induces sickness behaviour in rats by a vagal mediated mechanism. C R Acad Sci III, 317(6), 499-503.

Bobyn, J., Mangano, E. N., Gandhi, A., Nelson, E., Moloney, K., Clarke, M., \& Hayley, S. (2012). Viral-toxin interactions and Parkinson's disease: poly I:C priming enhanced the neurodegenerative effects of paraquat. J Neuroinflammation, 9, 86. doi: 10.1186/1742-2094-9-86

Borland, L. M., Shi, G., Yang, H., \& Michael, A. C. (2005). Voltammetric study of extracellular dopamine near microdialysis probes acutely implanted in the striatum of the anesthetized rat. J Neurosci Methods, 146(2), 149-158. doi: 10.1016/j.jneumeth.2005.02.002

Braak, H., \& Braak, E. (1998). Argyrophilic grain disease: frequency of occurrence in different age categories and neuropathological diagnostic criteria. J Neural Transm, 105(8-9), 801-819.

Brothers, H. M., Bardou, I., Hopp, S. C., Kaercher, R. M., Corona, A. W., Fenn, A. M., ... Wenk, G. L. (2013). Riluzole partially rescues age-associated, but not LPS-induced, loss of glutamate transporters and spatial memory. J Neuroimmune Pharmacol, 8(5), 10981105. doi: $10.1007 / \mathrm{s} 11481-013-9476-2$

Buckingham, S. C., Campbell, S. L., Haas, B. R., Montana, V., Robel, S., Ogunrinu, T., \& Sontheimer, H. (2011). Glutamate release by primary brain tumors induces epileptic activity. Nat Med, 17(10), 1269-1274. doi: 10.1038/nm.2453

Burmeister, J. J., \& Gerhardt, G. A. (2001). Self-referencing ceramic-based multisite microelectrodes for the detection and elimination of interferences from the measurement of L-glutamate and other analytes. Anal Chem, 73(5), 1037-1042.

Burmeister, J. J., Moxon, K., \& Gerhardt, G. A. (2000). Ceramic-based multisite microelectrodes for electrochemical recordings. Anal Chem, 72(1), 187-192.

Burmeister, J. J., Pomerleau, F., Palmer, M., Day, B. K., Huettl, P., \& Gerhardt, G. A. (2002a). Improved ceramic-based multisite microelectrode for rapid measurements of Lglutamate in the CNS. J Neurosci Methods., 119(2), 163-171. 
Burmeister, J. J., Pomerleau, F., Palmer, M., Day, B. K., Huettl, P., \& Gerhardt, G. A. (2002b). Improved ceramic-based multisite microelectrode for rapid measurements of Lglutamate in the CNS. J Neurosci Methods, 119(2), 163-171.

Busche, M. A., Chen, X., Henning, H. A., Reichwald, J., Staufenbiel, M., Sakmann, B., \& Konnerth, A. (2012). Critical role of soluble amyloid-beta for early hippocampal hyperactivity in a mouse model of Alzheimer's disease. Proc Natl Acad Sci U S A, 109(22), 8740-8745. doi: 10.1073/pnas.1206171109

Campbell, I. L., Abraham, C. R., Masliah, E., Kemper, P., Inglis, J. D., Oldstone, M. B., \& Mucke, L. (1993). Neurologic disease induced in transgenic mice by cerebral overexpression of interleukin 6. Proc Natl Acad Sci U S A, 90(21), 10061-10065.

Carret-Rebillat, A. S., Pace, C., Gourmaud, S., Ravasi, L., Montagne-Stora, S., Longueville, S., .. . Hugon, J. (2015). Neuroinflammation and Abeta accumulation linked to systemic inflammation are decreased by genetic PKR down-regulation. Sci Rep, 5, 8489. doi: $10.1038 /$ srep08489

Cavus, I., Kasoff, W. S., Cassaday, M. P., Jacob, R., Gueorguieva, R., Sherwin, R. S., . . Abi-Saab, W. M. (2005). Extracellular metabolites in the cortex and hippocampus of epileptic patients. Ann Neurol, 57(2), 226-235. doi: 10.1002/ana.20380

Cerri, C., Genovesi, S., Allegra, M., Pistillo, F., Puntener, U., Guglielmotti, A., . . Caleo, M. (2016). The Chemokine CCL2 Mediates the Seizure-enhancing Effects of Systemic Inflammation. J Neurosci, 36(13), 3777-3788. doi: 10.1523/jneurosci.0451-15.2016

Chan, J., Jones, N. C., Bush, A. I., O'Brien, T. J., \& Kwan, P. (2015). A mouse model of Alzheimer's disease displays increased susceptibility to kindling and seizureassociated death. Epilepsia, 56(6), e73-77. doi: 10.1111/epi.12993

Chapman, A. G. (2000). Glutamate and epilepsy. J Nutr, 130(4S Suppl), 1043S-1045S.

Cho, J., Nelson, T. E., Bajova, H., \& Gruol, D. L. (2009). Chronic CXCL10 alters neuronal properties in rat hippocampal culture. J Neuroimmunol, 207(1-2), 92-100. doi: 10.1016/j.jneuroim.2008.12.007

Cordonnier, C., Henon, H., Derambure, P., Pasquier, F., \& Leys, D. (2007). Early epileptic seizures after stroke are associated with increased risk of new-onset dementia. $J$ Neurol Neurosurg Psychiatry, 78(5), 514-516. doi: 10.1136/jnnp.2006.105080

Cunningham, C., Campion, S., Teeling, J., Felton, L., \& Perry, V. H. (2007). The sickness behaviour and CNS inflammatory mediator profile induced by systemic challenge of mice with synthetic double-stranded RNA (poly I:C). Brain Behav Immun, 21(4), 490-502. doi: 10.1016/j.bbi.2006.12.007

Cunningham, C., Wilcockson, D. C., Campion, S., Lunnon, K., \& Perry, V. H. (2005). Central and systemic endotoxin challenges exacerbate the local inflammatory response and increase neuronal death during chronic neurodegeneration. J Neurosci, 25(40), 9275-9284. doi: 10.1523/jneurosci.2614-05.2005

Dantzer, R. (2006). Cytokine, sickness behavior, and depression. Neurol Clin, 24(3), 441-460. doi: 10.1016/j.ncl.2006.03.003

Dantzer, R., \& Kelley, K. W. (2007). Twenty years of research on cytokine-induced sickness behavior. Brain Behav Immun, 21(2), 153-160. doi: 10.1016/j.bbi.2006.09.006

Dantzer, R., O'Connor, J. C., Freund, G. G., Johnson, R. W., \& Kelley, K. W. (2008). From inflammation to sickness and depression: when the immune system subjugates the brain. Nat Rev Neurosci, 9(1), 46-56. doi: 10.1038/nrn2297

de Rooij, S. E., van Munster, B. C., Korevaar, J. C., \& Levi, M. (2007). Cytokines and acute phase response in delirium.J Psychosom Res, 62(5), 521-525. doi: 10.1016/j.jpsychores.2006.11.013 
de Vries, H. E., Blom-Roosemalen, M. C., van Oosten, M., de Boer, A. G., van Berkel, T. J., Breimer, D. D., \& Kuiper, J. (1996). The influence of cytokines on the integrity of the blood-brain barrier in vitro. J Neuroimmunol, 64(1), 37-43.

Deleidi, M., Hallett, P. J., Koprich, J. B., Chung, C. Y., \& Isacson, O. (2010). The Toll-like receptor-3 agonist polyinosinic:polycytidylic acid triggers nigrostriatal dopaminergic degeneration. J Neurosci, 30(48), 16091-16101. doi: 10.1523/jneurosci.2400-10.2010

den Haan, J. M., Arens, R., \& van Zelm, M. C. (2014). The activation of the adaptive immune system: cross-talk between antigen-presenting cells, T cells and B cells. Immunol Lett, 162(2 Pt B), 103-112. doi: 10.1016/j.imlet.2014.10.011

Diamond, J. S. (2005). Deriving the glutamate clearance time course from transporter currents in CA1 hippocampal astrocytes: transmitter uptake gets faster during development. J Neurosci, 25(11), 2906-2916. doi: 10.1523/jneurosci.5125-04.2005

Dobbs, R. J., Charlett, A., Purkiss, A. G., Dobbs, S. M., Weller, C., \& Peterson, D. W. (1999). Association of circulating TNF-alpha and IL-6 with ageing and parkinsonism. Acta Neurol Scand, 100(1), 34-41.

Dube, C., Vezzani, A., Behrens, M., Bartfai, T., \& Baram, T. Z. (2005). Interleukin-1beta contributes to the generation of experimental febrile seizures. Ann Neurol, 57(1), 152-155. doi: 10.1002/ana.20358

During, M. J., \& Spencer, D. D. (1993). Extracellular hippocampal glutamate and spontaneous seizure in the conscious human brain. Lancet, 341(8861), 1607-1610.

Edwards, S., Zvartau, M., Clarke, H., Irving, W., \& Blumhardt, L. D. (1998). Clinical relapses and disease activity on magnetic resonance imaging associated with viral upper respiratory tract infections in multiple sclerosis. J Neurol Neurosurg Psychiatry, 64(6), 736-741.

Elkind, M. S., Cheng, J., Rundek, T., Boden-Albala, B., \& Sacco, R. L. (2004). Leukocyte count predicts outcome after ischemic stroke: the Northern Manhattan Stroke Study.J Stroke Cerebrovasc Dis, 13(5), 220-227. doi: 10.1016/j.jstrokecerebrovasdis.2004.07.004

Elvington, A., Atkinson, C., Zhu, H., Yu, J., Takahashi, K., Stahl, G. L., ... Tomlinson, S. (2012). The alternative complement pathway propagates inflammation and injury in murine ischemic stroke. J Immunol, 189(9), 4640-4647. doi: 10.4049/jimmunol.1201904

Feddersen, B., Remi, J., Einhellig, M., Stoyke, C., Krauss, P., \& Noachtar, S. (2014). Parkinson's disease: less epileptic seizures, more status epilepticus. Epilepsy Res, 108(2), 349354. doi: 10.1016/j.eplepsyres.2013.11.013

Field, R., Campion, S., Warren, C., Murray, C., \& Cunningham, C. (2010). Systemic challenge with the TLR3 agonist poly I:C induces amplified IFNalpha/beta and IL-1beta responses in the diseased brain and exacerbates chronic neurodegeneration. Brain Behav Immun, 24(6), 996-1007. doi: 10.1016/j.bbi.2010.04.004

Fil, D., Borysiewicz, E., \& Konat, G. W. (2011). A broad upregulation of cerebral chemokine genes by peripherally-generated inflammatory mediators. Metab Brain Dis, 26(1), 49-59. doi: 10.1007/s11011-010-9231-9

Forster, C., Burek, M., Romero, I. A., Weksler, B., Couraud, P. O., \& Drenckhahn, D. (2008). Differential effects of hydrocortisone and TNFalpha on tight junction proteins in an in vitro model of the human blood-brain barrier. J Physiol, 586(7), 1937-1949. doi: 10.1113/jphysiol.2007.146852

Fortier, M. E., Kent, S., Ashdown, H., Poole, S., Boksa, P., \& Luheshi, G. N. (2004). The viral mimic, polyinosinic:polycytidylic acid, induces fever in rats via an interleukin-1dependent mechanism. Am J Physiol Regul Integr Comp Physiol, 287(4), R759-766. doi: 10.1152/ajpregu.00293.2004 
Fotuhi, M., Standaert, D. G., Testa, C. M., Penney, J. B., Jr., \& Young, A. B. (1994). Differential expression of metabotropic glutamate receptors in the hippocampus and entorhinal cortex of the rat. Brain Res Mol Brain Res, 21(3-4), 283-292.

Galic, M. A., Riazi, K., Henderson, A. K., Tsutsui, S., \& Pittman, Q. J. (2009). Viral-like brain inflammation during development causes increased seizure susceptibility in adult rats. Neurobiol Dis, 36(2), 343-351. doi: 10.1016/j.nbd.2009.07.025

Galic, M. A., Riazi, K., \& Pittman, Q. J. (2012). Cytokines and brain excitability. Front Neuroendocrinol, 33(1), 116-125. doi: 10.1016/j.yfrne.2011.12.002

Ganong, W. F. (2000). Circumventricular organs: definition and role in the regulation of endocrine and autonomic function. Clin Exp Pharmacol Physiol, 27(5-6), 422-427.

Garcia-Oscos, F., Salgado, H., Hall, S., Thomas, F., Farmer, G. E., Bermeo, J., . . A Atzori, M. (2012). The stress-induced cytokine interleukin-6 decreases the inhibition/excitation ratio in the rat temporal cortex via trans-signaling. Biol Psychiatry, 71(7), 574-582. doi: 10.1016/j.biopsych.2011.11.018

George, J., Bleasdale, S., \& Singleton, S. J. (1997). Causes and prognosis of delirium in elderly patients admitted to a district general hospital. Age Ageing, 26(6), 423-427.

Goldberg, E. M., \& Coulter, D. A. (2013). Mechanisms of epileptogenesis: a convergence on neural circuit dysfunction. Nat Rev Neurosci, 14(5), 337-349. doi: 10.1038/nrn3482

Guha-Thakurta, N., \& Majde, J. A. (1997). Early induction of proinflammatory cytokine and type I interferon mRNAs following Newcastle disease virus, poly [rI:rC], or low-dose LPS challenge of the mouse. J Interferon Cytokine Res, 17(4), 197-204.

Hascup, Hascup, E. R., Stephens, M. L., Glaser, P. E., Yoshitake, T., Mathe, A. A., . . Kehr, J. (2011). Resting glutamate levels and rapid glutamate transients in the prefrontal cortex of the Flinders Sensitive Line rat: a genetic rodent model of depression. Neuropsychopharmacology., 36(8), 1769-1777. doi: 1710.1038/npp.2011.1760. Epub 2011 Apr 1727.

Hascup, Erin R., Hascup, Kevin N., Stephens, Michelle, Pomerleau, Francois, Huettl, Peter, Gratton, Alain, \& Gerhardt, Greg A. (2010). Rapid microelectrode measurements and the origin and regulation of extracellular glutamate in rat prefrontal cortex. Journal of Neurochemistry, 115(6), 1608-1620. doi: 10.1111/j.1471-4159.2010.07066.x

He, X., Li, Y., Liu, Z., Yue, X., Zhao, P., Hu, J., . . Shao, J. (2013). The association between CCL2 polymorphisms and drug-resistant epilepsy in Chinese children. Epileptic Disord, 15(3), 272-277. doi: 10.1684/epd.2013.0603

Hillered, L., Vespa, P. M., \& Hovda, D. A. (2005). Translational neurochemical research in acute human brain injury: the current status and potential future for cerebral microdialysis. J Neurotrauma, 22(1), 3-41. doi: 10.1089/neu.2005.22.3

Hollmann, M., \& Heinemann, S. (1994). Cloned glutamate receptors. Annu Rev Neurosci, 17, 31-108. doi: 10.1146/annurev.ne.17.030194.000335

Holmes, C., El-Okl, M., Williams, A. L., Cunningham, C., Wilcockson, D., \& Perry, V. H. (2003). Systemic infection, interleukin 1beta, and cognitive decline in Alzheimer's disease. $J$ Neurol Neurosurg Psychiatry, 74(6), 788-789.

Homan, E. R., Zendzian, R. P., Schott, L. D., Levy, H. B., \& Adamson, R. H. (1972). Studies on poly I:C toxicity in experimental animals. Toxicol Appl Pharmacol, 23(4), 579-588.

Hu, S., Sheng, W. S., Ehrlich, L. C., Peterson, P. K., \& Chao, C. C. (2000). Cytokine effects on glutamate uptake by human astrocytes. Neuroimmunomodulation, 7(3), 153-159. doi: 26433

Huckans, M., Seelye, A., Parcel, T., Mull, L., Woodhouse, J., Bjornson, D., .. Hauser, P. (2009). The cognitive effects of hepatitis $C$ in the presence and absence of a history of substance use disorder. J Int Neuropsychol Soc, 15(1), 69-82. doi: $10.1017 / \mathrm{s} 1355617708090085$ 
Hunsberger, H. C., Rudy, C. C., Batten, S. R., Gerhardt, G. A., \& Reed, M. N. (2015). P301L tau expression affects glutamate release and clearance in the hippocampal trisynaptic pathway. J Neurochem, 132(2), 169-182. doi: 10.1111/jnc.12967

Hunsberger, H. C., Wang, D., Petrisko, T. J., Alhowail, A., Setti, S. E., Suppiramaniam, V., ... Reed, M. N. (2016). Peripherally restricted viral challenge elevates extracellular glutamate and enhances synaptic transmission in the hippocampus. J Neurochem. doi: $10.1111 /$ jnc.13665

Hunsberger, H. C., Weitzner, D. S., Rudy, C. C., Hickman, J. E., Libell, E. M., Speer, R. R., ... Reed, M. N. (2015). Riluzole rescues glutamate alterations, cognitive deficits, and tau pathology associated with P301L tau expression. J Neurochem, 135(2), 381-394. doi: $10.1111 /$ jnc. 13230

Isaacs, A., \& Lindenmann, J. (1957). Virus interference. I. The interferon. Proc R Soc Lond B Biol Sci, 147(927), 258-267.

Jacobs, B. L., \& Langland, J. O. (1996). When two strands are better than one: the mediators and modulators of the cellular responses to double-stranded RNA. Virology, 219(2), 339-349. doi: 10.1006/viro.1996.0259

Jaquins-Gerstl, A., \& Michael, A. C. (2009). Comparison of the brain penetration injury associated with microdialysis and voltammetry. J Neurosci Methods, 183(2), 127135. doi: 10.1016/j.jneumeth.2009.06.023

Jin, S., Kawanokuchi, J., Mizuno, T., Wang, J., Sonobe, Y., Takeuchi, H., \& Suzumura, A. (2007). Interferon-beta is neuroprotective against the toxicity induced by activated microglia. Brain Res, 1179, 140-146. doi: 10.1016/j.brainres.2007.08.055

Kakkar, A. K., \& Dahiya, N. (2015). Management of Parkinsons disease: Current and future pharmacotherapy. Eur J Pharmacol, 750, 74-81. doi: 10.1016/j.ejphar.2015.01.030

Kalueff, A. V., Lehtimaki, K. A., Ylinen, A., Honkaniemi, J., \& Peltola, J. (2004). Intranasal administration of human IL-6 increases the severity of chemically induced seizures in rats. Neurosci Lett, 365(2), 106-110. doi: 10.1016/j.neulet.2004.04.061

Kandel, E. R., \& Spencer, W. A. (1961). Excitation and inhibition of single pyramidal cells during hippocampal seizure. Exp Neurol, 4, 162-179.

Kerrigan, T. L., Brown, J. T., \& Randall, A. D. (2014). Characterization of altered intrinsic excitability in hippocampal CA1 pyramidal cells of the Abeta-overproducing PDAPP mouse. Neuropharmacology, 79, 515-524. doi: 10.1016/j.neuropharm.2013.09.004

Kimura-Takeuchi, M., Majde, J. A., Toth, L. A., \& Krueger, J. M. (1992). The role of doublestranded RNA in induction of the acute-phase response in an abortive influenza virus infection model. J Infect Dis, 166(6), 1266-1275.

Kirschman, L. T., Borysiewicz, E., Fil, D., \& Konat, G. W. (2011). Peripheral immune challenge with dsRNA enhances kainic acid-induced status epilepticus. Metab Brain Dis, 26(1), 91-93. doi: 10.1007/s11011-011-9236-z

Kitazawa, M., Oddo, S., Yamasaki, T. R., Green, K. N., \& LaFerla, F. M. (2005). Lipopolysaccharide-induced inflammation exacerbates tau pathology by a cyclindependent kinase 5-mediated pathway in a transgenic model of Alzheimer's disease. J Neurosci, 25(39), 8843-8853. doi: 10.1523/jneurosci.2868-05.2005

Kolev, M. V., Ruseva, M. M., Harris, C. L., Morgan, B. P., \& Donev, R. M. (2009). Implication of complement system and its regulators in Alzheimer's disease. Curr Neuropharmacol, 7(1), 1-8. doi: 10.2174/157015909787602805

Konat, G. (2016). Cerebral Response to Peripheral Challenge with a Viral Mimetic. Neurochem Res, 41(1-2), 144-155. doi: 10.1007/s11064-015-1746-3

Konat, G. W., Borysiewicz, E., Fil, D., \& James, I. (2009). Peripheral challenge with doublestranded RNA elicits global up-regulation of cytokine gene expression in the brain. $J$ Neurosci Res, 87(6), 1381-1388. doi: 10.1002/jnr.21958 
Koprich, J. B., Reske-Nielsen, C., Mithal, P., \& Isacson, O. (2008). Neuroinflammation mediated by IL-1beta increases susceptibility of dopamine neurons to degeneration in an animal model of Parkinson's disease. J Neuroinflammation, 5, 8. doi: 10.1186/1742-2094-5-8

Kostic, M., Zivkovic, N., \& Stojanovic, I. (2013). Multiple sclerosis and glutamate excitotoxicity. Rev Neurosci, 24(1), 71-88. doi: 10.1515/revneuro-2012-0062

Kountouras, J., Boziki, M., Gavalas, E., Zavos, C., Deretzi, G., Grigoriadis, N., . . Michailidou, I. (2009). Increased cerebrospinal fluid Helicobacter pylori antibody in Alzheimer's disease. Int J Neurosci, 119(6), 765-777. doi: 10.1080/00207450902782083

Kountouras, J., Tsolaki, M., Gavalas, E., Boziki, M., Zavos, C., Karatzoglou, P., ... Venizelos, I. (2006). Relationship between Helicobacter pylori infection and Alzheimer disease. Neurology, 66(6), 938-940. doi: 10.1212/01.wnl.0000203644.68059.5f

Kranjac, D., McLinden, K. A., Koster, K. M., Kaldenbach, D. L., Chumley, M. J., \& Boehm, G. W. (2012). Peripheral administration of poly I:C disrupts contextual fear memory consolidation and BDNF expression in mice. Behav Brain Res, 228(2), 452-457. doi: 10.1016/j.bbr.2011.12.031

Krstic, D., Madhusudan, A., Doehner, J., Vogel, P., Notter, T., Imhof, C., . . Knuesel, I. (2012). Systemic immune challenges trigger and drive Alzheimer-like neuropathology in mice. J Neuroinflammation, 9, 151. doi: 10.1186/1742-2094-9-151

Kunzmann, V., Kretzschmar, E., Herrmann, T., \& Wilhelm, M. (2004). Polyinosinicpolycytidylic acid-mediated stimulation of human gammadelta T cells via CD11c dendritic cell-derived type I interferons. Immunology, 112(3), 369-377. doi: 10.1111/j.1365-2567.2004.01908.x

Lax, P., Limatola, C., Fucile, S., Trettel, F., Di Bartolomeo, S., Renzi, M., ... Eusebi, F. (2002). Chemokine receptor CXCR2 regulates the functional properties of AMPA-type glutamate receptor GluR1 in HEK cells. J Neuroimmunol, 129(1-2), 66-73.

Leroy, K., Yilmaz, Z., \& Brion, J. P. (2007). Increased level of active GSK-3beta in Alzheimer's disease and accumulation in argyrophilic grains and in neurones at different stages of neurofibrillary degeneration. Neuropathol Appl Neurobiol, 33(1), 43-55. doi: 10.1111/j.1365-2990.2006.00795.x

Lian, H., Yang, L., Cole, A., Sun, L., Chiang, A. C., Fowler, S. W., ... Zheng, H. (2015). NFkappaBactivated astroglial release of complement C3 compromises neuronal morphology and function associated with Alzheimer's disease. Neuron, 85(1), 101-115. doi: 10.1016/j.neuron.2014.11.018

Libbey, J. E., Kirkman, N. J., Wilcox, K. S., White, H. S., \& Fujinami, R. S. (2010). Role for complement in the development of seizures following acute viral infection. J Virol, 84(13), 6452-6460. doi: 10.1128/jvi.00422-10

Loftis, J. M., Huckans, M., Ruimy, S., Hinrichs, D. J., \& Hauser, P. (2008). Depressive symptoms in patients with chronic hepatitis $C$ are correlated with elevated plasma levels of interleukin-1beta and tumor necrosis factor-alpha. Neurosci Lett, 430(3), 264-268. doi: 10.1016/j.neulet.2007.11.001

Lomo, T. (2009). Excitability changes within transverse lamellae of dentate granule cells and their longitudinal spread following orthodromic or antidromic activation. Hippocampus, 19(7), 633-648. doi: 10.1002/hipo.20538

Lu, Y., Zhong, C., Wang, L., Wei, P., He, W., Huang, K., ... Wang, L. (2016). Optogenetic dissection of ictal propagation in the hippocampal-entorhinal cortex structures. Nat Commun, 7, 10962. doi: 10.1038/ncomms10962

Lue, L. F., Brachova, L., Civin, W. H., \& Rogers, J. (1996). Inflammation, A beta deposition, and neurofibrillary tangle formation as correlates of Alzheimer's disease neurodegeneration. J Neuropathol Exp Neurol, 55(10), 1083-1088. 
Ma, L., Zhang, H., Liu, N., Wang, P. Q., Guo, W. Z., Fu, Q., ... Mi, W. D. (2016). TSPO ligand PK11195 alleviates neuroinflammation and beta-amyloid generation induced by systemic LPS administration. Brain Res Bull, 121, 192-200. doi: 10.1016/j.brainresbull.2016.02.001

Marchi, N., Fan, Q., Ghosh, C., Fazio, V., Bertolini, F., Betto, G., ... Janigro, D. (2009). Antagonism of peripheral inflammation reduces the severity of status epilepticus. Neurobiol Dis, 33(2), 171-181. doi: 10.1016/j.nbd.2008.10.002

Marchi, N., Teng, Q., Ghosh, C., Fan, Q., Nguyen, M. T., Desai, N. K., ... Janigro, D. (2010). Blood-brain barrier damage, but not parenchymal white blood cells, is a hallmark of seizure activity. Brain Res, 1353, 176-186. doi: 10.1016/j.brainres.2010.06.051

McColl, B. W., Rothwell, N. J., \& Allan, S. M. (2007). Systemic inflammatory stimulus potentiates the acute phase and CXC chemokine responses to experimental stroke and exacerbates brain damage via interleukin-1- and neutrophil-dependent mechanisms. J Neurosci, 27(16), 4403-4412. doi: 10.1523/jneurosci.5376-06.2007

McCoy, M. K., Martinez, T. N., Ruhn, K. A., Szymkowski, D. E., Smith, C. G., Botterman, B. R., .. . Tansey, M. G. (2006). Blocking soluble tumor necrosis factor signaling with dominant-negative tumor necrosis factor inhibitor attenuates loss of dopaminergic neurons in models of Parkinson's disease. J Neurosci, 26(37), 9365-9375. doi: 10.1523/jneurosci.1504-06.2006

McCusker, R. H., \& Kelley, K. W. (2013). Immune-neural connections: how the immune system's response to infectious agents influences behavior. J Exp Biol, 216(Pt 1), 8498. doi: 10.1242/jeb.073411

McLinden, K. A., Kranjac, D., Deodati, L. E., Kahn, M., Chumley, M. J., \& Boehm, G. W. (2012). Age exacerbates sickness behavior following exposure to a viral mimetic. Physiol Behav, 105(5), 1219-1225. doi: 10.1016/j.physbeh.2011.04.024

Merega, E., Di Prisco, S., Lanfranco, M., Severi, P., \& Pittaluga, A. (2014). Complement selectively elicits glutamate release from nerve endings in different regions of mammal central nervous system. J Neurochem, 129(3), 473-483. doi: $10.1111 /$ jnc. 12650

Michalovicz, L. T., \& Konat, G. W. (2014). Peripherally restricted acute phase response to a viral mimic alters hippocampal gene expression. Metab Brain Dis, 29(1), 75-86. doi: 10.1007/s11011-013-9471-6

Michalovicz, L.T., Lally, B., \& Konat, G.W. (2015). Peripheral challenge with a viral mimic upregulates expression of the complement genes in the hippocampus. $J$ Neuroimmunol (submitted).

Michaud, M., Balardy, L., Moulis, G., Gaudin, C., Peyrot, C., Vellas, B., ... Nourhashemi, F. (2013). Proinflammatory cytokines, aging, and age-related diseases. J Am Med Dir Assoc, 14(12), 877-882. doi: 10.1016/j.jamda.2013.05.009

Mizuno, T., Zhang, G., Takeuchi, H., Kawanokuchi, J., Wang, J., Sonobe, Y., ... Suzumura, A. (2008). Interferon-gamma directly induces neurotoxicity through a neuron specific, calcium-permeable complex of IFN-gamma receptor and AMPA GluR1 receptor. FASEB J, 22(6), 1797-1806. doi: 10.1096/fj.07-099499

Mogi, M., Harada, M., Kondo, T., Riederer, P., Inagaki, H., Minami, M., \& Nagatsu, T. (1994). Interleukin-1 beta, interleukin-6, epidermal growth factor and transforming growth factor-alpha are elevated in the brain from parkinsonian patients. Neurosci Lett, 180(2), 147-150.

Monaghan, D. T., \& Cotman, C. W. (1982). The distribution of [3H] kainic acid binding sites in rat CNS as determined by autoradiography. Brain Res, 252(1), 91-100. 
Morrison, R. S., Wenzel, H. J., Kinoshita, Y., Robbins, C. A., Donehower, L. A., \& Schwartzkroin, P. A. (1996). Loss of the p53 tumor suppressor gene protects neurons from kainateinduced cell death. J Neurosci, 16(4), 1337-1345.

Muller, U., Steinhoff, U., Reis, L. F., Hemmi, S., Pavlovic, J., Zinkernagel, R. M., \& Aguet, M. (1994). Functional role of type I and type II interferons in antiviral defense. Science, 264(5167), 1918-1921.

Murray, A. M., Levkoff, S. E., Wetle, T. T., Beckett, L., Cleary, P. D., Schor, J. D., ... Evans, D. A. (1993). Acute delirium and functional decline in the hospitalized elderly patient. $J$ Gerontol, 48(5), M181-186.

Nee, L. E., \& Lippa, C. F. (1999). Alzheimer's disease in 22 twin pairs--13-year follow-up: hormonal, infectious and traumatic factors. Dement Geriatr Cogn Disord, 10(2), 148151. doi: 17115

Nelson, T. E., \& Gruol, D. L. (2004). The chemokine CXCL10 modulates excitatory activity and intracellular calcium signaling in cultured hippocampal neurons. $J$ Neuroimmunol, 156(1-2), 74-87. doi: 10.1016/j.jneuroim.2004.07.009

Nistri, A., \& Cherubini, E. (1991). Depression of a sustained calcium current by kainate in rat hippocampal neurones in vitro. J Physiol, 435, 465-481.

Obrenovitch, T. P., Urenjak, J., Zilkha, E., \& Jay, T. M. (2000). Excitotoxicity in neurological disorders--the glutamate paradox. Int J Dev Neurosci, 18(2-3), 281-287.

Paxinos, G, \& Franklin, K. (2012). Mouse Brain in Stereotaxic Coordinates (Vol. 4th): Academic Press.

Perry, V. H., Newman, T. A., \& Cunningham, C. (2003). The impact of systemic infection on the progression of neurodegenerative disease. Nat Rev Neurosci, 4(2), 103-112. doi: $10.1038 / \mathrm{nrn} 1032$

Pineda, E., Shin, D., You, S. J., Auvin, S., Sankar, R., \& Mazarati, A. (2013). Maternal immune activation promotes hippocampal kindling epileptogenesis in mice. Ann Neurol, 74(1), 11-19. doi: 10.1002/ana.23898

Possin, K. L., Sanchez, P. E., Anderson-Bergman, C., Fernandez, R., Kerchner, G. A., Johnson, E. T., ... Finkbeiner, S. (2016). Cross-species translation of the Morris maze for Alzheimer's disease. J Clin Invest, 126(2), 779-783. doi: 10.1172/jci78464

Pribiag, H., \& Stellwagen, D. (2013). TNF-alpha downregulates inhibitory neurotransmission through protein phosphatase 1-dependent trafficking of GABA(A) receptors. J Neurosci, 33(40), 15879-15893. doi: 10.1523/jneurosci.0530-13.2013

Prow, N. A., \& Irani, D. N. (2008). The inflammatory cytokine, interleukin-1 beta, mediates loss of astroglial glutamate transport and drives excitotoxic motor neuron injury in the spinal cord during acute viral encephalomyelitis. J Neurochem, 105(4), 12761286. doi: 10.1111/j.1471-4159.2008.05230.x

Quan, N., \& Banks, W. A. (2007). Brain-immune communication pathways. Brain Behav Immun, 21(6), 727-735. doi: 10.1016/j.bbi.2007.05.005

Rahkonen, T., Luukkainen-Markkula, R., Paanila, S., Sivenius, J., \& Sulkava, R. (2000). Delirium episode as a sign of undetected dementia among community dwelling elderly subjects: a 2 year follow up study. J Neurol Neurosurg Psychiatry, 69(4), 519521.

Ravizza, T., Gagliardi, B., Noe, F., Boer, K., Aronica, E., \& Vezzani, A. (2008). Innate and adaptive immunity during epileptogenesis and spontaneous seizures: evidence from experimental models and human temporal lobe epilepsy. Neurobiol Dis, 29(1), 142 160. doi: 10.1016/j.nbd.2007.08.012

Riazi, K., Galic, M. A., Kentner, A. C., Reid, A. Y., Sharkey, K. A., \& Pittman, Q. J. (2015). Microglia-dependent alteration of glutamatergic synaptic transmission and 
plasticity in the hippocampus during peripheral inflammation. J Neurosci, 35(12), 4942-4952. doi: 10.1523/jneurosci.4485-14.2015

Robinson, J. H., \& Deadwyler, S. A. (1981). Kainic acid produces depolarization of CA3 pyramidal cells in the vitro hippocampal slice. Brain Res, 221(1), 117-127.

Rowley, H. L., Martin, K. F., \& Marsden, C. A. (1995). Decreased GABA release following tonic-clonic seizures is associated with an increase in extracellular glutamate in rat hippocampus in vivo. Neuroscience, 68(2), 415-422.

Rutherford, E. C., Pomerleau, F., Huettl, P., Stromberg, I., \& Gerhardt, G. A. (2007). Chronic second-by-second measures of L-glutamate in the central nervous system of freely moving rats. J Neurochem, 102(3), 712-722. doi: 10.1111/j.1471-4159.2007.04596.x

Samland, H., Huitron-Resendiz, S., Masliah, E., Criado, J., Henriksen, S. J., \& Campbell, I. L. (2003). Profound increase in sensitivity to glutamatergic- but not cholinergic agonist-induced seizures in transgenic mice with astrocyte production of IL-6.J Neurosci Res, 73(2), 176-187. doi: 10.1002/jnr.10635

Santello, M., Bezzi, P., \& Volterra, A. (2011). TNFalpha controls glutamatergic gliotransmission in the hippocampal dentate gyrus. Neuron, 69(5), 988-1001. doi: 10.1016/j.neuron.2011.02.003

Sarma, J. V., \& Ward, P. A. (2011). The complement system. Cell Tissue Res, 343(1), 227-235. doi: $10.1007 / \mathrm{s} 00441-010-1034-0$

Schapira, A. H. (2010). Safinamide in the treatment of Parkinson's disease. Expert Opin Pharmacother, 11(13), 2261-2268. doi: 10.1517/14656566.2010.511612

Sloviter, R. S., \& Lomo, T. (2012). Updating the lamellar hypothesis of hippocampal organization. Front Neural Circuits, 6, 102. doi: 10.3389/fncir.2012.00102

Smith, G. A., Rocha, E. M., Rooney, T., Barneoud, P., McLean, J. R., Beagan, J., . . Isacson, O. (2015). A Nurr1 agonist causes neuroprotection in a Parkinson's disease lesion model primed with the toll-like receptor 3 dsRNA inflammatory stimulant poly(I:C). PLoS ONE, 10(3), e0121072. doi: 10.1371/journal.pone.0121072

Soria, F. N., Perez-Samartin, A., Martin, A., Gona, K. B., Llop, J., Szczupak, B., . . Domercq, M. (2014). Extrasynaptic glutamate release through cystine/glutamate antiporter contributes to ischemic damage. J Clin Invest, 124(8), 3645-3655. doi: $10.1172 /$ jci71886

Soukupova, M., Binaschi, A., Falcicchia, C., Palma, E., Roncon, P., Zucchini, S., \& Simonato, M. (2015). Increased extracellular levels of glutamate in the hippocampus of chronically epileptic rats. Neuroscience, 301, 246-253. doi: 10.1016/j.neuroscience.2015.06.013

Stein, P. S., Desrosiers, M., Donegan, S. J., Yepes, J. F., \& Kryscio, R. J. (2007). Tooth loss, dementia and neuropathology in the Nun study. J Am Dent Assoc, 138(10), 13141322; quiz 1381-1312.

Stellwagen, D., Beattie, E. C., Seo, J. Y., \& Malenka, R. C. (2005). Differential regulation of AMPA receptor and GABA receptor trafficking by tumor necrosis factor-alpha. $J$ Neurosci, 25(12), 3219-3228. doi: 10.1523/jneurosci.4486-04.2005

Stephens, M. L., Williamson, A., Deel, M. E., Bensalem-Owen, M., Davis, V. A., Slevin, J., ... Gerhardt, G. A. (2014). Tonic glutamate in CA1 of aging rats correlates with phasic glutamate dysregulation during seizure. Epilepsia, 55(11), 1817-1825. doi: 10.1111/epi.12797

Strohmeyer, R., Shen, Y., \& Rogers, J. (2000). Detection of complement alternative pathway mRNA and proteins in the Alzheimer's disease brain. Brain Res Mol Brain Res, 81(12), 7-18. 
Tellez-Zenteno, J. F., Matijevic, S., \& Wiebe, S. (2005). Somatic comorbidity of epilepsy in the general population in Canada. Epilepsia, 46(12), 1955-1962. doi: 10.1111/j.15281167.2005.00344.x

Theofilopoulos, A. N., Baccala, R., Beutler, B., \& Kono, D. H. (2005). Type I interferons (alpha/beta) in immunity and autoimmunity. Annu Rev Immunol, 23, 307-336. doi: 10.1146/annurev.immunol.23.021704.115843

Tilleux, S., \& Hermans, E. (2008). Down-regulation of astrocytic GLAST by microglia-related inflammation is abrogated in dibutyryl cAMP-differentiated cultures. J Neurochem, 105(6), 2224-2236. doi: 10.1111/j.1471-4159.2008.05305.x

Traynor, T. R., Majde, J. A., Bohnet, S. G., \& Krueger, J. M. (2004). Intratracheal doublestranded RNA plus interferon-gamma: a model for analysis of the acute phase response to respiratory viral infections. Life Sci, 74(20), 2563-2576. doi: 10.1016/j.lfs.2003.10.010

Treves, A., \& Rolls, E. T. (1992). Computational constraints suggest the need for two distinct input systems to the hippocampal CA3 network. Hippocampus, 2(2), 189-199. doi: 10.1002/hipo.450020209

van Munster, B. C., Korevaar, J. C., Zwinderman, A. H., Levi, M., Wiersinga, W. J., \& De Rooij, S. E. (2008). Time-course of cytokines during delirium in elderly patients with hip fractures. J Am Geriatr Soc, 56(9), 1704-1709. doi: 10.1111/j.15325415.2008.01851.x

Vezzani, A., Fujinami, R. S., White, H. S., Preux, P. M., Blumcke, I., Sander, J. W., \& Loscher, W. (2016). Infections, inflammation and epilepsy. Acta Neuropathol, 131(2), 211-234. doi: $10.1007 / \mathrm{s} 00401-015-1481-5$

Vezzani, A., \& Granata, T. (2005). Brain inflammation in epilepsy: experimental and clinical evidence. Epilepsia, 46(11), 1724-1743. doi: 10.1111/j.1528-1167.2005.00298.x

Vincent, P., \& Mulle, C. (2009). Kainate receptors in epilepsy and excitotoxicity. Neuroscience, 158(1), 309-323. doi: 10.1016/j.neuroscience.2008.02.066

Vitkovic, L., Konsman, J. P., Bockaert, J., Dantzer, R., Homburger, V., \& Jacque, C. (2000). Cytokine signals propagate through the brain. Mol Psychiatry, 5(6), 604-615.

Viviani, B., Bartesaghi, S., Gardoni, F., Vezzani, A., Behrens, M. M., Bartfai, T., ... Marinovich, M. (2003). Interleukin-1beta enhances NMDA receptor-mediated intracellular calcium increase through activation of the Src family of kinases. J Neurosci, 23(25), 8692-8700.

Vlkolinsky, R., Siggins, G. R., Campbell, I. L., \& Krucker, T. (2004). Acute exposure to CXC chemokine ligand 10, but not its chronic astroglial production, alters synaptic plasticity in mouse hippocampal slices. J Neuroimmunol, 150(1-2), 37-47. doi: 10.1016/j.jneuroim.2004.01.011

Wang, Cheng, Q., Malik, S., \& Yang, J. (2000). Interleukin-1beta inhibits gamma-aminobutyric acid type A (GABA(A)) receptor current in cultured hippocampal neurons. J Pharmacol Exp Ther, 292(2), 497-504.

Wang, J. G., Strong, J. A., Xie, W., Yang, R. H., Coyle, D. E., Wick, D. M., . . Zhang, J. M. (2008). The chemokine CXCL1/growth related oncogene increases sodium currents and neuronal excitability in small diameter sensory neurons. Mol Pain, 4, 38. doi: 10.1186/1744-8069-4-38

Wang, Q., \& Mao-Draayer, Y. (2015). Interferon beta (IFN-beta) treatment exerts potential neuroprotective effects through neurotrophic factors and novel neurotensin/neurotensin high affinity receptor 1 pathway. Neural Regen Res, 10(12), 1932-1933. doi: 10.4103/1673-5374.169636 
Wang, S., Cheng, Q., Malik, S., \& Yang, J. (2000). Interleukin-1beta inhibits gammaaminobutyric acid type A (GABA(A)) receptor current in cultured hippocampal neurons. J Pharmacol Exp Ther, 292(2), 497-504.

Watkins, L. R., Wiertelak, E. P., Goehler, L. E., Mooney-Heiberger, K., Martinez, J., Furness, L., . .. Maier, S. F. (1994). Neurocircuitry of illness-induced hyperalgesia. Brain Res, 639(2), 283-299.

Weber, F., Wagner, V., Rasmussen, S. B., Hartmann, R., \& Paludan, S. R. (2006). Doublestranded RNA is produced by positive-strand RNA viruses and DNA viruses but not in detectable amounts by negative-strand RNA viruses. J Virol, 80(10), 5059-5064. doi: 10.1128/jvi.80.10.5059-5064.2006

Wei, H., Chadman, K. K., McCloskey, D. P., Sheikh, A. M., Malik, M., Brown, W. T., \& Li, X. (2012). Brain IL-6 elevation causes neuronal circuitry imbalances and mediates autism-like behaviors. Biochim Biophys Acta, 1822(6), 831-842. doi: 10.1016/j.bbadis.2012.01.011

Weintraub, M. K., Kranjac, D., Eimerbrink, M. J., Pearson, S. J., Vinson, B. T., Patel, J., .. . Chumley, M. J. (2014). Peripheral administration of poly I:C leads to increased hippocampal amyloid-beta and cognitive deficits in a non-transgenic mouse. Behav Brain Res, 266, 183-187. doi: 10.1016/j.bbr.2014.03.009

Weller, C., Oxlade, N., Dobbs, S. M., Dobbs, R. J., Charlett, A., \& Bjarnason, I. T. (2005). Role of inflammation in gastrointestinal tract in aetiology and pathogenesis of idiopathic parkinsonism. FEMS Immunol Med Microbiol, 44(2), 129-135. doi: 10.1016/j.femsim.2005.01.011

Westerink, B. H., Damsma, G., Rollema, H., De Vries, J. B., \& Horn, A. S. (1987). Scope and limitations of in vivo brain dialysis: a comparison of its application to various neurotransmitter systems. Life Sci, 41(15), 1763-1776.

Westphalen, R. I., \& Hemmings, H. C., Jr. (2003). Effects of isoflurane and propofol on glutamate and GABA transporters in isolated cortical nerve terminals. Anesthesiology, 98(2), 364-372.

Westphalen, R. I., Kwak, N. B., Daniels, K., \& Hemmings, H. C., Jr. (2011). Regional differences in the effects of isoflurane on neurotransmitter release. Neuropharmacology, 61(4), 699-706. doi: 10.1016/j.neuropharm.2011.05.013

White, J. D., Eimerbrink, M. J., Hayes, H. B., Hardy, A., Van Enkevort, E. A., Peterman, J. L., ... Boehm, G. W. (2016). Hippocampal Abeta expression, but not phosphorylated tau, predicts cognitive deficits following repeated peripheral poly I:C administration. Behav Brain Res, 313, 219-225. doi: 10.1016/j.bbr.2016.07.032

Wilkinson, M. F., Mathieson, W. B., \& Pittman, Q. J. (1993). Interleukin-1 beta has excitatory effects on neurons of the bed nucleus of the stria terminalis. Brain Res, 625(2), 342346.

Yamaguchi, S., Meguro, K., Itoh, M., Hayasaka, C., Shimada, M., Yamazaki, H., \& Yamadori, A. (1997). Decreased cortical glucose metabolism correlates with hippocampal atrophy in Alzheimer's disease as shown by MRI and PET.J Neurol Neurosurg Psychiatry, 62(6), 596-600.

Yanamadala, V., \& Friedlander, R. M. (2010). Complement in neuroprotection and neurodegeneration. Trends Mol Med, 16(2), 69-76. doi: 10.1016/j.molmed.2009.12.001

Ye, L., Huang, Y., Zhao, L., Li, Y., Sun, L., Zhou, Y., ... Zheng, J. C. (2013). IL-1beta and TNFalpha induce neurotoxicity through glutamate production: a potential role for neuronal glutaminase. J Neurochem, 125(6), 897-908. doi: 10.1111/jnc.12263 
